\title{
Modeling particle nucleation and growth over northern California during the 2010 CARES campaign
}

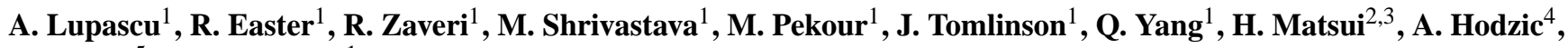 \\ Q. Zhang ${ }^{5}$, and J. D. Fast ${ }^{1}$ \\ ${ }^{1}$ Pacific Northwest National Laboratory, Richland, Washington, USA \\ ${ }^{2}$ Graduate School of Environmental Studies, Nagoya University, Nagoya, Japan \\ ${ }^{3}$ Department of Environmental Geochemical Cycle Research, Japan Agency for Marine-Earth Science and Technology, \\ Yokohama, Japan \\ ${ }^{4}$ National Center for Atmospheric Research, Boulder, Colorado, USA \\ ${ }^{5}$ Department of Environmental Toxicology, University of California, Davis, California, USA
}

Correspondence to: J. D. Fast (jerome.fast@pnnl.gov)

Received: 17 June 2015 - Published in Atmos. Chem. Phys. Discuss.: 20 July 2015

Revised: 22 October 2015 - Accepted: 23 October 2015 - Published: 6 November 2015

\begin{abstract}
Accurate representation of the aerosol lifecycle requires adequate modeling of the particle number concentration and size distribution in addition to their mass, which is often the focus of aerosol modeling studies. This paper compares particle number concentrations and size distributions as predicted by three empirical nucleation parameterizations in the Weather Research and Forecast coupled with chemistry (WRF-Chem) regional model using 20 discrete size bins ranging from $1 \mathrm{~nm}$ to $10 \mu \mathrm{m}$. Two of the parameterizations are based on $\mathrm{H}_{2} \mathrm{SO}_{4}$, while one is based on both $\mathrm{H}_{2} \mathrm{SO}_{4}$ and organic vapors. Budget diagnostic terms for transport, dry deposition, emissions, condensational growth, nucleation, and coagulation of aerosol particles have been added to the model and are used to analyze the differences in how the new particle formation parameterizations influence the evolving aerosol size distribution. The simulations are evaluated using measurements collected at surface sites and from a research aircraft during the Carbonaceous Aerosol and Radiative Effects Study (CARES) conducted in the vicinity of Sacramento, California.

While all three parameterizations captured the temporal variation of the size distribution during observed nucleation events as well as the spatial variability in aerosol number, all overestimated by up to a factor of 2.5 the total particle number concentration for particle diameters greater than $10 \mathrm{~nm}$. Using the budget diagnostic terms, we demonstrate that the combined $\mathrm{H}_{2} \mathrm{SO}_{4}$ and low-volatility organic vapor parame-
\end{abstract}

terization leads to a different diurnal variability of new particle formation and growth to larger sizes compared to the parameterizations based on only $\mathrm{H}_{2} \mathrm{SO}_{4}$. At the CARES urban ground site, peak nucleation rates are predicted to occur around 12:00 Pacific (local) standard time (PST) for the $\mathrm{H}_{2} \mathrm{SO}_{4}$ parameterizations, whereas the highest rates were predicted at 08:00 and 16:00 PST when low-volatility organic gases are included in the parameterization. This can be explained by higher anthropogenic emissions of organic vapors at these times as well as lower boundary-layer heights that reduce vertical mixing. The higher nucleation rates in the $\mathrm{H}_{2} \mathrm{SO}_{4}$-organic parameterization at these times were largely offset by losses due to coagulation. Despite the different budget terms for ultrafine particles, the $10-40 \mathrm{~nm}$ diameter particle number concentrations from all three parameterizations increased from 10:00 to 14:00 PST and then decreased later in the afternoon, consistent with changes in the observed size and number distribution. We found that newly formed particles could explain up to $20-30 \%$ of predicted cloud condensation nuclei at $0.5 \%$ supersaturation, depending on location and the specific nucleation parameterization. A sensitivity simulation using 12 discrete size bins ranging from $1 \mathrm{~nm}$ to $10 \mu \mathrm{m}$ diameter gave a reasonable estimate of particle number and size distribution compared to the 20 size bin simulation, while reducing the associated computational cost by $\sim 36 \%$. 


\section{Introduction}

Aerosol particles are ubiquitous in the atmosphere and are important for their potential climate impact and role in atmospheric chemistry. They absorb and scatter solar radiation, act as cloud condensation nuclei (CCN) and ice nuclei (IN), and induce an overall cooling effect (IPCC, 2007, 2013). They are classified depending on their origin and source as primary or secondary particles. Primary particles originate from natural sources, such as dust and sea salt, as well as anthropogenic sources, such as combustion. Secondary particles are formed through gas-to-particle partitioning processes. The formation of secondary aerosol particles and their subsequent growth have been observed in rural (Place et al., 2010; Ziemba et al., 2006), urban (Betha et al., 2013; Matsui et al., 2011; Jeong et al., 2004), marine (Hoppel et al., 1994; O'Dowd and Hoffmann, 2005), and high-altitude (Venzac et al., 2009; Boulon et al., 2011; Cui et al., 2014) environments. Makkonen et al. (2009), Spracklen et al. (2006, $2008,2010)$ and many others have shown that secondary particle formation contributes to cloud condensation nuclei (CCN) and subsequently influences cloud droplet number concentrations and other cloud processes.

Sulfuric acid gas $\left(\mathrm{H}_{2} \mathrm{SO}_{4}\right)$ plays an important role in the formation of small secondary aerosol particles, due to its very low vapor pressure. Recent studies showed that $\mathrm{H}_{2} \mathrm{SO}_{4}$ alone cannot explain the abundance of new particles in the troposphere (Merikanto et al., 2007; Kirkby et al., 2011; Schobesberger et al., 2013). Thus, several mechanisms have been proposed to describe the formation of new particles in the troposphere: the binary homogeneous mechanism (BHN) involving $\mathrm{H}_{2} \mathrm{SO}_{4}-\mathrm{H}_{2} \mathrm{O}$ (Wexler et al., 1994; McMurry, 1980; McMurry et al., 2000; Kulmala et al., 1998; Vehkamäki et al., 2002), the ternary nucleation (TN) mechanism involving $\mathrm{H}_{2} \mathrm{SO}_{4}-\mathrm{H}_{2} \mathrm{O}$-ammonia $\left(\mathrm{NH}_{3}\right)$ (Napari et al., 2002; Merikanto et al., 2007), the ion-induced nucleation mechanism (IIN) (Turco et al, 1998; Yu and Turco, 2000, 2001; Yu et al., 2008; Kazil et al., 2008), empirical particle formation mechanisms involving $\mathrm{H}_{2} \mathrm{SO}_{4}$ (Kulmala et al., 2006; Sihto et al., 2006; Riipinen et al., 2007; Kuang et al., 2008), and the combined organic and sulfuric acid (kinetic-type) empirical mechanism (ORG) (Metzger et al., 2010; Paasonen et al., 2010; Schobesberger et al., 2013; Ehn et al., 2014; Riccobono et al., 2014). In the empirical particle formation mechanisms, the nucleation rate is proportional to the $\mathrm{H}_{2} \mathrm{SO}_{4}$ concentration to the power of 1-2; the activation mechanism (ACT) (Kulmala et al., 2006) uses a power of 1, while the kinetic nucleation mechanism (KIN) (McMurry and Friedlander, 1979; Kuang et al., 2008) uses a power of 2. Due to its dependency on temperature, the BHN mechanism produces new particles in the upper and free troposphere (e.g., Spracklen et al., 2005), while the use of state-of-the-science empirical parameterizations like ACT, KIN or ORG leads to better agreement between modeled and observed total num- ber concentrations in the boundary layer (i.e., Zhang et al., 2010a; Reddington et al., 2011).

In spite of recent advances, aerosol nucleation and growth processes are not yet completely understood, mainly due to limited coincident measurements of aerosol nucleation precursors (such as $\mathrm{H}_{2} \mathrm{SO}_{4}, \mathrm{NH}_{3}$, and organic acids), and the size, composition, and concentration of newly formed nanometer-sized particles. During the Cosmics Leaving OUtdoor Droplets (CLOUD) experiment, Kirkby et al. (2011) showed that ternary nucleation involving $\mathrm{H}_{2} \mathrm{SO}_{4}-\mathrm{H}_{2} \mathrm{O}-$ $\mathrm{NH}_{3}$, with and without ions, did not explain the observed boundary-layer nucleation, suggesting that organic vapors participated in atmospheric nucleation. Several studies (i.e., Kuang et al., 2010, 2012; Smith et al., 2008) show that in many environments, $\mathrm{H}_{2} \mathrm{SO}_{4}$ accounts for less than half of the total growth of the particles. Setyan et al. (2012) suggested that organic vapors and, to a lesser extent, $\mathrm{H}_{2} \mathrm{SO}_{4}$, play key roles in new particle growth. Recent studies (e.g., Ehn et al., 2014; Jokinen et al., 2015) further demonstrate that the organic vapors with extremely low volatility can enhance, or even dominate, the formation and growth of aerosol particles. Still, the role of organic vapors in particle nucleation and subsequent growth processes is quantitatively very uncertain.

Several studies have been conducted to assess how the choice of nucleation scheme affects simulated particle number concentration (PNC) and their size distribution using global and regional models. For example, Jung et al. (2008) analyzed the impact of different nucleation parameterizations on the modeled size distribution predicted by the Dynamic Model for Aerosol Nucleation (DMAN) and its ability to reproduce the nucleation events and non-events observed during the Pittsburgh Air Quality Study (PAQS) conducted between July 2001 and September 2002. They showed that most of the nucleation schemes included in their study had difficulty reproducing the observed events, except for the ternary mechanism of Napari et al. (2002) that predicts the occurrence of the events during the analyzed period. The empirical particle formation mechanism (Sihto et al., 2006) performed well on $70 \%$ of the analyzed days, but still it predicted nucleation events on days when nucleation was not observed. The BHN mechanism of Vehkamäki et al. (2002) did not reproduce any observed nucleation events, and the scaling of the nucleation rate by a correction factor of $10^{10}$ led to a predicted event on a non-event day. Zhang et al. (2010a) quantified the impact of 11 nucleation schemes on predicted PNC, volume, and surface area using the US Environmental Protection Agency Community Multiscale Air Quality (CMAQ) modeling system version 4.4. They concluded that, although all the parameterizations underpredicted the total PNC (by a factor of 1.3-14.5), the ACT empirical formation mechanism (Sihto et al., 2006) led to the best prediction, while the least reliable prediction was given by the Merikanto et al. (2007) TN parameterization. Using the Global Model of Aerosol Processes (GLOMAP), Reddington et al. (2011) 
showed that the use of ACT, KIN and ORG parameterizations led to underpredictions spanning from -53 to $-11 \%$ of total PNC in the boundary layer for continental European monitoring stations. In contrast, Jung et al. (2010) found that the PMCAMx-UF model using the TN nucleation parameterization (Napari et al., 2002), with the nucleation rate corrected using a nucleation tuner equal to $10^{-5}$, overpredicted by $22 \%$ the total number concentration of particles having a diameter larger than $3 \mathrm{~nm}$, while this overprediction was greater than $49 \%$ for particles having a diameter larger than $10 \mathrm{~nm}$. Westervelt et al. (2013) have the Goddard Earth Observing System global chemical transport model (GEOS-Chem) coupled to the TwO-Moment Aerosol Sectional (TOMAS) scheme to evaluate the performance of a ternary nucleation parameterization (Napari et al., 2002, with an added $10^{-5}$ nucleation tuning factor) and the ACT nucleation parameterization (Sihto et al., 2006). Using metrics such as nucleation rate, growth rate, condensation and coagulation sink, survival probability, and CCN formation, they investigated the limitation of nucleation and SOA parameterizations at five locations in the various location and environments showing that, although the model gave reasonable results on average, the largest discrepancies between model and measurements were obtained using the ACT parameterization at the urban sites (up to a factor of 5 for the formation rate of $3 \mathrm{~nm}$ particles). Yu (2011), Riipinen et al. (2011), Pierce et al. (2011), and Patoulias et al. (2015) studied the impact of secondary organic vapor condensation and the average saturation concentration of these vapors on formation of new particles and their growth to larger sizes. They found that the condensation of these vapors can contribute to new particle formation as well to the growth of these ultrafine particles. A recent study of Yu et al. (2015) compared the ion-mediation nucleation (IMN) mechanism and the organics-mediated mechanism derived from the Cosmics Leaving Outdoor Droplets (CLOUD) chamber experiment (Riccobono et al., 2014) for several locations in North America. It was shown that the frequency of nucleation and the intensity of NPF predicted by the organics-mediated mechanism was too high, while IMN parameterization was closer to the observed values, especially during the spring. That study suggested that the spatial and temporal differences in the behavior of the two nucleation parameterizations could be related to differences in the predicted aerosol first indirect radiative forcing, a lower concentration of organic compounds in the atmosphere compared to those used in chamber studies, and the temperature influence on atmospheric nucleation rate compared to the derived empirical coefficient at a $278 \mathrm{~K}$ temperature and $39 \%$ relative humidity.

The aim of this study is to determine the performance of several new particle formation parameterizations implemented in the chemistry version of the Weather Research and Forecasting model (WRF-Chem) and investigate how differences in the parameterization formulations affect simulated spatial and temporal variations in boundary-layer particle number concentrations during the Carbonaceous Aerosol and Radiative Effects Study (CARES) (Zaveri et al., 2012). The principal objectives of CARES were to examine the interaction between anthropogenic and biogenic precursors associated with secondary organic aerosol formation, the evolving mixing state of secondary organic and black carbon aerosols, and the impact of aerosols on optical and $\mathrm{CCN}$ activation properties. A complete overview of the research objectives and the ground and aircraft measurements collected during the CARES campaign is given by Zaveri et al. (2012). Although the primary objectives of the campaign did not include examining the formation of new particles, measurements of particle number concentration and size distribution showed that new particle formation events frequently occurred in the vicinity of Sacramento and over the western Sierra foothills. This environment is influenced by the $\mathrm{SO}_{2}$ emissions originating from oil refineries located in the vicinity of the Carquinez Strait and the San Francisco Bay area. Setyan et al. (2014) showed that on days with new particle formation events during CARES, the concentration of organics and sulfate significantly increased in particles in the Aitken mode, and that the concentrations of species representative of urban emissions together with the photooxidation products of biogenic volatile organic compounds (VOCs) and the biogenically influenced secondary organic aerosols (SOAs) were on average $50 \%$ higher during the event days compared to the non-event days. These findings provide means to test several particle formation mechanisms that include the effect of sulfuric acid alone or the combined effect of sulfuric acid and organic vapors, in addition to the BHN mechanism currently available in WRF-Chem.

The CARES measurements are described in Sect. 2. Key features and details of the WRF-Chem model and the simulations are described in Sect. 3. Section 4 presents the simulated evolution of the particle number concentration compared with surface and aircraft measurements collected on days in which new particle formation and growth events did and did not occur, and Sect. 5 summarizes the results.

\section{Measurements}

During the CARES campaign, ground measurements were acquired at two sites in northern California: one in Sacramento $\left(38.645^{\circ} \mathrm{N}, 121.34^{\circ} \mathrm{W}, \sim 30 \mathrm{~m}\right.$ a.s.l.) and the other in $\operatorname{Cool}\left(38.89^{\circ} \mathrm{N}, 120.97^{\circ} \mathrm{W}, \sim 450 \mathrm{~m}\right.$ a.s.1.), a small town located about $40 \mathrm{~km}$ northeast of Sacramento. Following Zaveri at al. (2010), we will refer to the Sacramento and Cool sites as "T0" and "T1", respectively. Aerosol particle size measurements at both sites were carried out using a Scanning Mobility Particle Sizer (SMPS) to measure the particle size distribution from 10 to $700 \mathrm{~nm}$. Due to the lack of measurements in the $1-10 \mathrm{~nm}$ size range, the formation of new particles was not observed. Therefore, in the forthcoming discussion, following Setyan et al.'s (2014) terminology, instead 
of "nucleation" and "new particle formation", we will use the term "new particle formation and growth event" (NPE). While the SMPS does not capture the initiation of NPEs, Zaveri et al. (2010) and Setyan et al. (2014) showed that the growth of small particles frequently occurred during the campaign. The $\mathrm{CCN}$ concentration at multiple supersaturations $(0.07-0.5 \%)$ was measured at both sites using Droplet Measurement Technologies CCN counters (models 200-013 and 100-081) (Zaveri et al., 2012). In addition to groundbased measurements, the ARM Aerial Facility Gulfstream1 (G-1) research aircraft sampled on 14 days during the CARES campaign. Aerosol instrumentation on the G-1 aircraft included CPC-3025 and CPC-3010 condensation particle counters (Sem, 2002) that measured particle number concentrations for particle diameters greater than 3 and $10 \mathrm{~nm}$, respectively.

\section{Model}

In this study, the WRF-Chem model version 3.5 was used (Grell et al., 2005; Fast et al., 2006) to simulate new particle formation events and their impact on aerosol size distributions and CCN concentrations. The model domain covers the area between 32.2 and $42.7^{\circ} \mathrm{N}$, and 127.5 and $113.4^{\circ} \mathrm{W}$, which encompassed all of California and Nevada and extended about $400 \mathrm{~km}$ into the Pacific (west of San Francisco), using a $4 \mathrm{~km}$ grid spacing and 65 vertically stretched layers from the ground up to $50 \mathrm{hPa}$. The physics options used for this study include the Morrison double-moment microphysics scheme (Morrison et al., 2009), the Kain-Fritsch cumulus parameterization (Kain, 2004), the Rapid Radiative Transfer Model (Iacono et al., 2008) for longwave and shortwave radiation, the Mellor-Yamada-Janjic boundary-layer parameterization (Janjic, 2001), and the Monin-Obukhov scheme for the surface layer.

Gas-phase chemistry is simulated using the SAPRC-99 mechanism (Carter, 2000). Aerosol lifecycle processes are represented by the Model for Simulating Aerosol Interactions and Chemistry (MOSAIC) (Zaveri et al., 2008), which has been used in numerous aerosol modeling studies (i.e., Cui et al., 2014; Ritter et al., 2013; Archer-Nicholls et al., 2014). Aerosol species in MOSAIC included sulfate, nitrate, ammonium, sodium, chloride, calcium, carbonate, other inorganics (i.e., dust), methanesulfonate, elemental carbon, primary organic aerosols (POAs), and aerosol water (Zaveri et al., 2008). Secondary organic aerosols (SOAs) are represented by the simplified volatility basis-set (VBS) approach of Shrivastava et al. (2011), with additional updates for biogenic SOA yields (Shrivastava et al., 2015). The VBS approach treats traditional and non-traditional SOA species and precursor gases that partition between particle and gas phases. Traditional SOA precursors derive from oxidation of anthropogenic (e.g., aromatics) and biogenic (e.g., isoprene and terpenes) primary gases, and these are represented with four volatility bins having saturation vapor concentrations $\left(\mathrm{C}^{*}\right)$ of $0.1,1,10$ and $100 \mathrm{\mu g} \mathrm{m}^{-3}$ (at $298 \mathrm{~K}$ ), with effective SOA yields derived from fitting smog chamber data and thus representing the first few generations of oxidation. Non-traditional SOA precursor gases derive from the oxidation of semi- and intermediate-volatility primary gases that are emitted during fossil and bio-fuel combustion and biomass burning; these are represented with two volatility bins having a $C^{*}$ of 0.001 and $10^{6} \mu \mathrm{g} \mathrm{m}^{-3}$. The SOA mass predicted by the simplified two-species VBS approach is aligned to a complex multigenerational nine-species VBS approach (reducing the reaction rate with $\mathrm{OH}$ radicals to compensate for the large volatility decrease of organic vapors, as described by Shrivastava et al., 2011). The $C^{*}$ of the lowest-volatility bin was reduced from the $0.01 \mu \mathrm{g} \mathrm{m}^{-3}$ used in Shrivastava et al. (2011) to $0.001 \mu \mathrm{g} \mathrm{m}^{-3}$ for this study to allow condensation onto $1 \mathrm{~nm}$ particles, for which the Kelvin effect is very large.

Initial and boundary conditions for the chemical species in our simulations, including the mass and number size distribution of primary aerosol species, are taken from the MOZART-4 global chemistry transport model (Emmons et al., 2010). We reduced the initial and boundary conditions of aerosol concentrations from MOZART- 4 by $50 \%$ since Fast et al. (2014) found that long-range transport was likely overestimated when comparing simulated values to aerosol optical depth and extinction profile measurements.

Biogenic trace gas emissions are calculated online using the MEGAN model (Guenther et al., 2006). Anthropogenic emissions are obtained from the California Air Resources Board (CARB) 2010 project emissions (available at http://www.arb.ca.gov/app/emsinv/fcemssumcat2009.php).

The lognormal size distribution of emitted anthropogenic primary particles uses a geometrical mean diameter of $50 \mathrm{~nm}$ and a standard deviation of 2 (Cui et al., 2014). To avoid an artificial increase of $1 \mathrm{~nm}$ particles, primary aerosol emissions for particles smaller than $10 \mathrm{~nm}$ are not considered. Mineral dust and sea salt emissions are calculated online (Shaw et al., 2008).

In the public release of WRF-Chem, MOSAIC uses a sectional framework where the aerosol size distribution is divided into four or eight discrete size bins spanning $39 \mathrm{~nm}$ to $10 \mu \mathrm{m}$ diameter. However, these bins do not capture the freshly nucleated particles that have diameters of a few nanometers. Recently, Matsui et al. $(2011,2013)$ and Cui at al. (2014) added a new sectional framework option for MOSAIC in WRF-Chem that uses 20 bins to represent nucleation and particle growth in the range of $1 \mathrm{~nm}$ to $10 \mu \mathrm{m}$, and a state-of-the-science empirical cluster activation (ACT) theory parameterization (Kulmala et al., 2006; Sihto et al., 2006). They compared new particle formation (NPF) and particle number concentrations predicted by that approach with land- and aircraft-based measurements. In Matsui et al. (2011), the use of empirical activation type nucleation inside WRF-Chem generally reproduced the number of observed event and non-event days for a measurement site lo- 
cated $\sim 50 \mathrm{~km}$ south of Beijing; however, the modeled $\mathrm{SO}_{2}$ concentration was overestimated by a factor of 6 for this location. Matsui et al. (2013) applied the same approach for another case using several stations located in Korea and Japan. In that study, the simulated average number concentration for particles having a diameter greater than $10 \mathrm{~nm}\left(\mathrm{CN}_{10}\right)$ was overestimated within a factor of 2 , while the temporal variation of $\mathrm{CN}_{10}$ was not well reproduced. Cui et al. (2014) showed that the use of the ACT parameterization combined with an improved treatment of SOA formation from biogenic emissions at a forest site in Colorado led to a more accurate simulation of aerosol particles in the $4-100 \mathrm{~nm}$ size range compared with the default WRF-Chem model, including onset times, number concentrations, and number mean diameters.

For this study, we performed simulations using the 20 size bin framework (Matsui et al., 2011, 2013; Cui at al., 2014) with five different nucleation parameterizations: two based on classical binary homogeneous nucleation theory (Wexler et al., 1994; Vehkamaki et al., 2002) and three newer empirical parameterizations. The Wexler parameterization is the default nucleation parameterization used with MOSAIC in the public release of WRF-Chem, and is used in our study for that reason. The Wexler parameterization defines a critical $\mathrm{H}_{2} \mathrm{SO}_{4}$ concentration at which the nucleation rate is approximately 1 particle $\mathrm{cm}^{-3} \mathrm{~s}^{-1}$, based on early classical BHN results. When the ambient gaseous $\mathrm{H}_{2} \mathrm{SO}_{4}$ concentration exceeds this critical concentration, all gaseous $\mathrm{H}_{2} \mathrm{SO}_{4}$ in excess of the critical value is used to produce new particles having a diameter equal to the smallest diameter covered by the model's sectional framework (e.g., $1 \mathrm{~nm}$ in the 20 size bin framework or $39 \mathrm{~nm}$ in the 8 size bin framework).

In the Vehkamaki parameterization, theoretical BHN nucleation rates (derived by Vehkamaki et al., 2002) over a wide range of temperature, relative humidity, and gaseous $\mathrm{H}_{2} \mathrm{SO}_{4}$ concentration are approximated (fitted) by a rather complicated analytical expression involving exponentials and polynomials of order $1-3$.

We performed simulations using the Wexler and Vehkamaki parameterizations with the 20 size bin sectional framework, and using the MOSAIC WRF-Chem default configuration of the Wexler parameterization with the 8 size bin sectional framework. Due their poor performance, the results from the 20 size bin Wexler and Vehkamaki simulations are not presented; these simulations were not able to reproduce either the observed new particle formation events or the observed particle number concentrations. In addition, Zhang et al. (2010b) note that the Wexler parameterization often produces unrealistically high nucleation rates. We performed simulations with three of the recent empirical nucleation parameterizations using the 20 size bin sectional framework. These parameterizations are used in the boundary layer, while following Matsui et al. (2011), the Wexler parameterization is applied in the free troposphere. For the activation type nucleation (ACT) and kinetic type nucleation
(KIN), the formation rates of $1 \mathrm{~nm}$ particles are linear or second-order functions of $\mathrm{H}_{2} \mathrm{SO}_{4}$ concentration defined as

$J=k_{\mathrm{ACT}} \times\left[\mathrm{H}_{2} \mathrm{SO}_{4}\right]$

and

$J=k_{\mathrm{KIN}} \times\left[\mathrm{H}_{2} \mathrm{SO}_{4}\right]^{2}$.

Previous studies showed that $k_{\mathrm{ACT}}$ and $k_{\mathrm{KIN}}$ coefficients derived from observations in different locations span several orders of magnitude: $k_{\mathrm{ACT}}$ ranges from $3.3 \times 10^{-8}$ to $3.5 \times 10^{-4} \mathrm{~s}^{-1}$ (i.e., Sihto et al., 2006; Riipinen et al., 2007), while $k_{\mathrm{KIN}}$ ranges from $2.4 \times 10^{-15}$ to $1.3 \times 10^{-10} \mathrm{~cm}^{3} \mathrm{~s}^{-1}$ (Riipinen et al., 2007; Kuang et al., 2008). In this study we use $k_{\mathrm{ACT}}=2 \times 10^{-6} \mathrm{~s}^{-1}$ and $k_{\mathrm{KIN}}=2 \times 10^{-12} \mathrm{~cm}^{3} \mathrm{~s}^{-1}$, following Reddington et al. (2011). Cui et al. (2014) also recommend the use of $k_{\mathrm{ACT}}=2 \times 10^{-6} \mathrm{~s}^{-1}$ based on the measured formation rates of ultrafine particles over a pine forest.

Although the ACT and KIN parameterizations have been used in many studies (i.e., Spracklen et al., 2006; Kuang et al., 2008), Mertzger et al. (2010) showed that organic vapors are important for the nucleation processes. We therefore performed an additional simulation using the combined organic and $\mathrm{H}_{2} \mathrm{SO}_{4}$ mechanism (ORG):

$J=k_{\mathrm{ORG}} \times\left[\mathrm{H}_{2} \mathrm{SO}_{4}\right] \times[\mathrm{NucOrg}]$,

where $k_{\mathrm{ORG}}=5 \times 10^{-13} \mathrm{~cm}^{-3} \mathrm{~s}^{-1}$ as in Reddington et al. (2011) and NucOrg are low-volatility organic vapors that are involved in the new particle formation process.

Previous studies have defined NucOrg in different ways, and there is considerable uncertainty involving these lowvolatility organic vapors. Metzger et al. (2010) assumed that the organic vapors involved in nucleation were the same as those involved in the initial condensational growth of the nuclei, and they derived NucOrg concentrations from laboratory experimental data and the initial growth rates. Redington et al. (2011) assumed that the organic vapors involved in NPF were the first-stage oxidation (with $\mathrm{O}_{3}, \mathrm{OH}$, and $\mathrm{NO}_{3}$ ) products of monoterpenes (with a $13 \%$ molar yield), and treated them as non-volatile. The studies done by Riipinen et al. (2011) and Yli-Juuti et al. (2011) assumed that the organic vapors have very low vapor pressures. Using the TOMAS model, Pierce et al. (2011) performed several sensitivity studies to analyze the impact of organic vapor saturation pressure on the growth of nanometer particles and showed that ultrafine-mode particle composition is dominated by low-volatility SOA species (those with $\mathrm{C}^{*}$ less than 0.001-0.01 $\mu \mathrm{g} \mathrm{m}^{-3}$ ). Recently, Schobesberger et al. (2013), Ehn et al. (2014), and Jokinen et al. (2015) used extremely low-volatility organic compounds (ELVOC) formed as first-stage oxidation products of monoterpene with different yields (1-17\%) to account for the role of organic vapors in the early stage of new particle formation.

In our model treatment, NucOrg consists of the organic vapors with the lowest $C^{*}$ of the VBS approach. 
This includes the $\mathrm{C}^{*}=0.001 \mu \mathrm{g} \mathrm{m}^{-3}$ species from the nontraditional SOA precursors (semi-volatile and intermediatevolatility organics associated with fossil and biofuel combustion and biomass burning) and the $\mathrm{C}^{*}=0.1 \mu \mathrm{g} \mathrm{m}^{-3}$ species from the traditional SOA precursors (isoprene, terpenes and aromatics) included in this study. Following Yli-Juuti et al. (2013), an upper limit of $10^{8}$ molecules $\mathrm{cm}^{-3}$ for the $\mathrm{Nu}-$ cOrg is used in Eq. (3). In our simulations, we find that during initial particle formation periods, $96-99 \%$ of the growth involves the $\mathrm{C}^{*}=0.001 \mu \mathrm{g} \mathrm{m}^{-3}$ organic vapors, while the $\mathrm{C}^{*}=0.1 \mu \mathrm{g} \mathrm{m}^{-3}$ species contribute on average $\sim 7$ times more to the ORG nucleation rate compared to those species having $\mathrm{C}^{*}=0.001 \mu \mathrm{g} \mathrm{m}^{-3}$. The volatilities of some of these species may in fact be too high to actually participate in nucleation, in which case they can be viewed as proxies for the even lower-volatility species that do participate.

Once formed, the new particles then grow by condensation of inorganic and organic gases, and for the small initial sizes, the Kelvin effect influences the condensation rates. MOSAIC treats the Kelvin effect for the condensation of inorganic gases (although $\mathrm{H}_{2} \mathrm{SO}_{4}$ is treated as non-volatile), but the SOA gas-particle partitioning treatment was modified to include the Kelvin effect. We assume a surface tension of $50 \mathrm{dyne}^{-1}$, and a molecular weight of $250.0 \mathrm{~g} \mathrm{~mol}^{-1}$ for the NucOrg organic vapors, so at $298 \mathrm{~K}$, the Kelvin effect increases the effective saturation vapor concentrations over $1 \mathrm{~nm}$ particles by a factor of 55 .

Budget diagnostics for aerosol nucleation, emission, condensational growth, coagulation, transport, dry deposition and total tendencies (the sum of all the individually computed tendencies) were saved to illustrate when and where new particle formation events occurred and to better understand how they influence the evolution of the aerosol size distribution.

We also performed two additional simulations with the ACT parameterization. One used 12 discrete size bins, also ranging from $1 \mathrm{~nm}$ to $10 \mu \mathrm{m}$ diameter, with good resolution in the size range of interest to this study (new particle formation). The other used the MOSAIC default 8 size bins, with diameters ranging from $40 \mathrm{~nm}$ to $10 \mu \mathrm{m}$, to quantify the performance and computational cost of this size bin structure compared to the 12-bin and 20-bin versions. In order to account for coagulation losses during nuclei condensational growth from 1 to $40 \mathrm{~nm}$ in the 8-bin version, we applied the Kerminen and Kulmala (2002) parameterization (KK2002 hereafter). The coagulation loss depends on the growth time from the initial nuclei size to a larger size, and KK2002 estimates this growth time by assuming that the growth is due to $\mathrm{H}_{2} \mathrm{SO}_{4}$ condensation only. This was modified as follows to also account for condensation of organic vapors. In the 20-bin simulations at individual grid points and times, the growth times from 1 to $40 \mathrm{~nm}$ due to $\mathrm{H}_{2} \mathrm{SO}_{4}$ condensation only and due to $\mathrm{H}_{2} \mathrm{SO}_{4}$ plus organics condensation were estimated using the condensed masses from the MOSAIC aerosol chemistry module, and the ratio of these two growth times gave an organics enhancement factor for
1-40 nm growth $(Y)$. The same calculations were done for growth from 40 to $63 \mathrm{~nm}$, giving another organics enhancement factor $(X)$, and both $X$ and $Y$ were output. After the simulation, a zero-intercept linear regression of $Y$ vs. $X$ was performed $(Y=a X)$, using the entire $X$ and $Y$ data. In the 8bin simulations, we calculated an organics enhancement factor for growth from 39 to $78 \mathrm{~nm}\left(X^{\prime}\right)$, which is the width of the first bin in this configuration. We then estimated the organics enhancement factor for $1-40 \mathrm{~nm}$ growth as $Y^{\prime}=a X^{\prime}$, and applied this enhancement factor to the $\mathrm{H}_{2} \mathrm{SO}_{4}$-only condensation growth time used in KK2002.

In addition to improving simulations of the aerosol formation and growth processes in MOSAIC, the results of this study will form the basis for incorporating one or more new nucleation schemes into the public version of WRF-Chem.

\section{Results}

The discussion of the model results focuses on the NPE observed between 7 and 16 June 2010. The prevailing westerly to southwesterly atmospheric flow on 7-9 and 15-16 June transported $\mathrm{SO}_{2}$ from the San Francisco Bay area to the vicinity of Sacramento and produced NPE on these days. Due to changes of synoptic conditions associated with a trough formed over the western US from 10 to 14 June 2010 (Fast et al., 2012), weak or no NPEs were observed at the T0 (urban) and T1 (rural) sites on these days. The shift to strong northerly winds led to a decrease of Bay Area emissions transported over Sacramento, consequently decreasing $\mathrm{SO}_{2}$ and the total observed particle number concentration. We first evaluate the overall impact of the nucleation parameterizations on particle number and size distribution at the surface and aloft, using measurements collected at the $\mathrm{T} 0$ and $\mathrm{T} 1$ sites as well as along G-1 aircraft flight paths during the 716 June period. We then provide a more detailed analysis of the simulated formation of new particles and growth at ground level for an observed NPE on 8 and 12 June 2010 when no NPE was observed. Finally, we determine how the differences in particle number and size distribution associated with the nucleation parameterizations affect predicted $\mathrm{CCN}$.

\subsection{Temporal variability in particle number concentration}

The ability of the model to simulate the observations is evaluated using statistical scores including normalized mean bias (NMB) and the correlation factor between simulated and measured values $(R)$. Due to the minimum cutoff size of the SMPS instrument, we investigated the behavior of $\mathrm{CN}_{10}$ (particle number concentration having $D_{\mathrm{p}} \geq 10 \mathrm{~nm}$ ), $\mathrm{CN}_{40}$ $\left(D_{\mathrm{p}} \geq 40 \mathrm{~nm}\right)$ and $\mathrm{CN}_{100}\left(D_{\mathrm{p}} \geq 100 \mathrm{~nm}\right)$. Tables 1 and 2 present NMB and $R$ for these three parameters from four model configurations at the T0 and T1 sites. Model perfor- 
Table 1. Observed mean and simulation summary statistics for aerosol number concentrations for particle diameters $\geq 10 \mathrm{~nm}\left(\mathrm{CN}_{10}\right)$, $\geq 40 \mathrm{~nm}\left(\mathrm{CN}_{40}\right)$, and $\geq 100 \mathrm{~nm}\left(\mathrm{CN}_{100}\right)$. The normalized mean bias (NMB) and correlation coefficient $(R)$ are calculated between simulated and observed number concentrations at the CARES T0 site during the 7-16 June 2010 period.

\begin{tabular}{|c|c|c|c|c|c|c|c|c|c|c|}
\hline \multirow[t]{2}{*}{ Analyzed period } & \multicolumn{3}{|c|}{ Observed mean } & \multirow[t]{2}{*}{ Model experiment } & \multicolumn{3}{|c|}{ NMB (\%) } & \multicolumn{3}{|c|}{$R$} \\
\hline & $\mathrm{CN}_{10}$ & $\mathrm{CN}_{40}$ & $\mathrm{CN}_{100}$ & & $\mathrm{CN}_{10}$ & $\mathrm{CN}_{40}$ & $\mathrm{CN}_{100}$ & $\mathrm{CN}_{10}$ & $\mathrm{CN}_{40}$ & $\mathrm{CN}_{100}$ \\
\hline \multirow[t]{4}{*}{ Entire period } & 8576 & 2748 & 366 & $\mathrm{ACT}$ & 184 & 66 & 78 & 0.71 & 0.56 & 0.53 \\
\hline & & & & KIN & 255 & 67 & 65 & 0.69 & 0.56 & 0.50 \\
\hline & & & & ORG & 233 & 71 & 68 & 0.66 & 0.57 & 0.51 \\
\hline & & & & $8 \mathrm{BIN}$ & - & -34 & -55 & - & 0.56 & 0.32 \\
\hline \multirow[t]{4}{*}{ Southwesterly flow } & 9885 & 3328 & 435 & ACT & 191 & 60 & 86 & 0.71 & 0.53 & 0.45 \\
\hline & & & & KIN & 278 & 63 & 71 & 0.68 & 0.52 & 0.40 \\
\hline & & & & ORG & 228 & 66 & 75 & 0.67 & 0.54 & 0.40 \\
\hline & & & & $8 \mathrm{BIN}$ & - & -68 & -47 & - & 0.15 & 0.53 \\
\hline \multirow[t]{4}{*}{ Northerly flow } & 6162 & 1686 & 202 & ACT & 168 & 87 & 49 & 0.48 & 0.17 & 0.08 \\
\hline & & & & KIN & 193 & 83 & 47 & 0.41 & 0.16 & 0.07 \\
\hline & & & & ORG & 247 & 88 & 42 & 0.44 & 0.20 & 0.03 \\
\hline & & & & $8 \mathrm{BIN}$ & - & -66 & -48 & - & 0.24 & 0.30 \\
\hline
\end{tabular}

Table 2. Same as Table 1, except for the CARES T1 site.

\begin{tabular}{|c|c|c|c|c|c|c|c|c|c|c|}
\hline \multirow[t]{2}{*}{ Analyzed period } & \multicolumn{3}{|c|}{ Observed mean } & \multirow[t]{2}{*}{ Model experiment } & \multicolumn{3}{|c|}{$\operatorname{NMB}(\%)$} & \multicolumn{3}{|c|}{$R$} \\
\hline & $\mathrm{CN}_{10}$ & $\mathrm{CN}_{40}$ & $\mathrm{CN}_{100}$ & & $\mathrm{CN}_{10}$ & $\mathrm{CN}_{40}$ & $\mathrm{CN}_{100}$ & $\mathrm{CN}_{10}$ & $\mathrm{CN}_{40}$ & $\mathrm{CN}_{100}$ \\
\hline \multirow[t]{4}{*}{ Entire period } & 6389 & 3121 & 518 & $\mathrm{ACT}$ & 178 & 31 & 25 & 0.74 & 0.70 & 0.51 \\
\hline & & & & KIN & 231 & 36 & 13 & 0.64 & 0.49 & 0.55 \\
\hline & & & & ORG & 239 & 36 & 16 & 0.67 & 0.69 & 0.51 \\
\hline & & & & $8 \mathrm{BIN}$ & - & -51 & -65 & - & 0.57 & 0.32 \\
\hline \multirow[t]{4}{*}{ Southwesterly flow } & 7960 & 4073 & 691 & ACT & 187 & 35 & 33 & 0.71 & 066 & 0.33 \\
\hline & & & & KIN & 347 & 27 & 6 & 0.62 & 0.43 & 0.41 \\
\hline & & & & ORG & 256 & 41 & 23 & 0.59 & 0.63 & 0.32 \\
\hline & & & & $8 \mathrm{BIN}$ & - & -58 & -62 & - & 0.51 & 0.03 \\
\hline \multirow[t]{4}{*}{ Northerly flow } & 4429 & 1878 & 289 & ACT & 129 & 19 & -12 & 0.67 & 0.11 & -0.13 \\
\hline & & & & KIN & 278 & 68 & 7 & 0.41 & 0.06 & 0.07 \\
\hline & & & & ORG & 158 & 18 & -16 & 0.68 & 0.10 & -0.16 \\
\hline & & & & $8 \mathrm{BIN}$ & - & -40 & -77 & - & 0.06 & -0.16 \\
\hline
\end{tabular}

mance in simulating $\mathrm{PM}_{1}$ and $\mathrm{PM}_{2.5}$ concentrations using the default WRF-Chem 8 size bin and Wexler nucleation parameterization configuration (WEX-8BIN) for the entire CARES domain, including the $\mathrm{T} 0$ and $\mathrm{T} 1$ sites, has been presented in Fast et al. (2014). In general, simulated PM1 is fairly close to that observed during 7-16 June 2010 both in terms of mass concentrations $(\mathrm{NMB}=15 \%$ at $\mathrm{T} 0$ and $\mathrm{NMB}=-18 \%$ at $\mathrm{T} 1)$ and temporal evolution $(R=0.56$ at $\mathrm{T} 0$ and $R=0.64$ at T1). However, the WEX-8BIN simulation does not reproduce as well the $\mathrm{CN}_{100}$ concentration $(\mathrm{NMB}=-55 \%$ at $\mathrm{T} 0$ and $\mathrm{NMB}=-65 \%$ at $\mathrm{T} 1)$ or the temporal evolution ( $R=0.32$ at both sites).

As shown in Figs. 1 and 2, the overall temporal variability of high particle concentrations before and after the passage of the trough between 10 and 14 June was generally captured by the explicit ( 20 size bin) nucleation schemes used in our study, although they usually overestimate the observed particle number concentrations.

First, we analyze how the standard configuration of WRFChem (8BIN) behaves compared to the measurements. Since the 8BIN simulation does not explicitly resolve nucleation and the geometric diameter range for the smallest size bin is from 39 to $78 \mathrm{~nm}$, only $\mathrm{CN}_{40}$ and $\mathrm{CN}_{100}$ are examined. As can be seen from Figs. 1 and 2, the WEX-8BIN simulation is able to reproduce the observed diurnal and multi-day variation of $\mathrm{CN}_{40}(R=0.31$ and 0.57 for the $\mathrm{T} 0$ and $\mathrm{T} 1$ sites, respectively), and largely underestimates the observed number concentration for both the $\mathrm{T} 0$ and $\mathrm{T} 1$ sites (see Tables 1 and 2). In the case of $\mathrm{CN}_{100}$, the $8 \mathrm{BIN}$ simulation also tends to underestimate the observed concentration (up to $65 \%$ at 


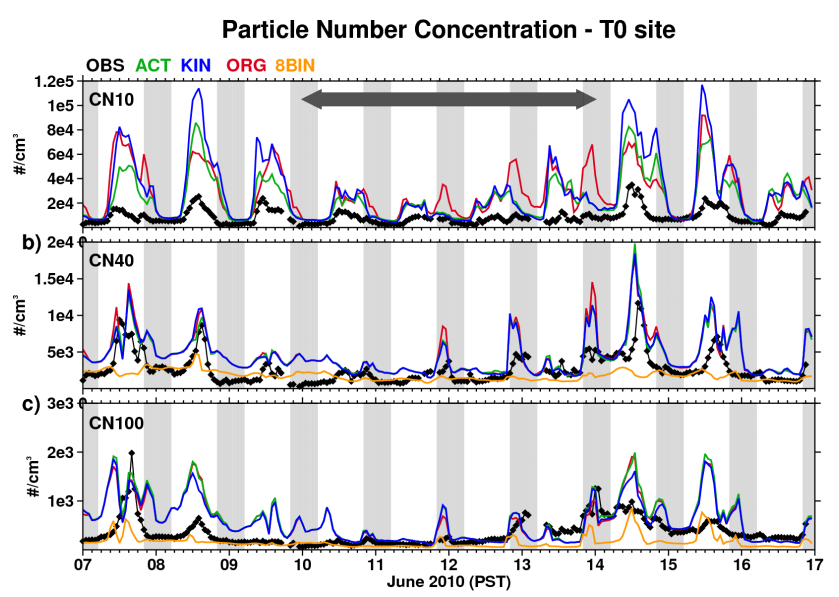

Figure 1. Observed and simulated time series of particle number concentration at the $\mathrm{T} 0$ site for (a) $\mathrm{CN}_{10}$, (b) $\mathrm{CN}_{40}$, and (c) $\mathrm{CN}_{100}$. Gray shading indicates nighttime and the arrow denotes the period of northerly synoptic flow associated with the passage of a trough over California. All times are local Pacific Standard Time (PST).

the T1 site) with $\mathrm{CN}_{100} R$ values of 0.60 and 0.32 calculated between observations and modeling results at the T0 and T1 sites, respectively.

We now discuss how well simulations conducted using the empirical nucleation parameterizations with 20 size bins agree with the measurements. All three empirical nucleation parameterizations reproduce the overall observed daily variability as shown Figs. 1 and 2, although during the NPEs they usually overestimate the PNC in different size ranges. The ACT, KIN and ORG simulations overestimate the observed $\mathrm{CN}_{10}$ (from $178 \%$ for ACT up to $255 \%$ for KIN), although the correlation coefficient suggests reasonable agreement in temporal variability between observations and modeling results $(R>0.70)$. The overestimation is reduced for the $\mathrm{CN}_{40}$ and $\mathrm{CN}_{100}$ particles, and the best results are obtained at the rural $\mathrm{T} 1$ site that is not influenced by as high anthropogenic emission rates (see Tables 1 and 2). Moreover, during the southwesterly flow periods, the maximum peaks of $\mathrm{CN}_{10}$ are overpredicted within a factor of 3 by all explicit mechanisms involved in our simulations, while the $\mathrm{CN}_{40}$ and $\mathrm{CN}_{100}$ maximum peaks tend to be overpredicted by a factor of 2 (Figs. 1 and 2). The normalized mean bias of $\mathrm{CN}_{10}$ during this period ranges from $187 \%$ for ACT to $347 \%$ for KIN. The overprediction factors for all three empirical parameterizations are reduced during the northerly flow period, when $\mathrm{SO}_{2}$ transport through the Carquinez Strait to the measurement sites is significantly reduced. During this period the normalized mean bias of $\mathrm{CN}_{10}$ particles is lower and ranges from $129 \%$ for ACT to $278 \%$ for KIN. Based on this analysis of PNC in several size ranges, we conclude that for both measurement sites, the ACT parameterization performs somewhat better than the KIN and ORG parameterizations.

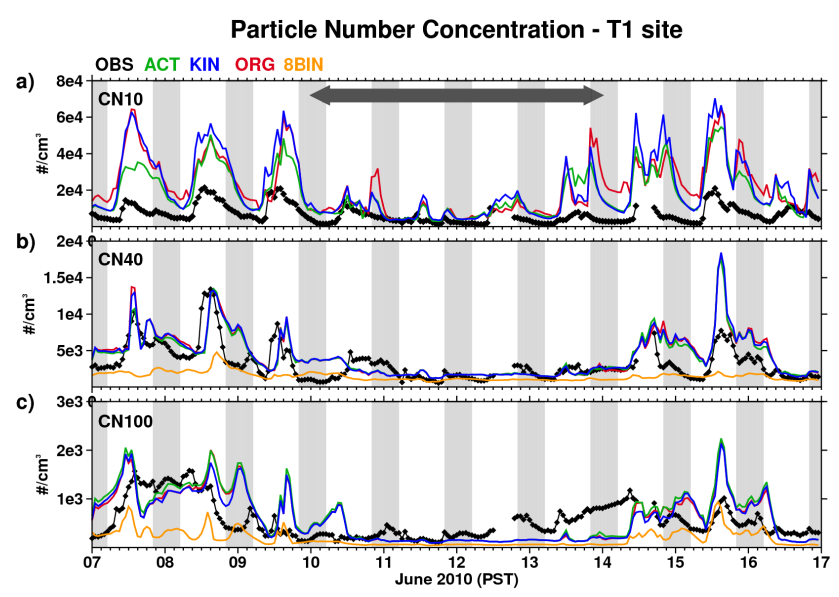

Figure 2. Same as Fig. 1, except for the T1 site.

New particle formation depends on the concentrations of low-volatility vapors involved in nucleation and the initial growth of the nucleated particles and the coagulation losses of new particles during their initial growth. The low-volatility vapor concentrations depend on their photochemical production and condensational loss to particles. When evaluating and comparing nucleation schemes, it is useful to compare measurement-based and simulated estimates of these sources and sinks. The concentrations and photochemical production of low-volatility vapors was not measured, but we can compare modeled and observed precursor gas (i.e., $\mathrm{SO}_{2}$ ) concentrations. For the entire period, the modeled $\mathrm{SO}_{2}$ concentrations at T0 were fairly close to observed, with NMBs of $30 \%$, but there was poor agreement in temporal variability ( $R=0.30)$. The coagulation sinks for $1 \mathrm{~nm}$ particles and the condensation sinks for $\mathrm{H}_{2} \mathrm{SO}_{4}$ and at T0 and $\mathrm{T} 1$ were calculated (offline) using observed and simulated size distributions of $10-700 \mathrm{~nm}$ particles. The temporal variability of the coagulation and condensation sinks is fairly well reproduced $(R$ between 0.67 and 0.76 ). At T0, the simulated coagulation and condensation sinks were about twice those calculated using observations (NMBs of 94 and $106 \%$ ), while at T1 the coagulation and condensation sinks had NMBs of 35 and $40 \%$. These biases are generally consistent with the $\mathrm{CN}_{100}$ biases at the two sites. The high biases for the condensation and coagulation sinks would tend to give lower new particle formation under the simulation conditions compared to observed conditions, and thus cannot account for the higher simulated NPF (e.g., $\mathrm{CN}_{10}$ ) in the simulations compared to observations. Also, differences among the simulations with different nucleation parameterizations for $\mathrm{SO}_{2}$ concentrations and the two sink terms were small, so biases in them compared to the observed (or observation-based) values should have had similar impacts on NPF in all three simulations. 

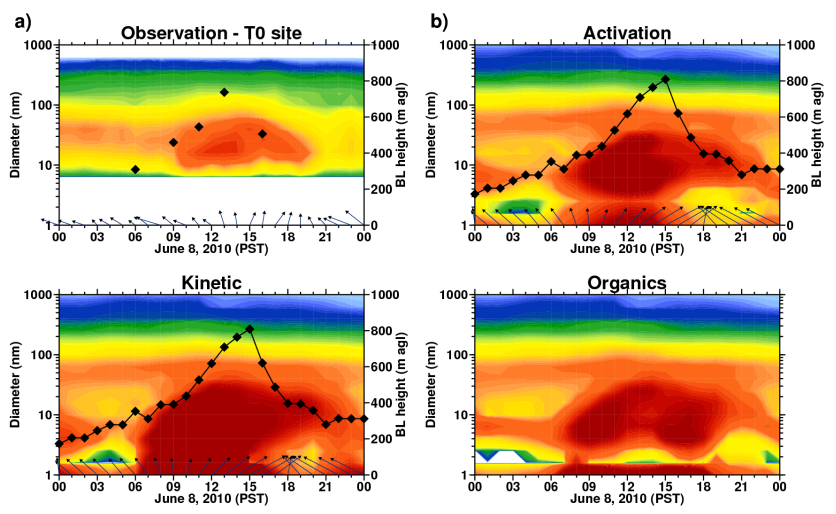

${ }^{10} \mathrm{~d} / \mathrm{d} / \log 10(\mathrm{Dp})\left(\# \mathrm{~cm}^{10}\right)$

Figure 3. Number size distribution as a function of geometric diameter and time at the T0 site on 8 June 2010 and from (a) observations and the (b) ACT, (c) KIN, and (d) ORG simulations. The vectors along the bottom of each panel represent the observed and calculated winds at $10 \mathrm{~m}$ above ground level (a.g.l.) at the T0 site. The maximum wind speed at about 15:00 PST in (b)-(d) is $6 \mathrm{~m} \mathrm{~s}^{-1}$. The black diamonds represent the observed (a) and simulated (b-d) boundary-layer heights.

\subsection{Analysis of the observed NPE on 8 June 2010}

Figures 3 and 4 compare the hourly modeled and observed number size distributions as a function of particle diameter at the T0 and T1 sites, respectively, on 8 June. For this study we have adopted the classification of the observed nucleation events given by Boy et al. (2008). Based on the occurrence and clarity of new particle formation events, they define four categories: A-event days, B-event days, undefined, and non-event days. According to their classification, an A-event shows clear nucleation-mode particles (the highest number of particles are observed at the lowest measurable SMPS size) and subsequent growth to larger sizes; a $\mathrm{B}$-event is less clear than an A-event (the highest number of particles are not observed in the first SMPS size bin, but at a greater diameter), and it is followed by the subsequent growth. Non-event days are those with no particle formation, while the days that cannot be classified as event or non-event days are called undefined days. Following this classification, on 8 June 2010 for both the T0 and T1 sites, a "class B" event occurred. Thus, the highest concentration of particles are not observed in the first SMPS size bin $(\sim 12.2$ and $8.75 \mathrm{~nm}$ diameter at the $\mathrm{T} 0$ and $\mathrm{T} 1$ sites), but at a greater diameter ( $~ 13.6$ and $16 \mathrm{~nm}$ diameter at the $\mathrm{T} 0$ and $\mathrm{T} 1$ sites on this day), and growth of these particles to Aitken mode was observed (Figs. 3a and 4a).

All of the simulations captured the observed NPE but with different PNC. The ACT, KIN, and ORG schemes behave similarly on this day, leading to a daily NMB for $\mathrm{CN}_{10}$ of 234, 346 and $206 \%$ at the T0 site and 143, 198 and $175 \%$ at the $\mathrm{T} 1$ site, respectively. Correlation coefficients were be-
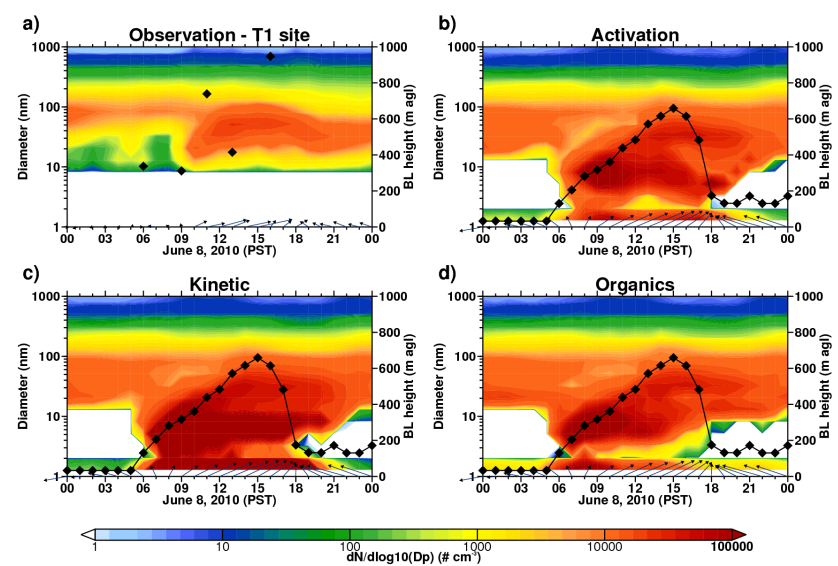

Figure 4. Same as Fig. 3, except for the T1 site.

tween 0.89 and 0.92 , indicating a good temporal agreement between observed and simulated $\mathrm{CN}_{10}$.

Observations at both sites show an increase of particles in the 10-20 nm range around 09:00 PST (Figs. 3a and 4a). These particles continue to grow in size in the following hours until they reach $80-100 \mathrm{~nm}$. Although the observed onset of nucleation starts around 09:00 PST, in our simulations the onset of nucleation is $2 \mathrm{~h}$ earlier (Figs. $3 b, \mathrm{c}, \mathrm{d}, 4 \mathrm{~b}, \mathrm{c}, \mathrm{d}$ ). This behavior could be attributed to the break-up of stable nocturnal boundary-layer and vertical mixing with cleaner air from the lower troposphere, which can trigger the formation of new particles (Kristensson et al., 2008). On this day, the simulated boundary-layer growth at the T0 site was very similar to that derived from radiosonde observations; therefore, vertical mixing associated with the growing convective boundary layer is likely reasonably simulated by the model. From the comparison of simulated $\mathrm{CN}_{10}$ aloft with the measurements during the morning G-1 flight on this day, the overestimation factors for $\mathrm{CN}_{10}$ aloft $(90,73$, and $118 \%$ for ACT, KIN, and ORG are much lower than for the surface sites. Therefore, the cleaner simulated free troposphere air could enhance formation of new particles near the surface as the boundary layer grows, as shown in Fig. 5. This figure also shows that for ACT the highest concentration of small particles coming from the nucleation process occurs at $\sim 2 / 3$ of the boundary-layer height. A higher number of small particles exist at this altitude compared to the number predicted at the surface, with concentrations aloft $\sim 30$ and $\sim 25 \%$ greater at $\mathrm{T} 0$ and $\mathrm{T} 1$, respectively. These particles formed aloft would be quickly transported to the surface by turbulent vertical mixing. KIN acts in a similar manner as ACT, although it predicts an increased number of small particles. In contrast, ORG predicts that the highest concentration of particles occurs at the surface. We can associate this with the relatively high NucOrg concentration predicted at the surface compared to the upper layers; therefore, enhanced particle production at this level is not unexpected when the ORG 

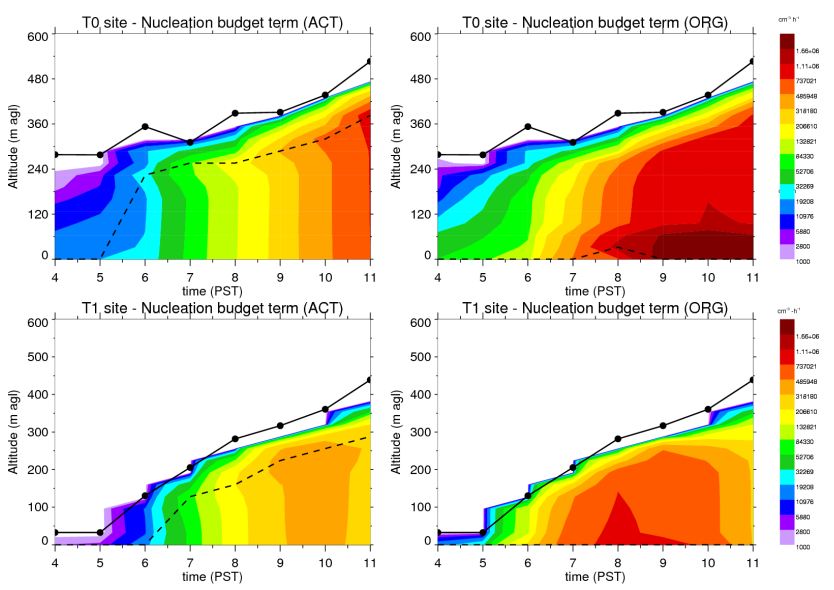

Figure 5. Particle production from the ACT and ORG parameterizations at the T0 and T1 sites on 8 June 2010 together with modeled BL height (circled line). The dashed line shows the altitude of the maximum predicted number of small particles.

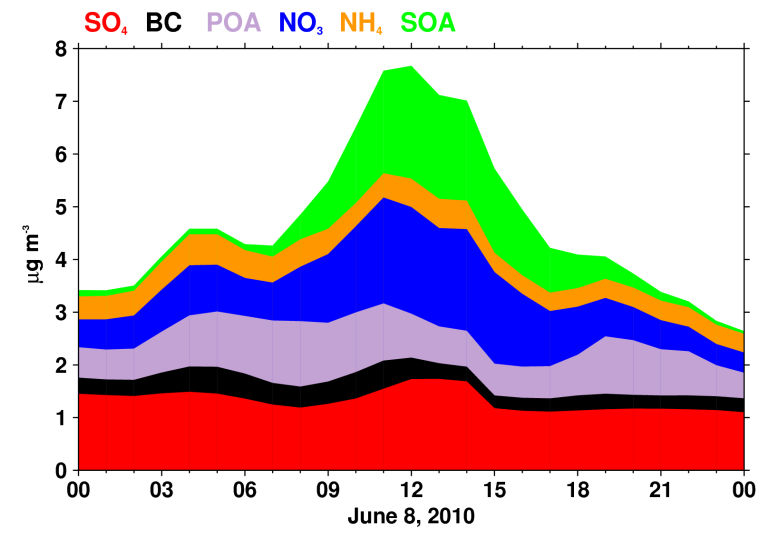

Figure 6. Simulated aerosol mass concentrations at the T0 site on 8 June 2010 predicted by the ACT parameterization.

parameterization is used. In addition, the simulated growth of particles corresponds to the increase of fine-particle SOA mass (Fig. 6), which also starts about $2 \mathrm{~h}$ before the observed NPE, indicating that SOA might have contributed to the simulated growth of ultrafine particles.

We calculated the observed and modeled growth rate of $10-40 \mathrm{~nm}$ particles as follows. Following Jeong et al. (2010), the geometric mean diameters (GMD) of $10-40 \mathrm{~nm}$ particles were calculated from the size distributions during the period when growth after formation was observed/modeled. The growth rate was obtained by fitting the GMD trend during the growth period:

$\mathrm{GR}=\frac{\Delta \mathrm{GMD}}{\Delta t}$.

Thus, we obtained at T0 a $\mathrm{GR}_{\mathrm{OBS}}=2.57 \mathrm{~nm} \mathrm{~h}^{-1}$, $\mathrm{GR}_{\mathrm{ACT}}=1.43 \mathrm{~nm} \mathrm{~h}^{-1}, \quad \mathrm{GR}_{\mathrm{KIN}}=1.14 \mathrm{~nm} \mathrm{~h}^{-1}, \quad$ and $\mathrm{GR}_{\mathrm{ORG}}=1.71 \mathrm{nmh}^{-1}$, and at $\mathrm{T} 1$ a GR $\mathrm{OBS}=3.69 \mathrm{~nm} \mathrm{~h}^{-1}$,
$\mathrm{GR}_{\mathrm{ACT}}=1.78 \mathrm{~nm} \mathrm{~h}^{-1}, \quad \mathrm{GR}_{\mathrm{KIN}}=1.51 \mathrm{~nm} \mathrm{~h}^{-1}, \quad$ and $\mathrm{GR}_{\mathrm{ORG}}=1.92 \mathrm{~nm} \mathrm{~h}^{-1}$. This indicates that the simulated growth rate was always slower than observed, which could be due to an underprediction in the concentration of condensable vapors compared to those in the ambient air or to the current treatment of SOA that does not include changes to viscosity and/or effective volatility by particlephase aging processes (Shrivastava et al., 2013; Zaveri et al., 2014).

The observed continuous growth of nucleation-mode particles through the day at both the T0 and T1 sites (Figs. 3a and 4a) suggests that nucleation and growth take place over regional scales. Figure 7a shows the simulated nucleation rate (from ACT) averaged from the surface to $\sim 130 \mathrm{~m}$ above ground level from 05:00 to 09:00 PST on 8 June 2010. Superimposed on this figure is a back trajectory (at $100 \mathrm{~m}$ a.g.l.) for air arriving at the T0 site at 09:00 PST on this day. The back trajectory indicates the air mass is transported by southwesterly winds from the San Francisco Bay area through the Carquinez Strait into the Central Valley before arriving in Sacramento. The peak nucleation rates occur over the industrialized region along northern San Francisco Bay that extends towards the T0 site. Nucleation also occurs over most of the Sacramento Valley, but the rates are about an order of magnitude lower than between the Carquienez Strait and Sacramento. Figure $7 \mathrm{~b}$ shows the computed $\mathrm{PNC}$ in the $1-10 \mathrm{~nm}$ $\left(\mathrm{CN}_{1-10}\right), 10-40 \mathrm{~nm}\left(\mathrm{CN}_{10-40}\right)$ and $40-100 \mathrm{~nm}\left(\mathrm{CN}_{40-100}\right)$ ranges along the trajectory. High concentrations of $\mathrm{CN}_{1-10}$ and $\mathrm{CN}_{10-40}$ particles occur along the trajectory prior to their arrival over the $\mathrm{T} 0$ site. The sharp increase in $\mathrm{CN}_{1-10}$ particles after 05:00 PST 8 June, followed $2 \mathrm{~h}$ later by the increase in $\mathrm{CN}_{10-40}$ particles, are associated with the early morning onset of nucleation. The model results indicate that nucleation and growth of aerosol particles were not only a local phenomenon, but also took place upwind of Sacramento before being transported over the T0 site (see Fig. 7a, b).

To obtain a better understanding of the factors that contribute to differences in the simulated number size distribution among the different parameterizations, we use budget diagnostics. These diagnostics are the tendencies associated with dry deposition plus vertical turbulent mixing, other transport (advection and horizontal turbulent mixing), emissions, condensation, nucleation, coagulation, and total tendency that affect PNC in the 1-10, 10-40, and 40-100 nm diameter ranges. (Note that the coagulation tendencies for each size range are combined losses from self-coagulation and coagulation with larger size particles.) As shown in Figs. 8, 9 , and 10, the use of different nucleation parameterizations leads to differences associated with the processes that contribute to aerosol formation and growth.

Even though both the ACT and KIN parameterizations depend only on $\mathrm{H}_{2} \mathrm{SO}_{4}$ concentration, the differences in their formulation lead to differences in the nucleation rates and consequently $\mathrm{CN}_{10}$ concentration, as shown previously. The KIN nucleation rates are higher than the ACT nucleation 
a)

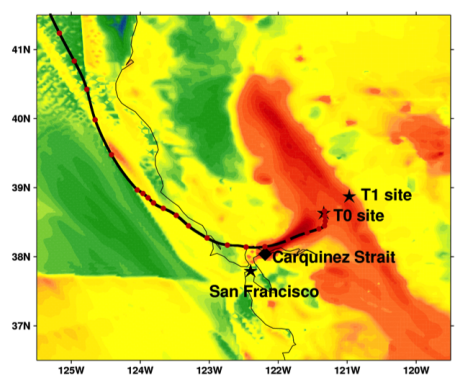

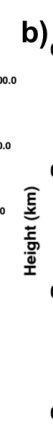

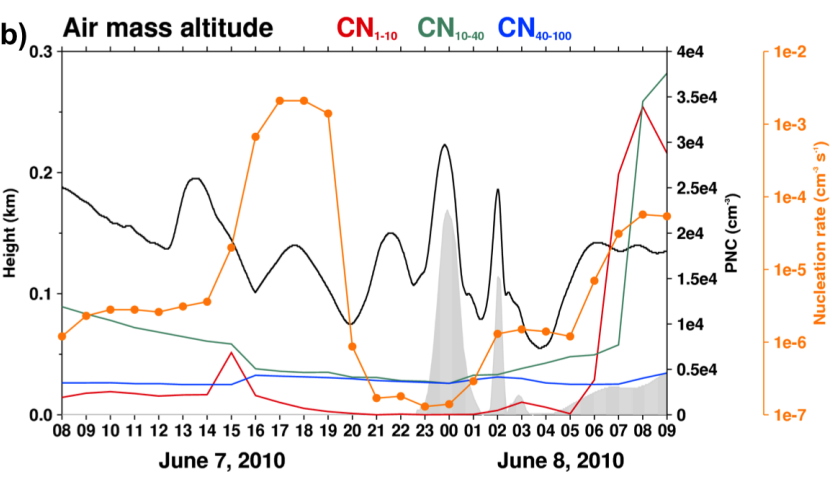

Figure 7. (a) Nucleation budget term $\left(\mathrm{cm}^{-3} \mathrm{~h}^{-1}\right)$ averaged over the first five model layers from 05:00 to 09:00 PST on 8 June 2010 from the ACT simulation, together with a backward trajectory from 08:00 PST on 7 June to 09:00 PST on 8 June 2010; the red dots denote the hourly locations of the air mass prior to its arrival at the T0; (b) altitude of the air mass (black line) together with particle number concentration in the $1-10 \mathrm{~nm}$ diameter range (red line), $10-40 \mathrm{~nm}$ range (green line), $40-100 \mathrm{~nm}$ range (blue line) and nucleation rate (orange circled line); the gray area denotes the terrain height.
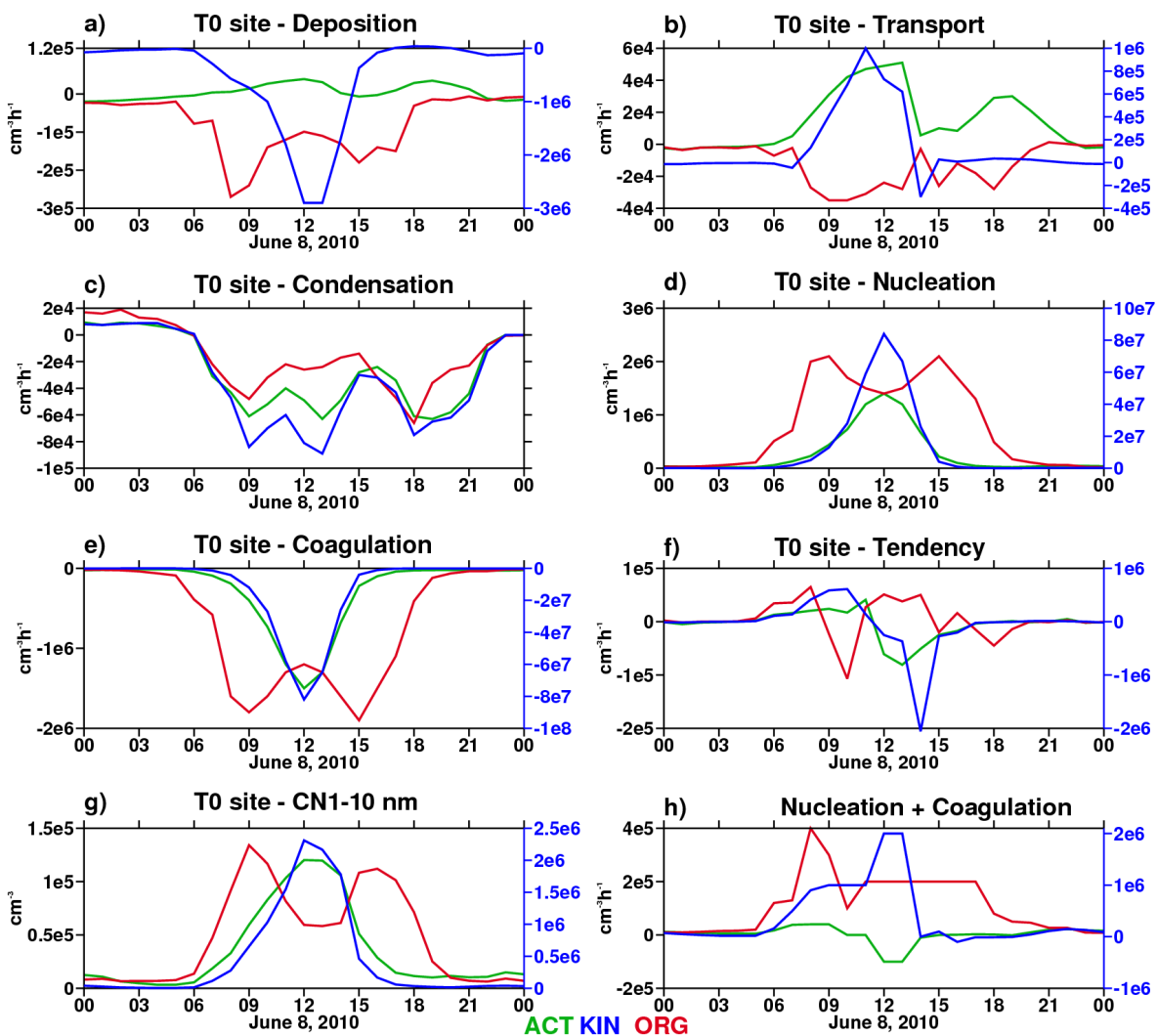

Figure 8. Budget diagnostic terms for 1-10 nm particles at the T0 site on 8 June: (a) dry deposition; (b) transport; (c) condensation; (d) nucleation; (e) coagulation; (f) total tendency; (g) particle number concentration; and (h) tendency of particles coming from nucleation and coagulation processes. The left-hand side (black) vertical axes are for ACT and ORG. The right-hand side (blue) axes are for KIN, which gave larger budget terms.

rates by as much as 1474 and $930 \%$ at the $\mathrm{T} 0$ and $\mathrm{T} 1$ sites, respectively. These differences in the nucleation rate could explain the differences in the magnitude of the budget terms associated with condensation (Figs. 8c, 9c, 10c), coagulation (Figs. 8e, 9e, 10e) and predicted particle number con- centration in the $1-10 \mathrm{~nm}$ range (Figs. $8 \mathrm{~g}, 9 \mathrm{~g}, 10 \mathrm{~g}$ ). Moreover, these differences in the nucleation rate could also explain the magnitude of combined nucleation and coagulation processes (Fig. 8h) that suggest for ACT the coagulation loss is more important than nucleation production. Similarly, the 

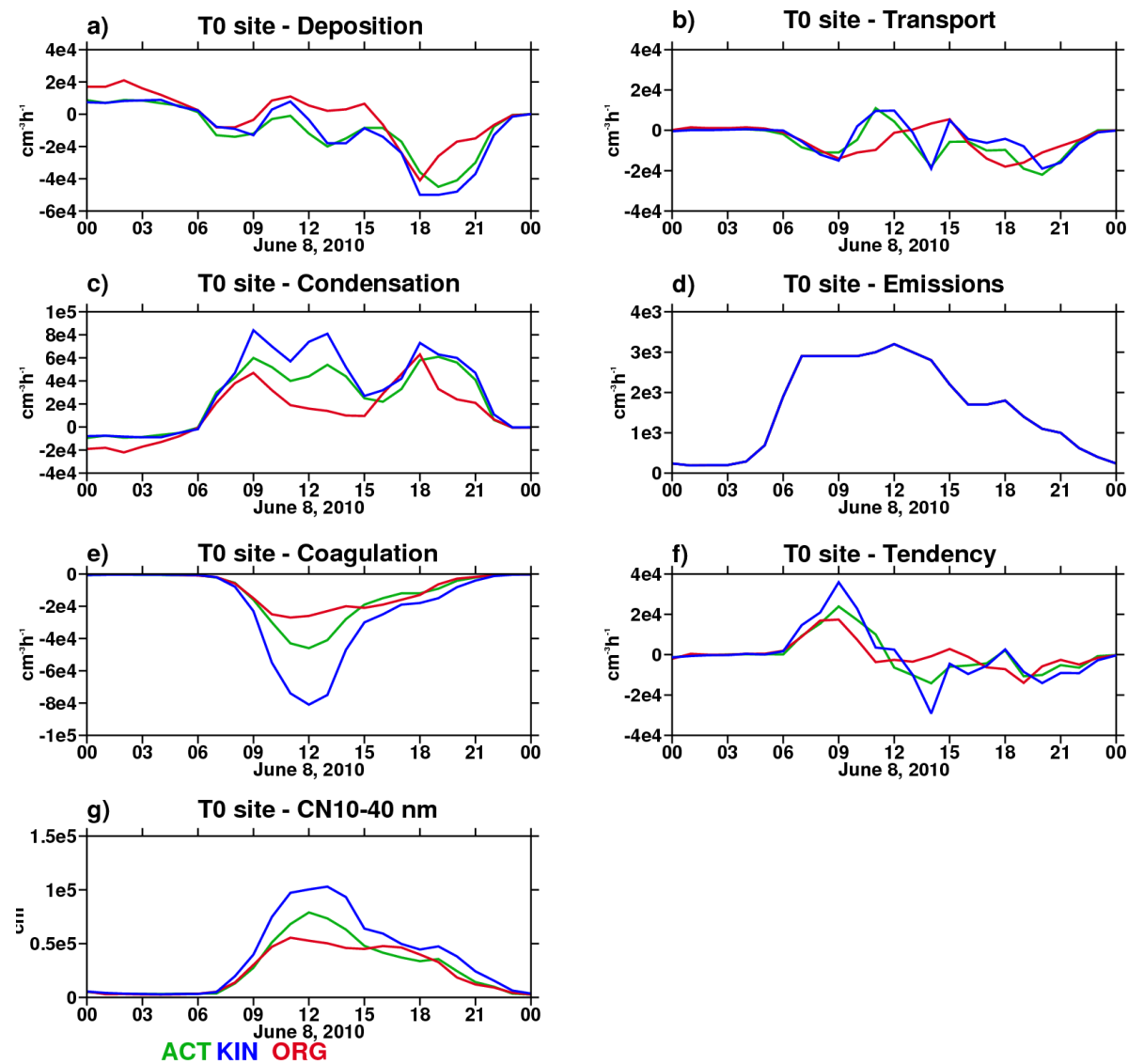

Figure 9. Budget diagnostic terms for 10-40 nm particles at the T0 site on 8 June: (a) deposition; (b) transport; (c) condensation; (d) emissions; (e) coagulation; (f) total tendency; and (g) particle number concentration.

higher predicted nucleation rate for KIN (Fig. 8d) could explain the difference in predicted number concentration in the $1-10 \mathrm{~nm}$ range (Fig. 8g). The aforementioned budget terms (nucleation, condensation, and coagulation) that contribute to the formation and growth of particles are strongly correlated with the diurnal variation of $\mathrm{H}_{2} \mathrm{SO}_{4}$ concentration at both sites on this day (less so with the ORG parameterization), although their magnitudes highly differ. Note that the diurnal variations of budget terms for dry deposition plus vertical mixing and for other transport for 10-40 and 40-100 nm particles are similar among the ACT, KIN, and ORG simulations (Figs. 9a, b, 10a, b), but the diurnal variations in these budget terms for $1-10 \mathrm{~nm}$ particles are quite different among the three nucleation parameterizations. Figure 8a shows that while the $\mathrm{CN}_{1-10}$ in $\mathrm{KIN}$ are lost through deposition and vertical mixing processes, a net gain of particles is predicted during mid-day hours and late afternoon using ACT, showing the impact of vertical mixing on predicted number concentration at the surface. Moreover, analysis of the other transport budget term (Fig. 8b) shows an increase of $\mathrm{CN}_{1-10}$ at T0 starting with the onset of modeled nucleation for both the ACT and KIN parameterizations, but a weak decrease for the ORG parameterization. These findings confirm that the nu- cleation and growth of aerosol particles are not just a local phenomenon but take place over a regional scale. A net gain of particles transported from upwind is simulated using ACT in the late afternoon (Fig. 8b), suggesting that the differences associated with the nucleation parameterization formulation and their strength impacts non-local phenomena such as horizontal transport.

We note that the use of the ACT and ORG schemes leads to similar results in terms of total PNC and size distribution during this day, whereas the budget diagnostic terms show several differences. Pierce et al. (2012) found a relatively small difference between ACT and ORG scheme simulations, which they attributed to high correlations of both $\mathrm{H}_{2} \mathrm{SO}_{4}$ and low-volatility organics with sunlight. In our simulation only $\mathrm{H}_{2} \mathrm{SO}_{4}$ is highly correlated with downward short wave flux ( $R=0.83$ over $06: 00$ to 20:00 PST), while the low-volatility NucOrg concentrations are relatively poorly correlated with the downward shortwave radiation flux $(R=0.38)$. As shown in Fig. 11 , the daily variability of $\mathrm{H}_{2} \mathrm{SO}_{4}$ and NucOrg concentrations present a different behavior, with $\mathrm{H}_{2} \mathrm{SO}_{4}$ concentrations peaking at $1.34 \times 10^{8}$ molecules $\mathrm{cm}^{-3}$ close to 13:00 PST and NucOrg concentrations peaking at $6.57 \times 10^{6}$ molecules $\mathrm{cm}^{-3}$ around 

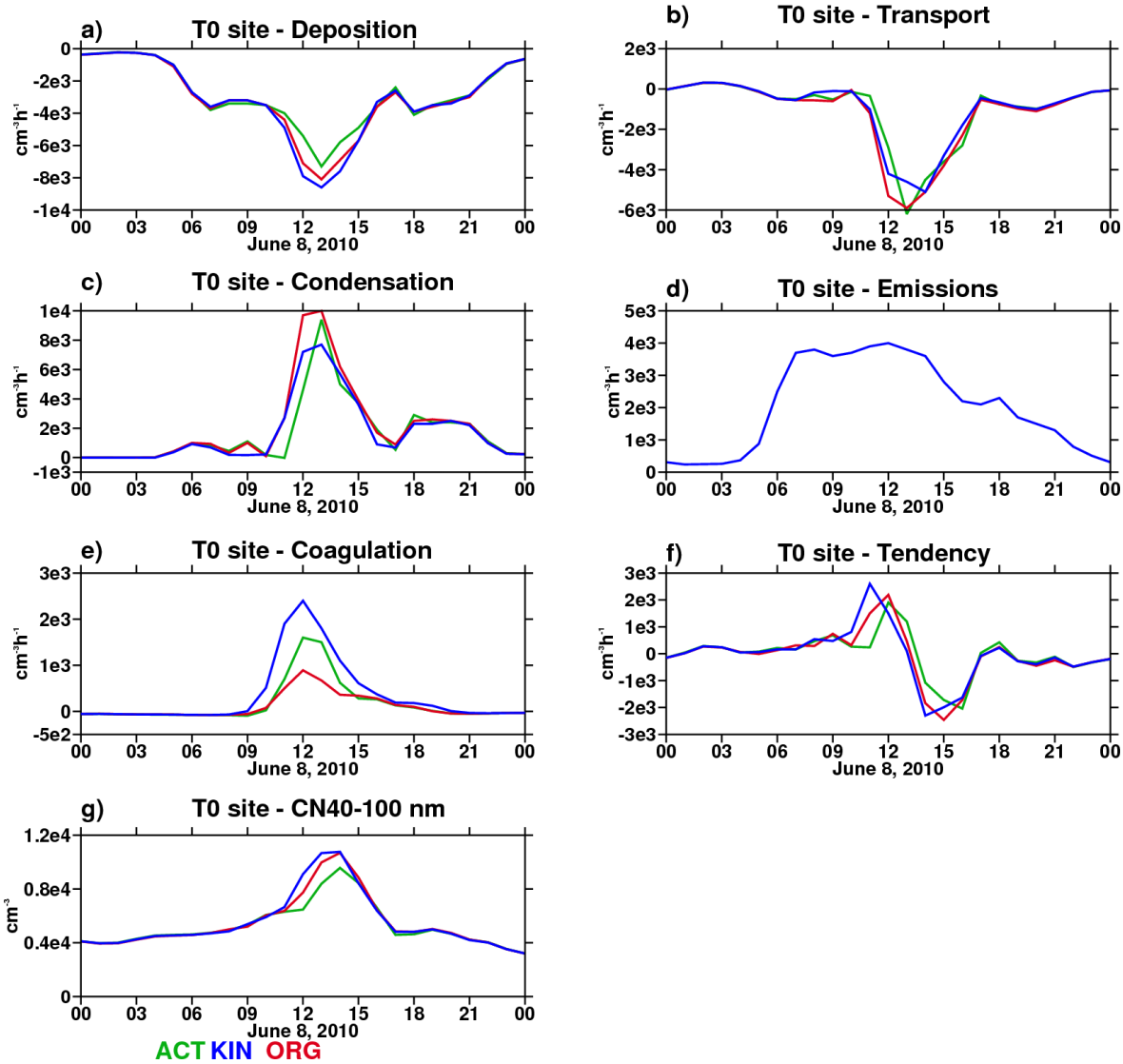

Figure 10. Budget diagnostic terms for 40-100 nm particles at the T0 site on 8 June: (a) deposition; (b) transport; (c) condensation; (d) emissions; (e) coagulation; (f) total tendency; and (g) particle number concentration.

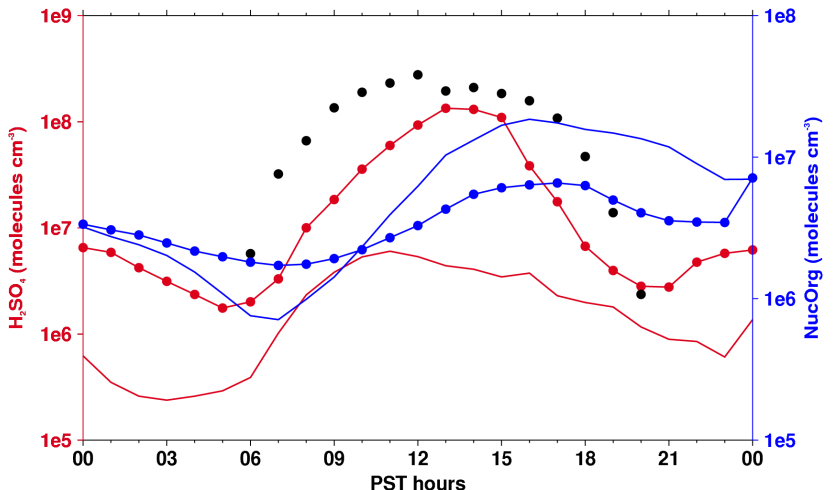

Figure 11. Modeled $\mathrm{H}_{2} \mathrm{SO}_{4}$ (red lines), and NucOrg concentrations (blue lines) at the T0 site on 8 June 2010 (lines with circles) and 12 June 2010 (lines without circles). The black dots represent the calculated $\mathrm{H}_{2} \mathrm{SO}_{4}$ proxy on 8 June 2010 . The $\mathrm{H}_{2} \mathrm{SO}_{4}$ proxy is not shown on 12 June 2010 due to missing measurements of $\mathrm{SO}_{2}$.

17:00 PST. Using the Mikkonen et al. (2011) method, we calculated the $\mathrm{H}_{2} \mathrm{SO}_{4}$ proxy concentration on 8 June using observed $\mathrm{SO}_{2}$ and particle concentrations. The average daytime concentration of this $\mathrm{H}_{2} \mathrm{SO}_{4}$ proxy is a factor of $\sim 3$ higher than the modeled $\mathrm{H}_{2} \mathrm{SO}_{4}$, but the proxy and modeled $\mathrm{H}_{2} \mathrm{SO}_{4}$ concentrations have similar temporal variations, peaking near noon PST. Although both $\mathrm{H}_{2} \mathrm{SO}_{4}$ and NucOrg are formed by oxidation of precursor gases by $\mathrm{OH}$ radicals, and hence are linked to solar radiation that regulates the intensity of photochemical reactions, their different diurnal patterns can be related to the diurnal patterns of their respective precursor gases. The anthropogenic organic vapor

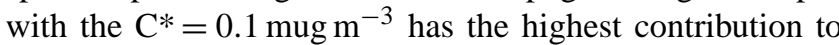
the NucOrg vapors concentration at T0, and their concentrations start to increase at 13:00 PST and reach a maximum around 18:00 PST. Their aromatic precursor gas has a similar temporal pattern during the afternoon, while $\mathrm{SO}_{2}$ is decreasing during this period (not shown).

The nucleation budget term demonstrates the impact of these low-volatility gases on the new particle formation. The ORG budget terms and particle number concentration for $1-10 \mathrm{~nm}$ particles have a different diurnal variability compared to ACT (Fig. 8). As can be seen from Fig. 8d and g, the ORG scheme shows two peaks in particle concentration that are associated with the increase of $\mathrm{H}_{2} \mathrm{SO}_{4}$ concentration in the morning, and the increase of low-volatility $\mathrm{Nu}$ cOrg concentration during the afternoon. As in the case of 


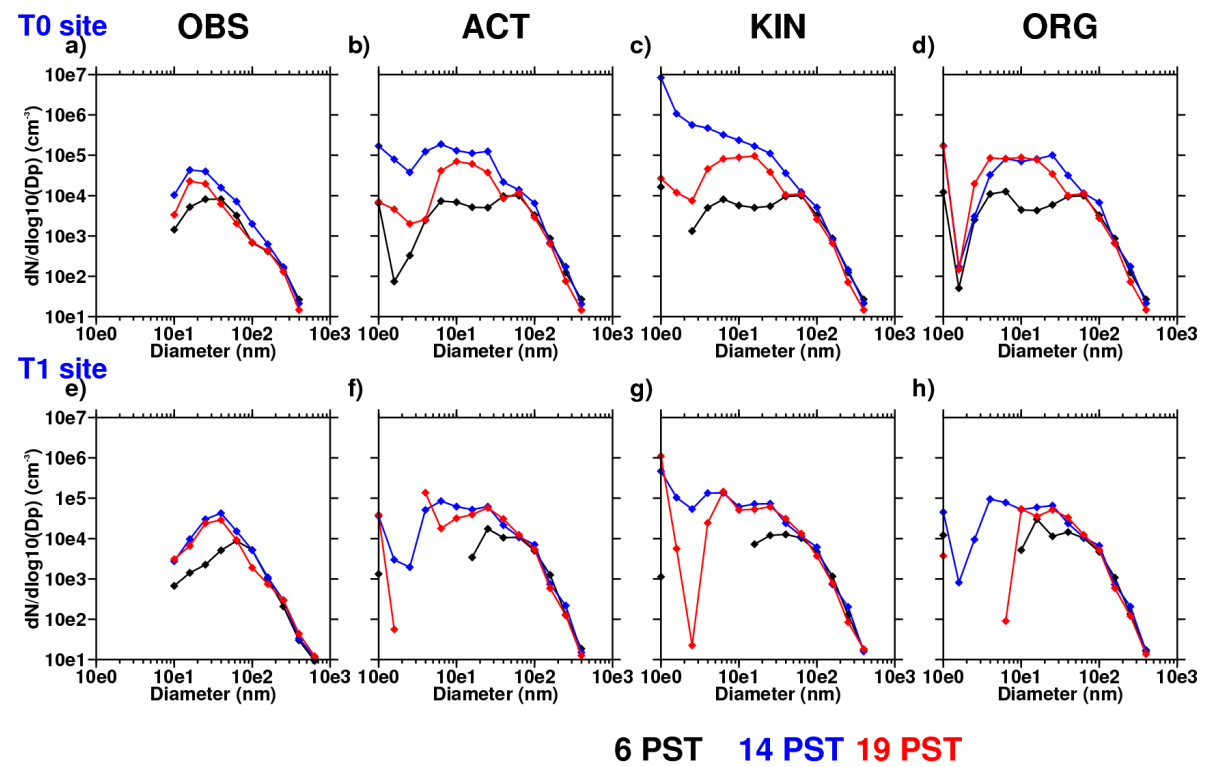

Figure 12. Particle number distribution for observations (OBS) and the ACT, KIN, and ORG simulations at the T0 (a-d) and T1 (e-h) sites at 10:00 PST (black line), 14:00 PST (blue line) and 19:00 PST (red line) on 8 June 2010. The missing line segments in the simulations correspond to particle numbers lower than $10 \mathrm{~cm}^{-3}$.

ACT and KIN, the ORG budget terms associated with condensation (Figs. 8c, 9c, 10c), nucleation (Fig. 8d) and coagulation (Figs. 8e, 9e, 10e) show the connection of these terms to the way that the nucleation is parameterized. Still, the budget terms and predicted number concentration (Figs. 9g and $10 \mathrm{~g}$ ) in the 10-40 and 40-100 $\mathrm{nm}$ size ranges present almost the same daily variability for all aforementioned parameterizations. Thus, we can say that even though the treatment of NPF has a great impact on the production rate of freshly nucleated aerosols (Fig. 8), removal processes through condensation, coagulation or dry deposition are efficient and could explain the relatively similar $\mathrm{CN}_{40}$ and $\mathrm{CN}_{100}$ predicted by ACT, KIN and ORG schemes. This is in agreement with the Westervelt et al. (2014) study with the GEOS-ChemTOMAS modeling system, which showed that $\mathrm{CN}_{10}$ concentrations are more sensitive to BL NPF parameterizations than $\mathrm{CCN}$-sized particle concentrations, consistent with the loss of newly formed particles through coagulation. Moreover, they investigated the nucleation rate and gas condensation sinks impact growth rate, coagulation sink, and survival probability, and showed that the relatively small differences in the predicted BL CCNs concentration are due to a strong damping effect. This might also explain the relative insensitivity of $\mathrm{CN}_{40}$ and $\mathrm{CN}_{100}$ to the choice of NPF mechanism in our study. Analyzing the total tendency of particle number, we note that particles in the $1-10 \mathrm{~nm}$ range have a net gain of particles starting around 05:00 PST (Fig. 8f); this trend is kept for larger particles, with a modeled net gain that starts around 06:00 PST for particles in the 10-40 nm range (Fig. 9f) and around 08:00 PST for particles in the $40-100 \mathrm{~nm}$ range (Fig. 10f). This behavior is in accord with new particle formation and growth processes.

In general, the simulations also capture the observed simultaneous decrease of particle size and number concentrations during the afternoon, as can be seen in Figs. 1 and 2 . The size distribution changes are more clearly seen in Fig. 12, which shows the observed and simulated particle number distributions at 06:00, 14:00, and 19:00 PST on 8 June 2010. The measurements show that the $20-100 \mathrm{~nm}$ PNC increases between 06:00 and 14:00 PST, presumably due to nucleation and condensational growth. Particle concentrations decrease later in the afternoon as nucleation rates decrease and the wind direction shifts. All nucleation schemes reproduced this variation in $20-100 \mathrm{~nm}$ PNC during the day at the T0 site, while at the T1 site both the observed and simulated PNC did not decrease between 14:00 and 19:00 LT. Southwesterly winds during the afternoon of 8 June transported air from the vicinity of Sacramento to the T1 site and kept concentrations of small particles relatively high.

In summary, we show that all the empirical parameterizations used in our simulations were able to qualitatively reproduce characteristics of the observed NPE on 8 June 2010. However, for all parameterizations the onset of the NPE was about $2 \mathrm{~h}$ too soon and the simulated PNC was too high. From the analysis of budget diagnostic terms for $1-10 \mathrm{~nm}$ particles, we find that at both $\mathrm{T} 0$ and $\mathrm{T} 1$ sites on this day, the ACT and KIN simulations exhibit almost the same temporal variability and are highly correlated with the diurnal variation of $\mathrm{H}_{2} \mathrm{SO}_{4}$ concentration. In contrast to the ACT and KIN simulations that show one peak in nucleation rate around noon, the diur- 

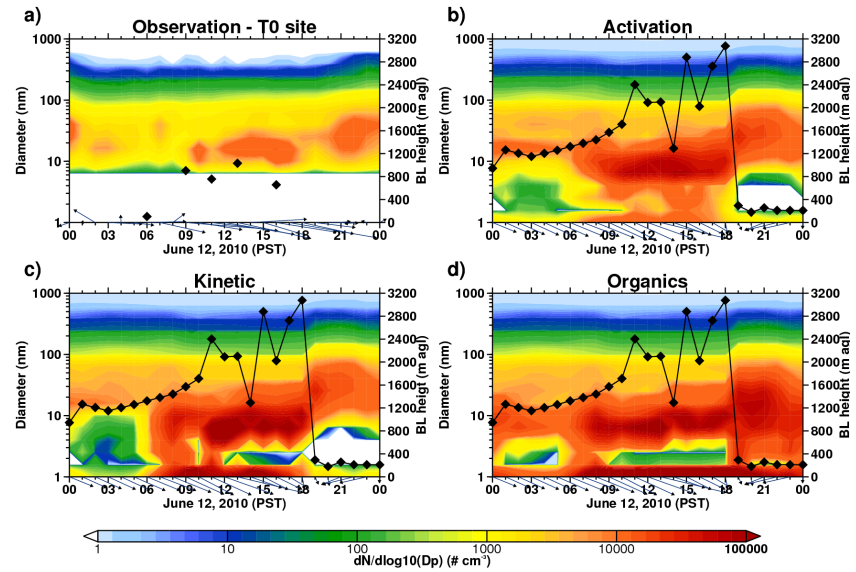

Figure 13. Number size distribution as a function of geometric diameter and time at the T0 site on 12 June 2010 from (a) observations and the (b) ACT, (c) KIN, and (d) ORG simulations. The vectors along the bottom of each panel represent the observed and calculated winds at $10 \mathrm{~m}$ a.g.1. at the T0 site. The maximum wind speed at about 12:00 PST in (b)-(d) is $10.4 \mathrm{~m} \mathrm{~s}^{-1}$. The black diamonds represent the observed (a) and simulated (b-d) boundarylayer heights.

nal variability from the ORG simulation is different, showing two peaks for nucleation rates and many other differences in budget diagnostic terms for $1-10 \mathrm{~nm}$ particles. Thus, the different nucleation parameterizations lead to different results in both particle number and size distribution.

\subsection{Analysis of an observed non-NPE on 12 June 2010}

On 12 June 2010, modest increases in $\mathrm{CN}_{10}$ were observed at the $\mathrm{T} 0$ and $\mathrm{T} 1$ sites during the day (Figs. 1 and 2). The observed size distributions in Figs. 13a and 14a show that the number of particles in the $10-30 \mathrm{~nm}$ size range increased during the day, but this was not followed by particle growth to larger sizes, as was the case on 8 June 2010. Although some nucleation was likely occurring, this behavior does not qualify as a nucleation event, based on the Boy et al. (2008) classification. The daily NMB values show that ACT, KIN, and ORG simulations overestimate $\mathrm{CN}_{10}$ by 192,199 , and $307 \%$, respectively, at the T0 site, and by 139,313 and $118 \%$, respectively, at the $\mathrm{T} 1$ site. Correlation coefficients between observed and simulated values range between 0.40 and 0.49 , indicating that these parameterizations coupled with other model processes did not capture the observed diurnal variability as well as on 8 June.

The observed particle number size distribution at the T0 site shows a shift in the maximum from the $10-30 \mathrm{~nm}$ range to the 20-50 nm range after 19:00 PST (Fig. 13a). All simulations reproduce this feature, although the shift in size is between 20 and $80 \mathrm{~nm}$ and the PNC is too high.

A possible explanation for this observed and also modeled feature can be related to the structure of the boundary
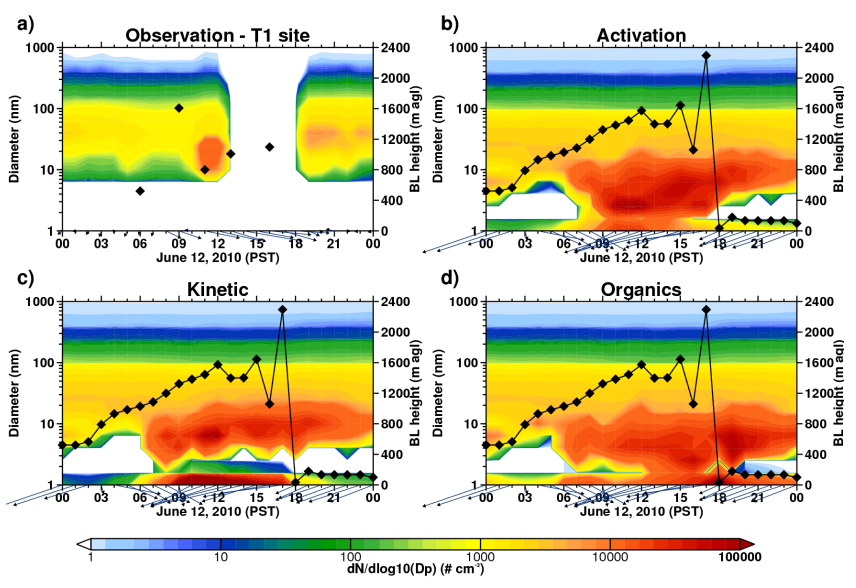

Figure 14. Same as Fig. 13, except for the T1 site.

layer. In contrast to the growth of the convective boundary layer during the day, the simulated boundary layer collapses after 18:00 PST, coinciding with increased stability near the surface. This stability does not allow vertical mixing of air near the surface with air aloft, so large particles remain near the surface, and this leads to the simulated increase in the $20-80 \mathrm{~nm}$ range. Again, as in the case of 8 June, we speculate that the change in wind direction and the decrease of wind speed between 18:00 and 19:00 PST might also explain the shift in particle size distribution. With lower wind speeds, we have a reduced effect of horizontal transport and vertical mixing on the $1-10$ and $10-40 \mathrm{~nm}$ range particles (Figs. 15b and 16b). At the same time we noticed a net gain of particles in the $40-100 \mathrm{~nm}$ size range (Fig. 17c), most likely coming from the condensation of NucOrg species, that is within an order of magnitude higher than the predicted $\mathrm{H}_{2} \mathrm{SO}_{4}$ (Fig. 11).

As in the case of 8 June 2010, the analysis of budget terms associated with the formation and growth of particles together with the predicted number concentration shows that the differences in the nucleation rate formulation lead to relatively large daily variability in the $1-10 \mathrm{~nm}$ size range (Fig. 15), while these differences are generally much smaller in the 10-40 and 40-100 nm size ranges (Figs. 16 and 17). For this particular case, most budget terms for ACT and KIN are similar for all size ranges (Figs. 15-17), although nucleation and coagulation for $1-10 \mathrm{~nm}$ particles is larger for KIN, while ORG shows the impact of low-volatility NucOrg organic vapors on the nucleation rate and subsequent influence on diurnal variation. During this period, the amount of $\mathrm{SO}_{2}$ transport to the site is small, so there is less $\mathrm{H}_{2} \mathrm{SO}_{4}$ present compared to the low-volatility NucOrg generated from local sources. Thus, nucleation and subsequent growth of new particles is greater in the case of the ORG simulation because of the local sources of NucOrg species, leading to the larger overestimation of $1-10 \mathrm{~nm}$ (Fig. 15g) and 10-40 nm particles (Fig. 16g) at the T0 site compared to the other mechanisms. 

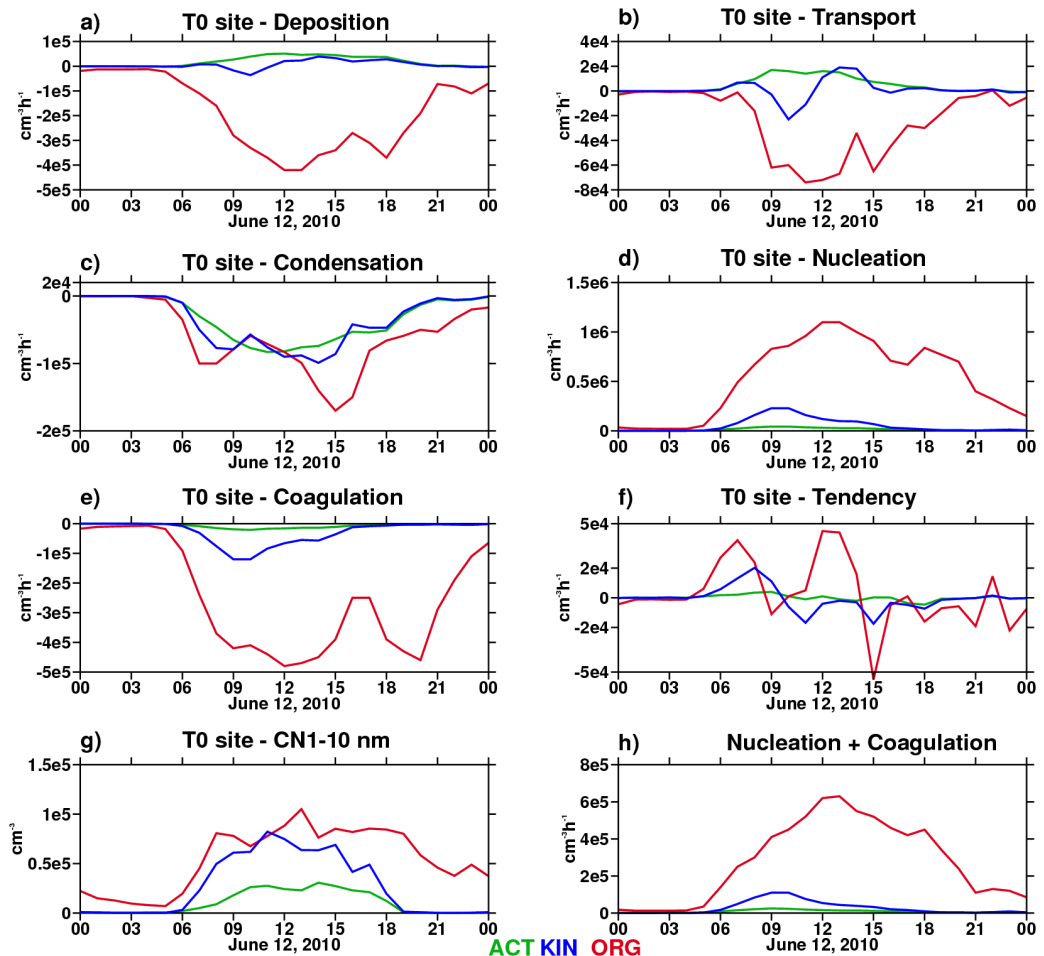

Figure 15. Budget diagnostic terms for 1-10 nm particles at the T0 site on 12 June: (a) deposition; (b) transport; (c) condensation; (d) nucleation; (e) coagulation; (f) total tendency; (g) particle number concentration in the 1-10 nm range; and (h) tendency of particles coming from nucleation and coagulation processes.
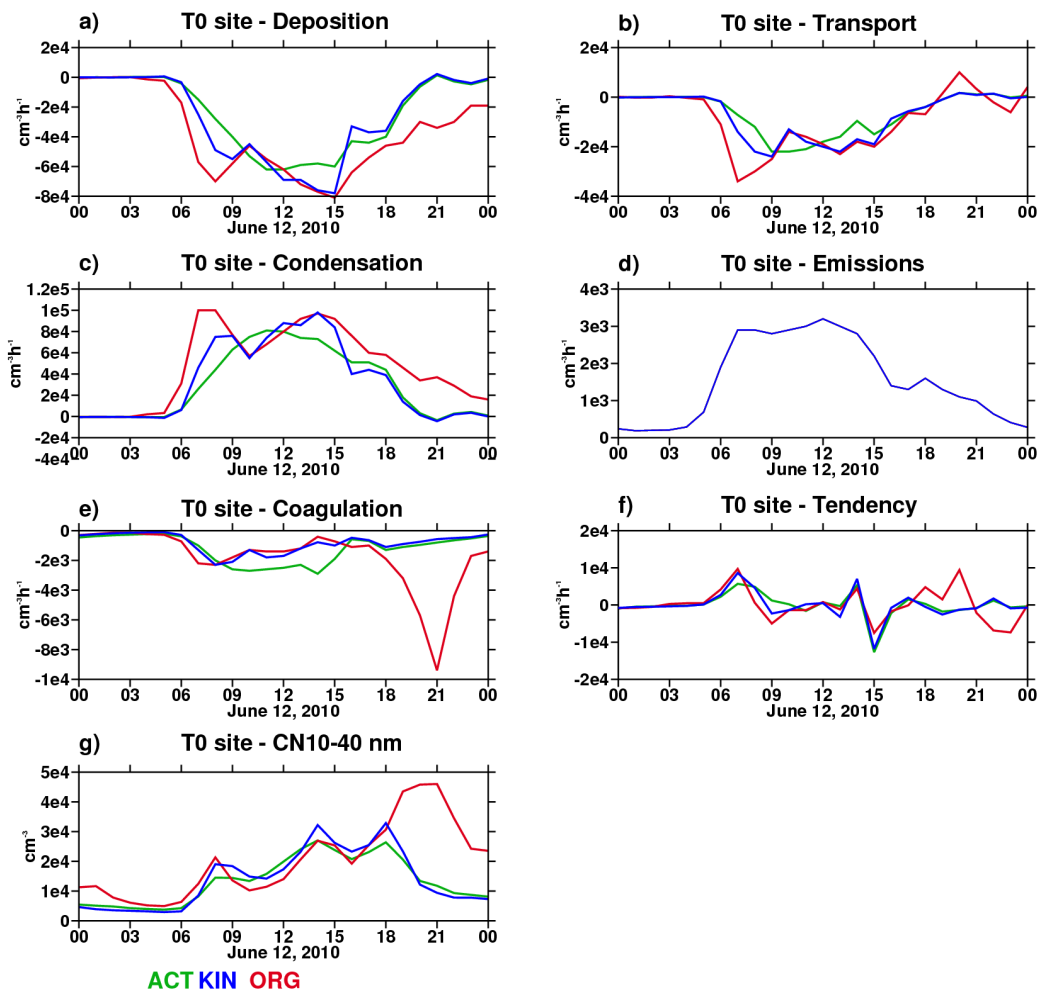

Figure 16. Budget diagnostic terms for 10-40 nm particles at the T0 site on 12 June: (a) deposition; (b) transport; (c) condensation; (d) emissions; (e) coagulation; (f) total tendency; and (g) particle number concentration. 
Table 3. Selected budget diagnostic terms $\left(\mathrm{cm}^{-3} \mathrm{~h}^{-1}\right)$ for all NPE days at the T0 and T1 sites, averaged over 04:00-16:00 PST on each day. The $\mathrm{CN}_{1-10}$ Transport + Deposition term includes advection, turbulent mixing, and dry deposition.

\begin{tabular}{|c|c|c|c|c|c|c|}
\hline NPE event & Experiment & $\begin{array}{r}\mathrm{CN}_{1-10} \\
\text { Transport }+ \text { Deposition }\end{array}$ & $\begin{array}{r}\mathrm{CN}_{1-10} \\
\text { Condensation }\end{array}$ & $\begin{array}{r}\mathrm{CN}_{1-10} \\
\text { Nucleation }\end{array}$ & $\begin{array}{r}\mathrm{CN}_{1-10} \\
\text { Coagulation }\end{array}$ & $\begin{array}{r}\mathrm{CN}_{10-100} \\
\text { Condensation }+ \text { Coagulation }\end{array}$ \\
\hline \multirow[t]{3}{*}{7 June 2010} & $\mathrm{ACT}$ & -467 & -6165 & 64200 & -56662 & 3113 \\
\hline & KIN & 34589 & -28112 & 568746 & -566077 & 7851 \\
\hline & ORG & -111977 & -34309 & 2295385 & -2127692 & 8648 \\
\hline \multirow[t]{3}{*}{8 June 2010} & $\mathrm{ACT}$ & 30028 & -33002 & 493769 & -498615 & 14378 \\
\hline & KIN & -706731 & -43362 & 22285077 & -21623692 & 11718 \\
\hline & ORG & -142762 & -19701 & 1323769 & -1147923 & 5311 \\
\hline \multirow[t]{3}{*}{9 June 2010} & $\mathrm{ACT}$ & 13514 & -44665 & 136923 & -105308 & 37167 \\
\hline & KIN & -78154 & -85439 & 1812308 & -1646923 & 71408 \\
\hline & ORG & -163368 & -56626 & 1868154 & -1646000 & 44537 \\
\hline \multirow[t]{3}{*}{10 June 2010} & $\mathrm{ACT}$ & 38646 & -53764 & 45238 & -29546 & 50833 \\
\hline & KIN & 7144 & -80066 & 307523 & -229331 & 78095 \\
\hline & ORG & -194592 & -77118 & 630231 & -352538 & 68368 \\
\hline \multirow[t]{3}{*}{11 June 2010} & ACT & 37617 & -50877 & 25515 & -11409 & 49099 \\
\hline & KIN & 8629 & -58040 & 100538 & -51247 & 56856 \\
\hline & ORG & -282259 & -84154 & 687231 & -310454 & 68239 \\
\hline \multirow[t]{3}{*}{14 June 2010} & $\mathrm{ACT}$ & 25291 & -31878 & 608846 & -594692 & 10094 \\
\hline & KIN & -1036169 & -50777 & 28470000 & -27343923 & 18983 \\
\hline & ORG & -72954 & -21925 & 900462 & -797923 & 8930 \\
\hline \multirow[t]{3}{*}{15 June 2010} & ACT & 5769 & -27877 & 267462 & -243431 & 11901 \\
\hline & KIN & -418362 & -25031 & 7323846 & -7022969 & 25423 \\
\hline & ORG & -77023 & -26138 & 1231000 & -1129462 & 17232 \\
\hline \multirow[t]{3}{*}{16 June 2010} & ACT & 54250 & -79367 & 84167 & -56858 & 74135 \\
\hline & KIN & -159425 & -49981 & 832727 & -615400 & 46482 \\
\hline & ORG & -142382 & -72017 & 425417 & -207458 & 64203 \\
\hline
\end{tabular}

Due to missing measurements between 12:00 and 18:00 PST, the evolving observed particle number size distribution at the T1 site (Fig. 14a) is not complete. Still, as for the T0 site, we can observe at $\mathrm{T} 1 \mathrm{a}$ maximum in size distribution at 11:00 PST in the $10-30 \mathrm{~nm}$ range that is shifted towards the $30-50 \mathrm{~nm}$ range after 18:00 PST. However, the simulations are not able to reproduce this feature, with the model indicating a shift from the 6-10 to $10-20 \mathrm{~nm}$ ranges. From an analysis of the budget terms and the NucOrg gas concentration, we can attribute the shift in the T1 size distribution around sunset to the same causes as the T0 shift, namely the boundary-layer collapse, variations in wind speed and direction, and (for the ORG parameterization) the condensation of NucOrg organic vapors.

\subsection{Impact of nucleation parameterizations on physical processes associated to the NPEs}

Table 3 shows selected budget terms on all NPE days (7-11 and 14-16 June 2010 at the T0 site, and 7-10 and 14-16 June at the T1 site) averaged over the period from 04:00 through 16:00 PST. These terms show how the particle number con- centrations are affected by the different processes. The four terms for $\mathrm{CN}_{1-10}$ particles comprise a complete budget: gain due to nucleation, loss due to coagulation, loss due to condensational growth to sizes $>10 \mathrm{~nm}$, and net transport plus deposition (advection, vertical mixing, and dry deposition). The single term for $\mathrm{CN}_{10-100}$ particles shows the net gain by condensational growth of smaller particles into this size range, modulated by coagulation loss of $\mathrm{CN}_{10-100}$ particles (which is significant on some days). On each NPE day, the nucleation budget terms for $1-10 \mathrm{~nm}$ particles from the three nucleation parameterizations differ by factors of about 10 50. The ACT nucleation term is always the smallest, and there are large differences between KIN and ORG on many days, with KIN largest on some days and ORG largest on others. Yet, the nucleation and coagulation terms are similar in magnitudes for any given parameterization and day, indicating that coagulation strongly moderates the large differences in nucleation rates. This confirms the findings from the diurnal variability analysis of 8 June 2010 NPE.

The $\mathrm{CN}_{1-10}$ condensation budget terms for all three parameterizations are much closer in magnitude to each other, 

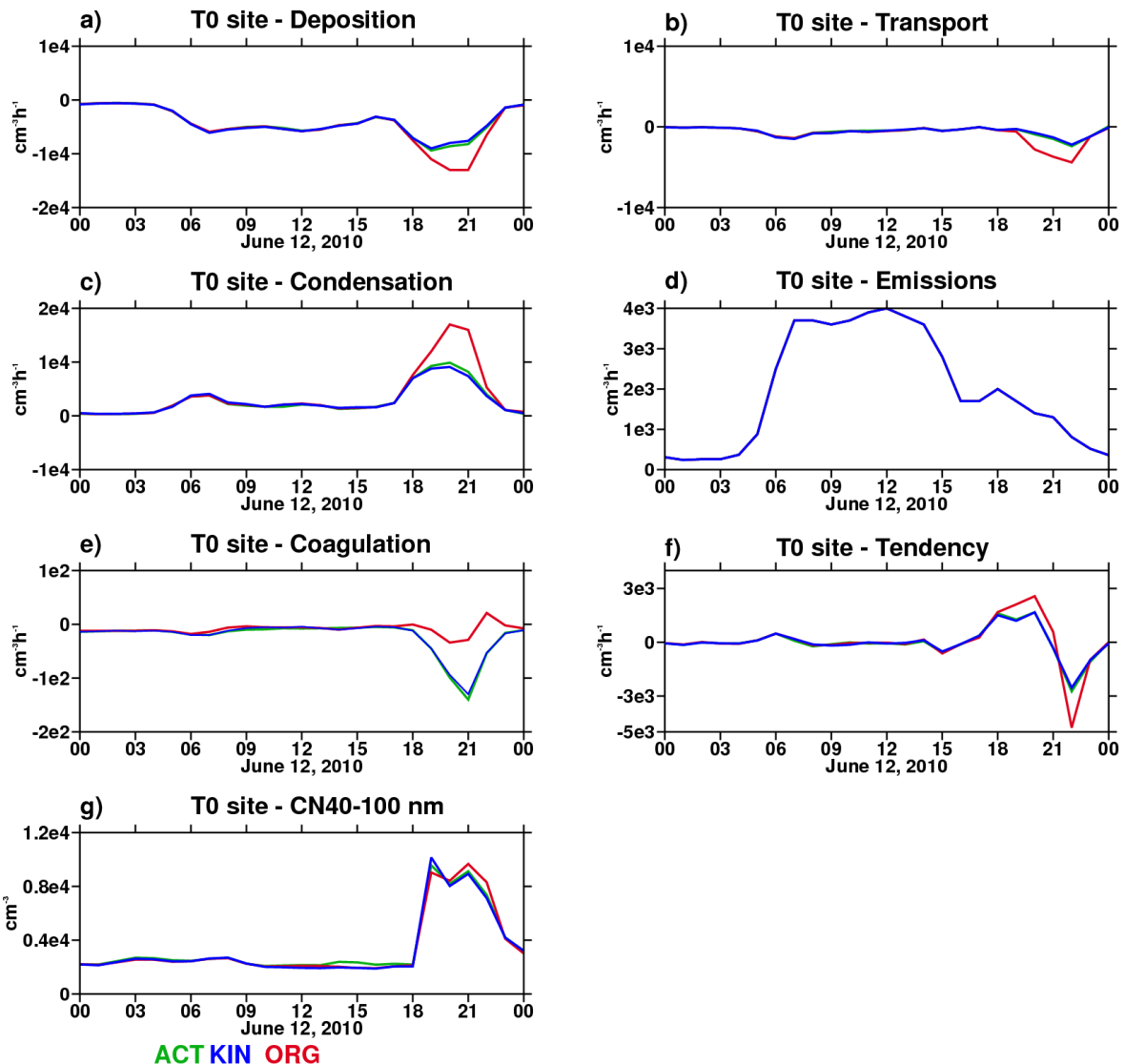

Figure 17. Budget diagnostic terms for $40-100 \mathrm{~nm}$ particles at the T0 site on 12 June: (a) deposition; (b) transport; (c) condensation; (d) emissions; (e) coagulation; (f) total tendency; and (g) particle number concentration.

generally within a factor of 2 , except for the 7 June 2010 case when the condensation budget terms are higher by factors of 4.6 and 5.6 for KIN and ORG compared to ACT. The $\mathrm{CN}_{1-10}$ condensation budget term (when multiplied by -1 ) gives the effective production of particles larger than $10 \mathrm{~nm}$ diameter. These effective $\mathrm{CN}>10$ production rates are thus much less sensitive to the nucleation parameterizations, and are also much smaller in magnitude than the nucleation rates, because of the strong modulation of nucleation by coagulation.

The combined condensation and coagulation budget terms for $10-100 \mathrm{~nm}$ particles are quite similar to the $\mathrm{CN}_{1-10}$ condensation on some days but are lower by factors of about 2-4 on other days, indicating further modulation of the new particle production by coagulation on some days. For the 7 June 2010 case noted above, the combined $\mathrm{CN}_{10-100}$ condensation and coagulation terms from the three nucleation parameterizations are somewhat closer (factor of 2.8 range) compared to the $\mathrm{CN}_{1-10}$ condensation (factor of 5.6 range) due to this additional modulation. Note that the $\mathrm{CN}_{10-100}$ condensation plus coagulation term for KIN is on average about $40 \%$ higher than for ACT, and this is in agreement with the $\mathrm{KIN}$ vs. ACT $\mathrm{CN}_{10}$ concentration differences presented in Sect. 4.1.

The differences in the $\mathrm{CN}_{1-10}$ budget terms for horizontal transport, vertical mixing and dry deposition indicate the impact of nucleation and growth processes over regional spatial scales. As stated previously, the efficiency of removal processes such as condensation, coagulation or dry deposition could explain the relatively small differences among simulations for the predicted particle number concentrations in the 10-40 and 40-100 nm size ranges (see Figs. 1 and 2 and Table 3). Once more, we have shown that although the formulation of the nucleation rate parameterization impacts the prediction of newly formed particles, removal processes strongly modulate the nucleation parameterization differences.

\subsection{Comparison with aircraft measurements in the and above boundary layer}

As shown in Table 4, all simulations produced average particle number concentrations aloft that were generally too high when compared to the CPC measurements collected during the eight aircraft flights. The statistics for particles with di- 
Table 4. Observed mean and simulation summary statistics for aerosol number concentrations for particle diameters $\geq 3 \mathrm{~nm}\left(\mathrm{CN}_{3}\right)$ and $\mathrm{CN}_{10}$. The observed mean, normalized mean bias (NMB) and correlation coefficient $(R)$ are calculated between simulated and observed number concentration collected during the CARES G-1 aircraft flights.

\begin{tabular}{|c|c|c|c|c|c|c|c|c|}
\hline \multirow[t]{2}{*}{$\mathrm{PNC}$} & \multirow[t]{2}{*}{ Flight } & \multirow[t]{2}{*}{ Observed mean } & \multicolumn{3}{|c|}{$\operatorname{NMB}(\%)$} & \multicolumn{3}{|c|}{$R$} \\
\hline & & & ACT & KIN & ORG & $\mathrm{ACT}$ & KIN & ORG \\
\hline \multirow[t]{9}{*}{$\mathrm{CN}_{3}$} & 8 June, morning (08a) & 20472 & 157 & 614 & 227 & 0.64 & 0.67 & 0.74 \\
\hline & 8 June, afternoon (08b) & 13990 & 274 & 603 & 204 & 0.84 & 0.79 & 0.67 \\
\hline & 10 June, morning (10a) & 17392 & 212 & 365 & 212 & 0.22 & 0.19 & -0.05 \\
\hline & 12 June, morning (12a) & 12340 & 198 & 162 & 243 & 0.40 & 0.29 & 0.50 \\
\hline & 12 June, afternoon (12b) & 14459 & 184 & 307 & 359 & -0.06 & 0.10 & 0.32 \\
\hline & 14 June, morning (14a) & 21913 & 259 & 824 & 368 & 0.56 & 0.57 & 0.51 \\
\hline & 15 June, morning (15a) & 24800 & 250 & 845 & 296 & 0.68 & 0.69 & 0.61 \\
\hline & 15 June, afternoon (15b) & 14800 & 260 & 776 & 330 & 0.75 & 0.46 & 0.38 \\
\hline & All flights & 17564 & 226 & 608 & 282 & 0.52 & 0.51 & 0.48 \\
\hline \multirow[t]{9}{*}{$\mathrm{CN}_{10}$} & 8 June, morning (08a) & 11588 & 90 & 173 & 118 & 0.57 & 0.58 & 0.58 \\
\hline & 8 June, afternoon (08b) & 10161 & 162 & 219 & 168 & 0.80 & 0.81 & 0.77 \\
\hline & 10 June, morning (10a) & 10804 & 95 & 138 & 92 & -0.03 & 0.03 & -0.12 \\
\hline & 12 June, morning (12a) & 6019 & 69 & 105 & 87 & 0.44 & 0.49 & 0.55 \\
\hline & 12 June, afternoon (12b) & 7940 & 128 & 128 & 105 & -0.05 & -0.04 & -0.04 \\
\hline & 14 June, morning (14a) & 11999 & 221 & 365 & 273 & 0.72 & 0.70 & 0.60 \\
\hline & 15 June, morning (15a) & 13601 & 216 & 338 & 250 & 0.71 & 0.70 & 0.61 \\
\hline & 15 June, afternoon (15b) & 12625 & 230 & 296 & 068 & 0.48 & 0.14 & 0.29 \\
\hline & All flights & 10641 & 162 & 239 & 184 & 0.54 & 0.51 & 0.49 \\
\hline
\end{tabular}

ameters greater than $3 \mathrm{~nm}\left(\mathrm{CN}_{3}\right)$ show that all parameterizations predicted more particles in the nucleation mode than were measured. The best results were obtained from the ACT simulation (NMB ranging from 157 to $274 \%$ ) and the worst results were obtained for the KIN simulation (NMB ranging from 162 to $845 \%$ ). A similar statistical trend occurred for $\mathrm{CN}_{10}$, except that the differences between model results and observations were greatly reduced compared to $\mathrm{CN}_{3}$. For $\mathrm{CN}_{10}$, the KIN simulation had a NMB between 105 and $338 \%$, while the ACT simulation had a NMB between 69 and $230 \%$.

There are a few instances, such as the flight during the afternoon on 8 June (flight 08b), in which the statistical analysis shows that all the simulations reproduced the observed spatial variability of $\mathrm{CN}_{3}$ and $\mathrm{CN}_{10}$ reasonably well ( $R>0.67$ and $R>0.77$ ), while overestimating the observed concentration $\left(\mathrm{CN}_{3}\right.$ concentration has a NMB ranging from $204 \%$ for ORG to $603 \%$ for KIN, while $\mathrm{CN}_{10}$ concentration has a NMB ranging from $162 \%$ for ACT to $219 \%$ for KIN). There are other cases for which the simulated $\mathrm{CN}_{3}$ and $\mathrm{CN}_{10}$ concentration have similar high biases, but the simulated spatial variabilities do not agree well with the measurements (low correlation), such as on the afternoon of 12 June 2010 (flight 12b).

To summarize the overall performance of the different simulations, we also computed statistics for all flights combined (see Table 4). As for individual flights, the best results were obtained when using the ACT parameterization (NMB of 226 and $162 \%$ for $\mathrm{CN}_{3}$ and $\mathrm{CN}_{10}$, respectively) and the worst results were obtained for the KIN parameterization (NMB of 608 and $239 \%$ for $\mathrm{CN}_{3}$ and $\mathrm{CN}_{10}$, respectively). The correlation coefficients (between 0.48 and 0.54 ) show a moderate agreement in capturing the observed spatial variability of both $\mathrm{CN}_{3}$ and $\mathrm{CN}_{10}$.

We also examined the model performance in simulating $\mathrm{CN}_{3}$ and $\mathrm{CN}_{10}$ as function of aircraft altitude, using intervals from the ground to 500, 500-1000, 1000-1500, and 1500 $2000 \mathrm{~m}$ a.g.l. Comparisons between the measured and predicted median PNC, together with the 25th and 75th percentiles, for the afternoon flights of 8 and 12 June, are shown in Figs. 18 and 19, respectively. Below $1000 \mathrm{~m}$ a.g.l., the simulated $\mathrm{CN}_{3}$ and $\mathrm{CN}_{10}$ concentrations are usually $100-200 \%$ higher than the corresponding measurements (see Figs. 18 and 19). Note that the afternoon maximum boundary-layer height on 8 June was $\sim 800 \mathrm{~m}$ a.g.l. (Fig. 3), suggesting that the majority of the measured and simulated $\mathrm{CN}_{3}$ and $\mathrm{CN}_{10}$ particles were located within the boundary layer. Comparison between modeled and observed $\mathrm{CN}_{3}$ and $\mathrm{CN}_{10}$ medians and interquartile ranges above $1000 \mathrm{~m}$ a.g.l. on 8 June 2010 (Fig. 18c, d, g, h) shows that all simulations reasonably represent the measurements. $\mathrm{CN}_{3}$ concentrations have a NMB ranging from $56 \%$ for ACT to $211 \%$ for $\mathrm{KIN}$, while $\mathrm{CN}_{10}$ is overestimated by $70-100 \%$. This behavior can be associated with lower $\mathrm{SO}_{2}$ concentrations at these altitudes (simulated but not measured), and consequently lower $\mathrm{H}_{2} \mathrm{SO}_{4}$ concentrations and less new particle formation.

The strong northerly winds present on 12 June 2010 led to much lower $\mathrm{SO}_{2}$ concentrations compared to 8 June, and this 
CN3 (500 m agl) CN3 (1000 m agl) CN3 (1500 m agl) CN3 (2000 m agl)
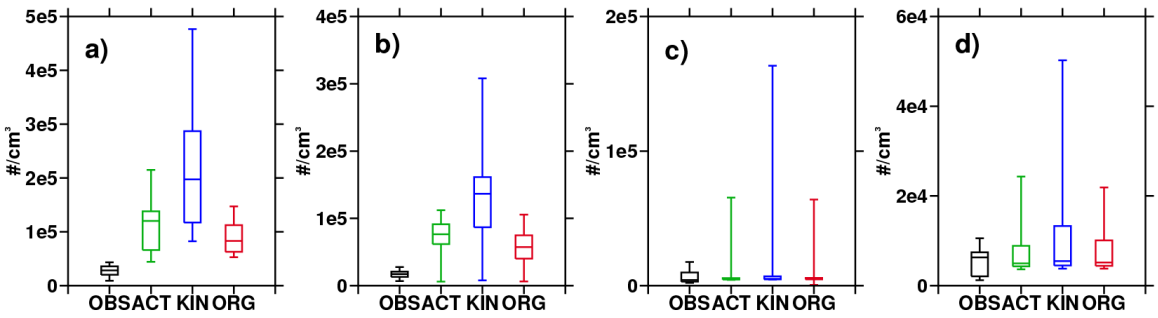

CN10 (500 m agl) CN10 (1000 m agl) CN10 (1500 m agl) CN10 (2000 m agl)
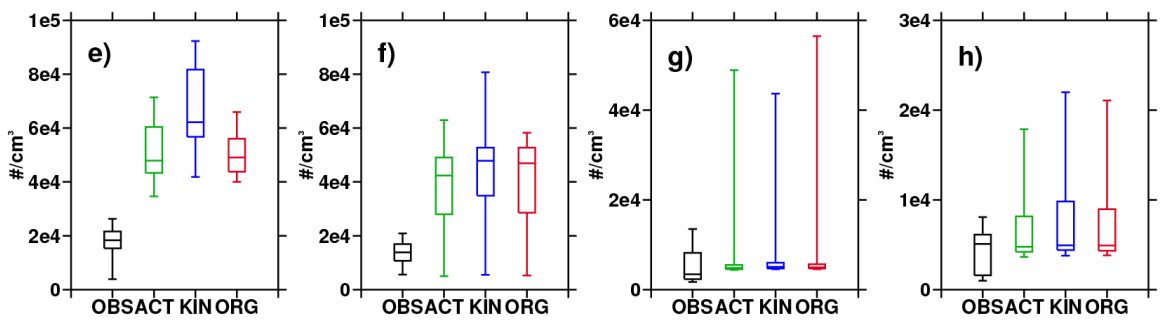

Figure 18. Boxplot for observed and simulated $\mathrm{CN}_{3}$ and $\mathrm{CN}_{10}$ at the surface to $500 \mathrm{~m}$ altitude (a and e); $500-1000 \mathrm{~m}$ altitude (b and f); 1000-1500 $\mathrm{m}$ altitude (c and $\mathbf{g}$ ); and 1500-2000 $\mathrm{m}$ altitude ( $\mathbf{d}$ and $\mathbf{h}$ ) for the 8 June 2010 afternoon G-1 flight. Observations are in black, ACT simulation values are in green, KIN in blue, and ORG in red. The line in the middle of each box is the median, while the boxes represent the 25th and 75th percentiles, and "whiskers" the 5th and 95th percentiles.
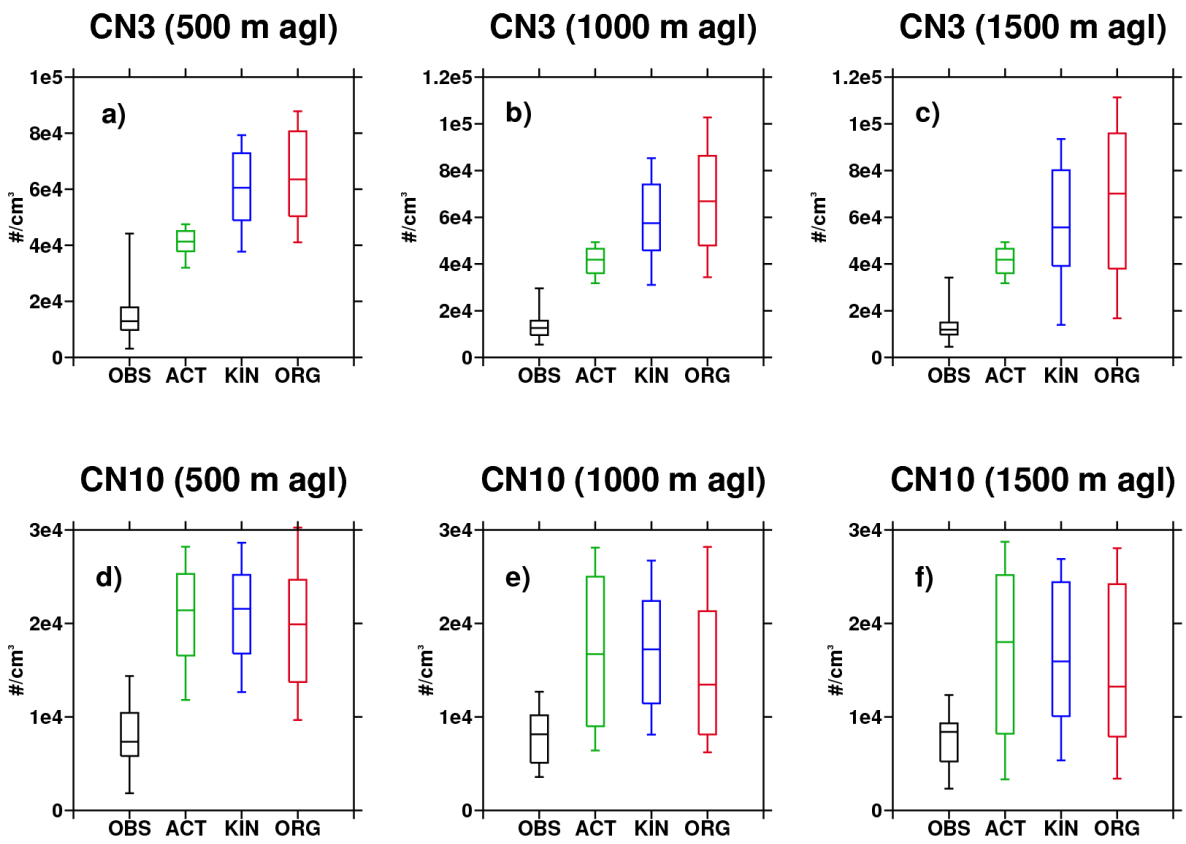

Figure 19. Same as Fig. 18, except for the 12 June 2010 afternoon G-1 flight.

might explain the relatively homogeneous observed and simulated particle number concentrations at different altitudes (Fig. 19). Yet, the median values of $\mathrm{CN}_{3}$ show that our simulations still overestimate number concentrations by up to a factor of 6, especially for KIN and ORG, while the overestimation factor reaches 4.5 for $\mathrm{CN}_{10}$.
This comparison of simulated particle concentrations with the aircraft measurements shows that the three nucleation parameterizations were able to reproduce the temporal and spatial variations in particle number for several flights; however, the simulated concentrations in the boundary layer are too high, especially for the smallest particles. 
Table 5. Summary statistics for $\mathrm{CCN}$ number concentration at several supersaturations $(\mathrm{SS}=0.1,0.2,0.35,0.5 \%)$. The observed mean, normalized mean bias (NMB) and correlation coefficient $(R)$ are calculated between simulated and observed number concentrations at the T0 site during the $7-16$ June 2010 period.

\begin{tabular}{|c|c|c|c|c|c|c|c|c|c|c|c|c|}
\hline \multicolumn{4}{|c|}{ Observed mean } & \multirow[t]{2}{*}{ Experiment } & \multicolumn{4}{|c|}{ NMB (\%) } & \multicolumn{4}{|c|}{$R$} \\
\hline $\mathrm{SS}_{0.1}$ & $\mathrm{SS}_{0.2}$ & $\mathrm{SS}_{0.35}$ & $\mathrm{SS}_{0.5}$ & & $\mathrm{SS}_{0.1}$ & $\mathrm{SS}_{0.2}$ & $\mathrm{SS}_{0.35}$ & $\mathrm{SS}_{0.5}$ & $\mathrm{SS}_{0.1}$ & $\mathrm{SS}_{0.2}$ & $\mathrm{SS}_{0.35}$ & $\mathrm{SS}_{0.5}$ \\
\hline 105 & 329 & 729 & 1067 & ACT & -49 & -34 & -5 & 29 & 0.39 & 0.23 & 0.39 & 0.30 \\
\hline & & & & KIN & -49 & -34 & -9 & 27 & 0.39 & 0.22 & 0.35 & 0.28 \\
\hline & & & & ORG & -49 & -33 & -8 & 26 & 0.38 & 0.23 & 0.36 & 0.29 \\
\hline
\end{tabular}

Table 6. Same as Table 5, except for the T1 site.

\begin{tabular}{|c|c|c|c|c|c|c|c|c|c|c|c|c|}
\hline \multicolumn{4}{|c|}{ Observed mean } & \multirow[t]{2}{*}{ Experiment } & \multicolumn{4}{|c|}{ NMB (\%) } & \multicolumn{4}{|c|}{$R$} \\
\hline $\mathrm{SS}_{0.1}$ & $\mathrm{SS}_{0.2}$ & $\mathrm{SS}_{0.35}$ & $\mathrm{SS}_{0.5}$ & & $\mathrm{SS}_{0.1}$ & $\mathrm{SS}_{0.2}$ & $\mathrm{SS}_{0.35}$ & $\mathrm{SS}_{0.5}$ & $\mathrm{SS}_{0.1}$ & $\mathrm{SS}_{0.2}$ & $\mathrm{SS}_{0.35}$ & $\mathrm{SS}_{0.5}$ \\
\hline \multirow[t]{3}{*}{109} & 333 & 729 & 1181 & ACT & -53 & -29 & 6 & 26 & 0.62 & 0.40 & 0.43 & 0.58 \\
\hline & & & & KIN & -53 & -32 & -1 & 22 & 0.64 & 0.39 & 0.40 & 0.57 \\
\hline & & & & ORG & -52 & -33 & 1 & 23 & 0.63 & 0.40 & 0.41 & 0.58 \\
\hline
\end{tabular}

\subsection{Impact of nucleation schemes on $\mathrm{CCN}$ concentration}

CCN concentration depends on both the particle size distribution and chemical composition. Observational studies have linked nucleation events to $\mathrm{CCN}$ production (e.g., Asmi et al., 2011; Wiedensohler et al., 2009). New particles can grow to the size of $\mathrm{CCN}$ through condensation and coagulation processes, although only a portion of these particles reach that size. As discussed in Kerminen et al. (2012) and references therein, the connection between the formation of new particles and CCN concentration has recently started to be investigated by using models. They note a nonlinear dependence between atmospheric $\mathrm{CCN}$ production and the nucleation process due to (1) the nucleation rate, (2) subsequent growth of nucleated particles to larger sizes, and (3) the presence of primary aerosol particles, and pointed out the challenge in accurately predicting $\mathrm{CCN}$ concentrations given these factors.

Several studies (e.g., Merikanto et al., 2009; Sihto et al., 2011; Westervelt et al., 2014) have shown that boundarylayer nucleation plays an important role in determining CCN number concentration. Kuang et al. (2009) quantified the role of self-coagulation loss (up to 20\%), coagulation (up to $10 \%$ ), condensation on pre-existing aerosols (up to $30 \%$ ), and condensation on nucleated particles (up to $80 \%$ ) to the $\mathrm{CN}_{100}$ particle concentration using field study data acquired at three North American locations for $20 \mathrm{CCN}$ formation events. They showed an enhancement on average by a factor of 3.8 of the pre-existing $\mathrm{CCN}$ number due to NPF. Using the GEOS-Chem-TOMAS model, Westervelt et al. (2014) calculated particle growth rates, condensation sinks, coagulation sinks, survival probabilities, and CCN formation rates for eight different nucleation parameterization.
Their study showed that increases in the nucleation rate led to decreased survival probability, so that the $\mathrm{CCN}$ number concentrations are relatively insensitive to the nucleation mechanism. During CARES, CCN number concentrations were measured at both the $\mathrm{T} 0$ and $\mathrm{T} 1$ sites for several supersaturations ( $\mathrm{SS}=0.1,0.2,0.35,0.5 \%)$. To assess the impact of the nucleation parameterizations on $\mathrm{CCN}$, we next compare observed $\mathrm{CCN}$ with simulated $\mathrm{CCN}$ number concentration calculated offline using the simulated chemical composition and the hygroscopicity of particles together with their sizedependent number concentration predicted by WRF-Chem. As shown in Tables 5 and 6, the calculated CCN number concentrations generally are weakly correlated with the measurements. The calculated CCN are generally lower than the measurements, except at $0.5 \%$ supersaturation. The underestimation at 0.1 and $0.2 \%$ supersaturations is likely to be closely linked to the large number of ultrafine particles that are not activated at these supersaturations, since the effective diameter of $\mathrm{CCN}$ is inversely correlated to the supersaturation (Yue et al., 2011). Using the simulated size-dependent particle composition, we calculated particle sizes having critical supersaturations corresponding to the $\mathrm{CCN}$ measurement supersaturations. For supersaturations of $0.5,0.35,0.2$, and $0.1 \%$, the diameters are $56,78,125$, and $168 \mathrm{~nm}$, respectively, with corresponding average hygroscopicities of 0.24 , $0.23,0.22$, and 0.20 . There is no clear distinction in these diameters between the $\mathrm{T} 0$ and $\mathrm{T} 1$ sites. The simulated $\mathrm{CCN}$ concentrations at 0.2 and $0.1 \%$ supersaturation thus correspond roughly to $\mathrm{CN}_{125}$ and $\mathrm{CN}_{168}$ concentrations. The simulated $\mathrm{CN}_{168}$ particle concentrations are biased high at $\mathrm{T} 0$ but low at T1 (NMBs of about 44 and $-16 \%$, respectively), which can explain the underestimations of $0.1 \%$ SS CCN at $\mathrm{T} 1$ but not at $\mathrm{T} 0$. The simulated $\mathrm{CN}_{125}$ have high biases at both T0 and T1 (NMBs of about 72 and $21 \%$, respectively), 


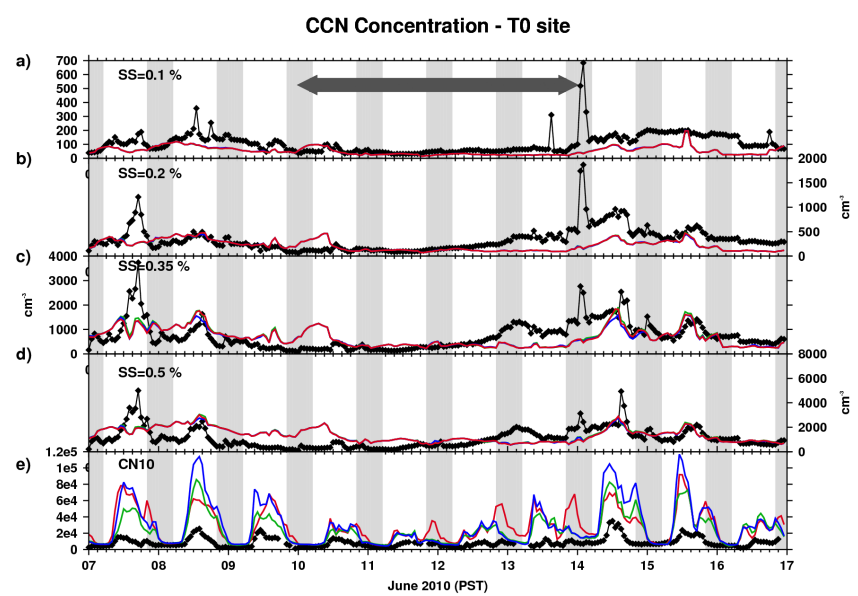

Figure 20. Observed and simulated time series of $\mathrm{CCN}$ number concentration at the $\mathrm{T} 0$ site for (a) $\mathrm{SS}=0.1 \%$, (b) $\mathrm{SS}=0.2 \%$, (c) $\mathrm{SS}=0.35 \%$, and (d) $\mathrm{SS}=0.5 \%$ together with (e) $\mathrm{CN}_{10}$ concentration. The gray shading area indicates nighttime, while the black arrow denotes the northerly synoptic flow associated with the passage of troughs over California.

so the cause of the simulations' underestimations of $0.2 \% \mathrm{SS}$ $\mathrm{CCN}$ is not clear. Mei et al. (2013) performed size-resolved CCN measurements of $100-170 \mathrm{~nm}$ diameter particles at the T1 site, and they found that $90 \%$ or more of the size-selected particles were $\mathrm{CCN}$ active and had hygroscopicities between 0.10 and 0.21 (mean of 0.15). This suggests that the simulated low biases for $0.2 \%$ supersaturation $\mathrm{CCN}$ are not due to differences in simulated vs. observed mixing state and/or hygroscopicity.

Figures 20 and 21 present the times series of observed and calculated $\mathrm{CCN}$ at both the $\mathrm{T} 0$ and $\mathrm{T} 1$ sites for five supersaturations. Comparing observed $\mathrm{CCN}$ and $\mathrm{CN}_{10}$ concentrations shows that several hours after the NPEs take place, an increase in CCN concentration is also observed. This is consistent with observational studies around the world that reported a clear increase in the $\mathrm{CCN}$ concentration after the occurrence of nucleation events (e.g., Kuwata et al., 2008; Levin et al., 2012). During the northerly wind period, the simulated $\mathrm{CCN}$ concentrations better match the observations at the T1 site compared to results at the T0 site. This is likely due to lower PNC biases for all size ranges at the $\mathrm{T} 1$ site during the same period, thus also demonstrating the connection between $\mathrm{PNC}$ and $\mathrm{CCN}$.

We next analyze how selection of the nucleation parameterization affects the predicted $\mathrm{CCN}$ number concentration for one supersaturation $(\mathrm{SS}=0.5 \%$ ). For this purpose we compare the ACT, KIN, and ORG results with a simulation in which nucleation (and NPF) was turned off. Compared to the simulation with no NPF, CCN levels at $\mathrm{SS}=0.5 \%$ from $\mathrm{ACT}, \mathrm{KIN}$, and ORG are around $18 \%$ higher at the T0 site and $26 \%$ higher at the $\mathrm{T} 1$ site. These changes indicate that nucleation and subsequent growth moderately influences the

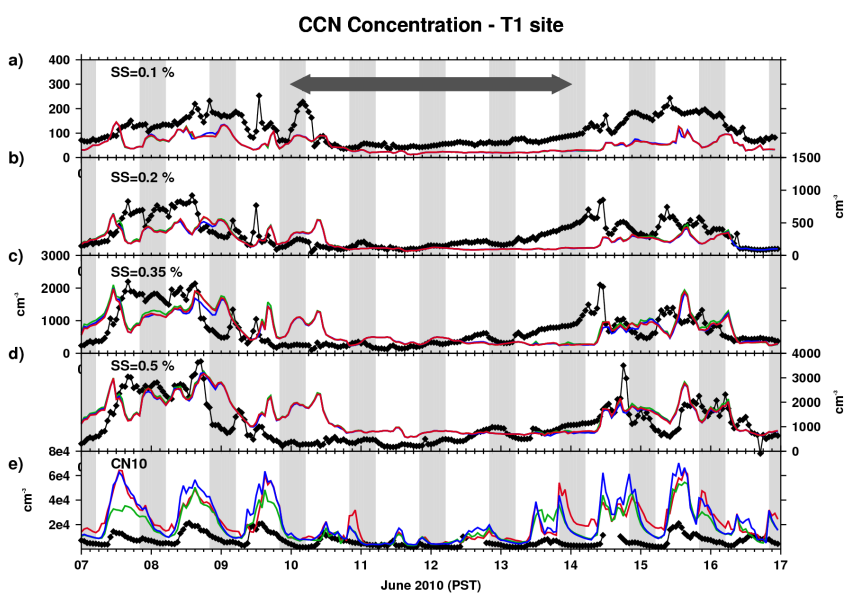

Figure 21. Same as Fig. 20, except for the T1 site.

$\mathrm{CCN}$ at this supersaturation. This result has been found in previous studies that report 5-70\% of the $\mathrm{CCN}$ could be attributed to nucleation (e.g., Spracklen et al., 2010; Pierce and Adams, 2009; Matsui et al., 2013).

For $\mathrm{SS}=0.5 \%$, the average activation ratios (AR), defined as $\mathrm{AR}=\mathrm{CCN} / \mathrm{CN}_{10}$, are around 0.10 at both measurement sites for all parameterizations. As pointed out by Andreae and Rosenfeld (2008), low AR are observed with fresh aerosols, whereas AR approaches 1 for aged aerosols. The relatively small ARs obtained for the ACT, KIN, and ORG parameterizations exhibit the importance of freshly formed secondary aerosols and are relatively close to the observed $\mathrm{AR}(0.14$ and 0.21 for the T0 and $\mathrm{T} 1$ sites, respectively).

Thus, from the statistical analysis and the temporal evolution of $\mathrm{CCN}$ at different supersaturations, we can conclude that nucleation affects both $\mathrm{CCN}$ concentrations and the fraction of particles that are available to act as CCN. However, the ACT, KIN, and ORG parameterizations give fairly similar results, especially for low supersaturations, suggesting that $\mathrm{CCN}$ at these supersaturations (and sizes) are less sensitive to the nucleation mechanism and rate, possibly due to a slow growth rate of freshly nucleated particles to these sizes and low survival probability (Westervelt et al., 2014), or that the concentrations of these are mainly driven by other processes (e.g., primary aerosol emissions).

\subsection{Impact of sectional bin number on predicted particle number and mass concentration}

Based on the statistics shown in Sect. 4.1, the ACT parameterization performed somewhat better for both surface measurement sites and for most of the G-1 aircraft flights. Therefore, we now focus on comparing the impact of sectional size resolution (number of bins and lowest diameter) on predicted particle number and mass concentrations when the ACT parameterization is used. In addition to the 20 size bin simulation presented previously (hereafter referred to as ACT- 
Table 7. Summary statistics for $\mathrm{CN}_{10}, \mathrm{CN}_{40}$ and $\mathrm{CN}_{100}$ when using the ACT parameterization in a sectional framework with different numbers of particle size bins together with statistics for default configuration of WRF-Chem (WEX-8BIN). It should be noted that WEX$8 \mathrm{BIN}$ statistical results are the same as the 8BIN simulation presented in Tables 1 and 2. The observed mean, normalized mean bias (NMB) and correlation coefficient $(R)$ are calculated between simulated and observed number concentration at the T0 site during the 7-16 June 2010 period.

\begin{tabular}{rrrlrrr|rrr}
\hline \multicolumn{3}{c}{ Observed mean } & \multirow{2}{*}{ Experiment } & \multicolumn{3}{c|}{$\mathrm{NMB}(\%)$} & \multicolumn{3}{c}{$R$} \\
\cline { 5 - 9 } $\mathrm{CN}_{10}$ & $\mathrm{CN}_{40}$ & $\mathrm{CN}_{100}$ & & $\mathrm{CN}_{10}$ & $\mathrm{CN}_{40}$ & $\mathrm{CN}_{100}$ & $\mathrm{CN}_{10}$ & $\mathrm{CN}_{40}$ & $\mathrm{CN}_{100}$ \\
\hline 8576 & 2748 & 366 & WEX-8BIN & - & -34 & -55 & - & 0.56 & 0.32 \\
& & & ACT-8BIN & - & -8 & -58 & - & 0.32 & 0.24 \\
& & ACT-12BIN & 188 & 18 & 49 & 0.72 & 0.46 & 0.48 \\
& & ACT-20BIN & 184 & 66 & 78 & 0.71 & 0.56 & 0.53 \\
\hline
\end{tabular}

Table 8. Same as Table 7, except for the T1 site.

\begin{tabular}{rrrlrrr|rrr}
\hline \multicolumn{3}{c}{ Observed mean } & \multirow{2}{*}{ Experiment } & \multicolumn{3}{c|}{$\mathrm{NMB}(\%)$} & \multicolumn{3}{c}{$R$} \\
\cline { 6 - 9 } $\mathrm{CNN}_{10}$ & $\mathrm{CN}_{40}$ & $\mathrm{CN}_{100}$ & & $\mathrm{CN}_{10}$ & $\mathrm{CN}_{40}$ & $\mathrm{CN}_{100}$ & $\mathrm{CN}_{10}$ & $\mathrm{CN}_{40}$ & $\mathrm{CN}_{100}$ \\
\hline 6389 & 3121 & 518 & WEX-8BIN & - & -51 & -65 & - & 0.57 & 0.32 \\
& & & ACT-8BIN & - & -17 & -67 & - & 0.43 & 0.36 \\
& & & ACT-12BIN & 187 & -8 & 4 & 0.72 & 0.63 & 0.48 \\
& & & ACT-20BIN & 178 & 31 & 25 & 0.74 & 0.70 & 0.51 \\
\hline
\end{tabular}

20BIN), we performed two additional simulations. The ACT12BIN simulation uses 12-particle size bins ranging from $1 \mathrm{~nm}$ to $10 \mu \mathrm{m}$ in dry diameter. This bin structure still explicitly resolves new particle formation, while reducing computational costs compared to ACT-20BIN by $36 \%$. Simulation ACT-8BIN employs the default eight-particle size bins ranging from $39 \mathrm{~nm}$ to $10 \mu \mathrm{m}$ used by MOSAIC in the publicly released version of WRF-Chem. Note that this configuration does not explicitly treat the growth of freshly nucleated particles (which are placed in the first size bin with $39 \mathrm{~nm}$ diameter), and the Kerminen and Kulmala (2002) parameterization is applied to estimate the coagulation loss of new particles during their growth from 1 to $39 \mathrm{~nm}$. Using ACT-8BIN reduces the computing cost by $45 \%$ compared to ACT-20BIN.

The comparison between the standard 8-bin configuration that uses the Wexler parameterization (WEX-8BIN) and the 8-bin version that uses ACT (ACT-8BIN) shows an improvement in the predicted $\mathrm{CN}_{40}$ concentration when ACT is used (Tables 7 and 8). For example, at the T0 site, the $\mathrm{CN}_{40} \mathrm{NMB}$ is reduced from $-34 \%$ for WEX-8BIN (Table 1 ) to $-8 \%$ for ACT-8BIN (Table 7). However, the statistics for the $\mathrm{CN}_{100}$ concentration shows a modest variation between simulations: ACT-8BIN has NMBs of -58 and $-67 \%$ at the T0 and T1 sites, respectively, compared to WEX-8BIN NMBs of -55 and $-65 \%$.

In our simulations, the ACT-8BIN configuration (which does not explicitly treat initial growth and loss of new particles) gives higher $\mathrm{CN}_{40}$ concentrations compared to the ACT-12BIN and ACT-20BIN configurations. This result runs counter to the Lee et al. (2013) study that used the TOMAS model with lowest bin diameters of 1 (explicit treatment of initial growth and coagulation loss) and 3 and $10 \mathrm{~nm}$ (Kerminen and Kulmala, 2002, parameterization), with 40, 36, and 30 size bins, respectively. They found that the $\mathrm{CN}_{10}$ particles were overpredicted when the Kerminen and Kulmala (2002) parameterization was used. Several factors may explain the differences between Lee et al. (2013) and our study: the nucleation parameterizations (binary/ternary vs. activation type mechanism), lower size bin (3/10 vs. $40 \mathrm{~nm})$, analysis period (average over the spring season vs. 10 days in summer), horizontal resolution $\left(4^{\circ}\right.$ latitude $\times 5^{\circ}$ longitude vs. $\left.4 \mathrm{~km}\right)$, emissions inventory, distribution of primary aerosol particles, gas-phase photochemistry, and the estimation of growth time from 1 to $40 \mathrm{~nm}$.

As can be seen from Tables 7 and 8, the ACT-12BIN simulation produces similar results for $\mathrm{CN}_{10}$ particles compared to the ACT-20BIN simulation, while also showing a visible improvement for $\mathrm{CN}_{40}$ and $\mathrm{CN}_{100}$ particles. The reduced overestimation of $\mathrm{CN}_{40}$ particles by more than $40 \%$ could at least partially be explained by the differences in the bin boundaries: the simulated $\mathrm{CN}_{40}$ are calculated as particles larger than 39.8 and $46.4 \mathrm{~nm}$ for the 20- and 12-bin configurations, respectively (i.e., no interpolation is used). For $\mathrm{CN}_{100}$ particles, the lower bin edge is at $100 \mathrm{~nm}$ for both ACT-12BIN and ACT-20BIN, so the lower $\mathrm{CN}_{100}$ (and $\mathrm{CN}_{40}$ ) with ACT-12BIN suggests that transfer of particles to larger sizes during condensational growth is somewhat slower with the coarser size resolution. The correlation coefficients between observed and ACT-12BIN simulated val- 
Table 9. Summary statistics for $\mathrm{CN}_{3}$ and $\mathrm{CN}_{10}$ when using the ACT parameterization in a sectional framework with different numbers of particle size bins. The observed mean, normalized mean bias (NMB) and correlation coefficient $(R)$ are calculated between simulated and observed number concentrations collected during the CARES G-1 aircraft flights.

\begin{tabular}{|c|c|c|c|c|c|c|}
\hline \multirow[t]{2}{*}{ PNC } & \multirow[t]{2}{*}{ Flights } & \multirow[t]{2}{*}{ Observed mean } & \multicolumn{2}{|c|}{$\operatorname{NMB}(\%)$} & \multicolumn{2}{|c|}{$R$} \\
\hline & & & ACT-12BIN & ACT-20BIN & ACT-12BIN & ACT-20BIN \\
\hline \multirow[t]{9}{*}{$\mathrm{CN}_{3}$} & 8 June, morning (08a) & 20472 & 151 & 157 & 0.68 & 0.64 \\
\hline & 8 June, afternoon (08b) & 13990 & 223 & 274 & 0.75 & 0.84 \\
\hline & 10 June, morning (10a) & 17392 & 141 & 212 & 0.21 & 0.22 \\
\hline & 12 June, morning (12a) & 12340 & 112 & 198 & 0.35 & 0.40 \\
\hline & 12 June, afternoon (12b) & 14459 & 175 & 184 & 0.11 & -0.06 \\
\hline & 14 June, morning (14a) & 21913 & 213 & 259 & 0.61 & 0.56 \\
\hline & 15 June, morning (15a) & 24800 & 242 & 250 & 0.64 & 0.68 \\
\hline & 15 June, afternoon (15b) & 14800 & 275 & 260 & 0.73 & 0.75 \\
\hline & All flights & 17564 & 194 & 226 & 0.37 & 0.52 \\
\hline \multirow[t]{9}{*}{$\mathrm{CN}_{10}$} & 8 June, morning (08a) & 11588 & 19 & 90 & 0.62 & 0.57 \\
\hline & 8 June, afternoon (08b) & 10161 & 165 & 162 & 0.74 & 0.80 \\
\hline & 10 June, morning (10a) & 10804 & 89 & 95 & -0.11 & -0.03 \\
\hline & 12 June, morning (12a) & 6019 & 61 & 69 & 0.39 & 0.44 \\
\hline & 12 June, afternoon (12b) & 7940 & 131 & 128 & -0.02 & -0.05 \\
\hline & 14 June, morning (14a) & 11999 & 219 & 221 & 0.72 & 0.72 \\
\hline & 15 June, morning (15a) & 13601 & 230 & 216 & 0.68 & 0.71 \\
\hline & 15 June, afternoon (15b) & 12625 & 260 & 230 & 0.73 & 0.48 \\
\hline & All flights & 10641 & 169 & 162 & 0.38 & 0.54 \\
\hline
\end{tabular}

ues are similar to the $R$ values between observed and ACT20BIN simulated values.

Applying the same statistics for the particles collected during the G-1 aircraft flights, we note that both ACT-12BIN and ACT-20BIN overestimate $\mathrm{CN}_{3}$ and $\mathrm{CN}_{10}$ particles (Table 9). However, the use of ACT-12BIN tends to decrease the overestimate of ACT-20BIN in predicted $\mathrm{CN}_{3}$ concentration up to $71 \%$ (10 June, morning flight). The statistics for all flights show an improvement in predicted $\mathrm{CN}_{3}$ number for ACT-12BIN, with a NMB of $194 \%$ compared to an ACT-20BIN NMB of $226 \%$, while for $\mathrm{CN}_{10}$ for all flights we obtain similar NMB scores (169 and $162 \%$ for ACT$12 \mathrm{BIN}$ and ACT-20BIN, respectively). This statistical analysis shows that the use of a 12-bin particle size distribution represents a good compromise between computational time and the aerosol physico-chemical processes included in WRF-Chem.

Analyzing the total mass of aerosol species obtained from the simulations in which the number of discrete size bins is varied, we note that differences between the 20-bin and 12-bin versions are very small. Over the entire analyzed period of 7-16 June 2010, the predicted mass concentration of aerosol compounds varies by $\pm 2 \%$ between ACT-12BIN and ACT-20BIN. The differences are larger when we compare ACT-20BIN and ACT-8BIN, with ACT-20BIN leading to $4 \%$ more $\mathrm{SO}_{4}$ mass, $6 \%$ more $\mathrm{NH}_{4}$ mass, $1 \%$ more $\mathrm{NO}_{3}$ mass and $5 \%$ less $\mathrm{OA}$ mass over the entire simulation period. These differences are partly related to the primary aerosol emissions in the 8-bin and 20-bin versions. A small fraction of aerosol mass emissions are in the $10-40 \mathrm{~nm}$ size range, so emissions in the ACT-20BIN simulation are about $1 \%$ larger than in ACT-8BIN. Another factor is the increased surface area of submicron aerosol in the ACT-20BIN simulation compared to the ACT-8BIN simulation.

\subsection{Sensitivity to the empirical coefficients of the BL nucleation parameterizations}

In order to test the sensitivity of the modeled PNC concentration to the empirical coefficients used in the BL nucleation parameterization, we performed additional sensitivity tests for all the ACT, KIN and ORG simulations in which the empirical coefficients were reduced by 1 and 2 orders of magnitude. Due to the expensive computational cost, we have done this sensitivity test only for the 8 June 2012 case. For $\mathrm{CN}_{10}$ concentrations at the T0 site on 8 June, ACT, KIN, and ORG had daily average NMB of 234, 346, and $206 \%$; tests with the empirical coefficients reduce by a factor of 10 had NMB of 130,291 , and $125 \%$; and tests with the empirical coefficients reduce by a factor of 100 had NMB of 28, 210, and $46 \%$. For the T1 site, ACT, KIN, and ORG had daily average NMB of 143, 198 and $175 \%$; tests with the empirical coefficients reduce by a factor of 10 had NMB of 103, 165, and $152 \%$ and tests with the empirical coefficients reduce by a factor of 100 had NMB of 38, 135, and $78 \%$. These sensitivity tests still overestimate the observed $\mathrm{CN}_{10}$ concentration, and also show that at T1 the model is less sensitive to the empirical coefficients than at T0. This suggests that 
not only the empirical coefficient is responsible for the simulated PNC, but other factors like model processes, uncertainties in emissions concentration and distribution of primary particles can affect the formation of new particles and their growth. For $\mathrm{CN}_{40}$ and $\mathrm{CN}_{100}$ particle concentrations, we find relatively small differences among different sensitivity tests (NMB variation of $\sim 15 \%$ or less), that shows a dampened response to BL nucleation. This demonstrates once again, as was shown in Sect. 4.4, the efficacy of removal processes that causes a greatly reduced survival probability for nucleated particles growing to CCN sizes (e.g., Kuang et al., 2009).

\section{Summary and conclusions}

The WRF-Chem model v.3.5 was used to simulate the particle number concentration $(\mathrm{CN})$ and size distribution during the CARES field campaign, which took place near Sacramento, CA, in June 2010. The MOSAIC aerosol model was extended to incorporate nm sizes of freshly nucleated particles and three state-of-the-science empirical nucleation mechanisms, which were used to investigate how different formulations of the nucleation rate impact the temporal and spatial variations of simulated $\mathrm{CN}$ and $\mathrm{CCN}$ number concentrations.

By comparing simulation results from the three empirical nucleation parameterizations explicitly treating nucleation using a 20 size bin sectional framework with measurements acquired during the CARES campaign, we showed that the parameterizations generally reproduced the overall observed spatial and temporal variability. However, the simulations with the activation (ACT), kinetic (KIN), and organics $+\mathrm{H}_{2} \mathrm{SO}_{4}(\mathrm{ORG})$ parameterizations overestimated the observed number concentration for particles with diameters $>10 \mathrm{~nm}\left(\mathrm{CN}_{10}\right)$. In terms of the normalized mean bias (NMB), the best results were obtained using the ACT parameterization (NMB of $178 \%$ over the entire analyzed period at the CARES T0 site), while the least favorable results were obtained for KIN (NMB of $255 \%$ at the T1 site). This overestimation was reduced for larger submicron particles $\left(\mathrm{CN}_{40}\right.$ and $\mathrm{CN}_{100}$ ). Measurements on a day with a new particle formation and growth event (NPE) indicated a diurnal cycle consisting of the onset of nucleation in the morning, subsequent particle growth, and particle number decrease during the afternoon. The cycles predicted from the ACT, KIN, and ORG simulations were similar to those observed; the simulated onset of nucleation, however, was $2 \mathrm{~h}$ earlier than observed and coincided with the onset of SOA formation. For a non-NPE day, our simulations reproduced the observed particle number concentration and the observed late afternoon shift in size distribution associated with the collapse of the boundary layer.

Using budget diagnostic terms, we were able to establish how the nucleation rate parameterization affects the source/sink of particles, and also to explain some simulated features. The different nucleation parameterizations led to differences in the daily variability and magnitude of the budget terms associated with condensation, nucleation and coagulation for particles in the $1-10 \mathrm{~nm}$ size range $\left(\mathrm{CN}_{1-10}\right)$. For example, ACT and KIN exhibit almost the same variability at model locations corresponding to the two surface observation sites on a NPE day, yield one peak in $\mathrm{CN}_{1-10}$ particle number concentration around noon local time, and are highly correlated to the diurnal variation of $\mathrm{H}_{2} \mathrm{SO}_{4}$ concentration. In contrast, ORG exhibits a different diurnal variation, showing two peaks (morning and afternoon) for most of the budget diagnostic terms for particles in the $1-10 \mathrm{~nm}$ range. Thus, the different nucleation parameterizations lead to different results in both particle number and size distribution. However, these differences are greatly reduced for larger particles. We conclude that the loss processes are efficient and could explain the relatively similar biases of $\mathrm{CN}_{40}$ and $\mathrm{CN}_{100}$ given by the ACT, KIN and ORG parameterizations. Moreover, the budget diagnostic terms help us to understand modeled features such as the late afternoon shift in the observed and simulated size distribution on the non-NPE day.

We also analyzed the impact of the various nucleation parameterizations on $\mathrm{CCN}$ concentrations. We found that although the nucleation process could explain a percentage of CCN number concentration (up to $20-30 \%$ at $0.5 \%$ supersaturation), the choice of nucleation parameterization had no impact on the magnitude of the predicted $\mathrm{CCN}$ number concentration.

Using an intermediate number of size bins (12) to represent the particle size distribution and to explicitly capture the new particle formation process, we obtain $\mathrm{CN}_{10}$ results similar to those obtained using 20 size bins, and improvements (relative to observations) for $\mathrm{CN}_{40}$ and $\mathrm{CN}_{100}$. Thus we can state that the use of a 12 size bin sectional framework represents a good compromise between computational time and the physico-chemical processes included in the WRF-Chem model. Simulations using the MOSAIC default 8 size bin ( $39 \mathrm{~nm}$ to $10 \mathrm{~mm}$ diameter) sectional framework and either the ACT or the default Wexler nucleation parameterization underestimate the observed $\mathrm{CN}_{40}$ and $\mathrm{CN}_{100}$ concentrations and do not reproduce the observed daily variability as well as the 20-bin simulations.

We also analyzed the impact of size distribution on predicted aerosol mass concentration. We noticed that between 12- and 20-bin frameworks there is little variation over the entire analyzed period. Larger differences are found when we compare 8- and 20-bin frameworks, with up to $6 \%$ more mass (in the case of $\mathrm{NH}_{4}$ ) predicted by the 20-bin version.

Our analyses also suggest that the ACT parameterization, where the nucleation rate is linearly proportional to the $\mathrm{H}_{2} \mathrm{SO}_{4}$ concentration, performs reasonably well for the CARES location and time period. However, sensitivity studies such as those employing uncertainty quantification (UQ) techniques are needed that adjust empirical coefficients to better reproduce the observed growth rate of ultrafine parti- 
cles and loss of particles through coagulation and condensation, and consequently the magnitude of total PNC over California. Since the aerosol size distribution is another source of uncertainty in models, additional studies testing the sensitivity of the size distribution to primary particle emissions may also improve the simulated particle number concentration and size distribution. Although the CARES campaign provided data to test and evaluate different new particle formation parameterizations, additional measurements such as $\mathrm{H}_{2} \mathrm{SO}_{4}$ and organic acid gas concentrations are necessary to better constrain the nucleation rate expressions.

Acknowledgements. We thank the numerous scientists, pilots, and other staff that contributed to the data collection during CARES. CARES was supported by the US Department of Energy's (DOE) Atmospheric Radiation Measurement (ARM) and Atmospheric System Research (ASR) programs. Funding for this research was provided by the US NOAA's Atmospheric Composition and Climate Program (NA11OAR4310160) and utilized resources provided by the Pacific Northwest National Laboratory (PNNL) Institutional Computing program. PNNL is operated for the US DOE by Battelle Memorial Institute.

Edited by: J. Thornton

\section{References}

Andreae, M. O. and Rosenfeld, D.: Aerosol-cloud-precipitation interactions. Part 1. The nature and sources of cloud-active aerosols, Earth-Sci. Rev., 89, 13-41, 2008.

Archer-Nicholls, S., Lowe, D., Utembe, S., Allan, J., Zaveri, R. A., Fast, J. D., Hodnebrog, Ø., Denier van der Gon, H., and McFiggans, G.: Gaseous chemistry and aerosol mechanism developments for version 3.5.1 of the online regional model, WRFChem, Geosci. Model Dev., 7, 2557-2579, doi:10.5194/gmd-72557-2014, 2014.

Asmi, E., Kivekäs, N., Kerminen, V.-M., Komppula, M., Hyvärinen, A.-P., Hatakka, J., Viisanen, Y., and Lihavainen, H.: Secondary new particle formation in Northern Finland Pallas site between the years 2000 and 2010, Atmos. Chem. Phys., 11, 1295912972, doi:10.5194/acp-11-12959-2011, 2011.

Betha, R., Spracklen, D. V., and Balasubramanian, R.: Observations of new aerosol particle formation in a tropical urban atmosphere, Atmos. Environ., 71, 340-351, doi:10.1016/j.atmosenv.2013.01.049, 2013.

Boulon, J., Sellegri, K., Hervo, M., Picard, D., Pichon, J.-M., Fréville, P., and Laj, P.: Investigation of nucleation events vertical extent: a long term study at two different altitude sites, Atmos. Chem. Phys., 11, 5625-5639, doi:10.5194/acp-11-56252011, 2011.

Boy, M., Karl, T., Turnipseed, A., Mauldin, R. L., Kosciuch, E., Greenberg, J., Rathbone, J., Smith, J., Held, A., Barsanti, K., Wehner, B., Bauer, S., Wiedensohler, A., Bonn, B., Kulmala, M., and Guenther, A.: New particle formation in the Front Range of the Colorado Rocky Mountains, Atmos. Chem. Phys., 8, 15771590, doi:10.5194/acp-8-1577-2008, 2008.
Carter, W. P. L.: Implementation of the SAPRC-99 chemical mechanism into the models-3 framework, report to the United States Environmental Protection Agency, available at: http:// www.cert.ucr.edu/ carter/absts.htm\#s99mod3 (last access: July 2015), 2000.

Cui, Y. Y., Hodzic, A., Smith, J. N., Ortega, J., Brioude, J., Matsui, H., Levin, E. J. T., Turnipseed, A., Winkler, P., and de Foy, B.: Modeling ultrafine particle growth at a pine forest site influenced by anthropogenic pollution during BEACHON-RoMBAS 2011, Atmos. Chem. Phys., 14, 1101111029, doi:10.5194/acp-14-11011-2014, 2014.

Ehn, M., Thornton, J. A., Kleist, E., Sipilä, M., Junninen, H., Pullinen, I., Springer, M., Rubach, F., Tillmann, R., Lee, B., LopezHilfiker, F., Andres, S., Acir, I.-H., Rissanen, M., Jokinen, T., Schobesberger, S., Kangasluoma, J., Kontkanen, J., Nieminen, T., Kurten, T., Nielsen, L. B., Jorgensen, S., Kjaergaard, H. G., Canagaratna, M., Maso, M. D., Berndt, T., Petaja, T., Wahner, A., Kerminen, V.-M., Kulmala, M., Worsnop, D. R., Wildt, J., and Mentel, T. F.: A large source of low-volatility secondary organic aerosol, Nature, 506, 476-479, doi:10.1038/nature13032, 2014.

Emmons, L. K., Walters, S., Hess, P. G., Lamarque, J.-F., Pfister, G. G., Fillmore, D., Granier, C., Guenther, A., Kinnison, D., Laepple, T., Orlando, J., Tie, X., Tyndall, G., Wiedinmyer, C., Baughcum, S. L., and Kloster, S.: Description and evaluation of the Model for Ozone and Related chemical Tracers, version 4 (MOZART-4), Geosci. Model Dev., 3, 43-67, doi:10.5194/gmd3-43-2010, 2010.

Fast, J. D., Gustafson Jr., W. I., Easter Jr., R. C., Zaveri, R. A., Barnard, J. C., Chapman, E. G., Grell, G., and Peckham, S. E.: Evolution of ozone, particulates, and aerosol direct radiative forcing in the vicinity of Houston using a fully coupled meteorology-chemistry-aerosol model, J. Geophys. Res.Atmos., 111, D21305, doi:10.1029/2005JD006721, 2006.

Fast, J. D., Gustafson Jr., W. I., Berg, L. K., Shaw, W. J., Pekour, M., Shrivastava, M., Barnard, J. C., Ferrare, R. A., Hostetler, C. A., Hair, J. A., Erickson, M., Jobson, B. T., Flowers, B., Dubey, M. K., Springston, S., Pierce, R. B., Dolislager, L., Pederson, J., and Zaveri, R. A.: Transport and mixing patterns over Central California during the carbonaceous aerosol and radiative effects study (CARES), Atmos. Chem. Phys., 12, 1759-1783, doi:10.5194/acp-12-1759-2012, 2012.

Fast, J. D., Allan, J., Bahreini, R., Craven, J., Emmons, L., Ferrare, R., Hayes, P. L., Hodzic, A., Holloway, J., Hostetler, C., Jimenez, J. L., Jonsson, H., Liu, S., Liu, Y., Metcalf, A., Middlebrook, A., Nowak, J., Pekour, M., Perring, A., Russell, L., Sedlacek, A., Seinfeld, J., Setyan, A., Shilling, J., Shrivastava, M., Springston, S., Song, C., Subramanian, R., Taylor, J. W., Vinoj, V., Yang, Q., Zaveri, R. A., and Zhang, Q.: Modeling regional aerosol and aerosol precursor variability over California and its sensitivity to emissions and long-range transport during the 2010 CalNex and CARES campaigns, Atmos. Chem. Phys., 14, 10013-10060, doi:10.5194/acp-14-10013-2014, 2014.

Grell, G. A., Peckham, S. E., Schmitz, R., McKeen, S. A., Frost, G., Skamarock, W. C., and Eder, B.: Fully coupled online chemistry within the WRF model, Atmos. Environ., 39, 6957-6975, 2005.

Guenther, A., Karl, T., Harley, P., Wiedinmyer, C., Palmer, P. I., and Geron, C.: Estimates of global terrestrial isoprene emissions using MEGAN (Model of Emissions of Gases and Aerosols from 
Nature), Atmos. Chem. Phys., 6, 3181-3210, doi:10.5194/acp-63181-2006, 2006.

Hoppel, W. A., Frick, G. M., Fitzgerald, J. W., and Larson, R. E.: Marine boundary layer measurements of new particle formation and the effects nonprecipitating clouds have on aerosol size distribution, J. Geophys. Res., 99, 14443-14459, 1994.

Iacono, M. J., Delamere, J. S., Mlawer, E. J., Shephard, M. W., Clough, S. A., and Collins, W. D.: Radiative forcing by long-lived greenhouse gases: calculations with the AER radiative transfer models, J. Geophys. Res., 113, D13103, doi:10.1029/2008JD009944, 2008.

IPCC 2007 - Denman, K. L., Brasseur, G., Chidthaisong, A., Ciais, P., Cox, P. M., Dickinson, R. E., Hauglustaine, D., Heinze, C., Holland, E., Jacob, D., Lohmann, U., Ramachandran, S., da Silva Dias, P. L., Wofsy, S. C., and Zhang, X.: Couplings between changes in the climate system and biogeochemistry, in: Climate Change 2007: the Physical Science Basis, contribution of Working Group I to the Fourth Assessment Report of the Intergovernmental Panel on Climate Change, edited by: Solomon, S., Qin, D., Manning, M., Chen, Z., Marquis, M., Averyt, K. B., Tignor, M., and Miller, H. L., Cambridge University Press, Cambridge, UK, and New York, NY, USA, 2007.

IPCC 2013 - Boucher, O., Randall, D., Artaxo, P., Bretherton, C., Feingold, G., Forster, P., Kerminen, V.-M., Kondo, Y., Liao, H., Lohmann, U., Rasch, P., Satheesh, S. K., Sherwood, S., Stevens, B., and Zhang, X. Y.: Clouds and aerosols, in: Climate Change 2013: the Physical Science Basis, contribution of Working Group I to the Fifth Assessment Report of the Intergovernmental Panel on Climate Change, edited by: Stocker, T. F., Qin, D., Plattner, G.-K., Tignor, M., Allen, S. K., Boschung, J., Nauels, A., Xia, Y., Bex, V., and Midgley, P. M., Cambridge University Press, Cambridge, UK, and New York, NY, USA, 2013.

Janjic, Z. I.: Nonsingular Implementation of the Mellor-Yamada Level 2.5 Scheme in the NCEP Meso model, Technical Report, National Centers for Environmental Prediction, Office Note No. 437, 61 pp., available at: http://www.emc.ncep.noaa.gov/ officenotes/newernotes/on437.pdf (last access: July 2015), 2001.

Jeong, C. H., Hopke, P. K., Chalupa, D., and Utell, M.: Characteristics of nucleation and growth events of ultrafine particles measured in Rochester, NY, Environ. Sci. Technol., 38, 1933-1940, 2004.

Jeong, C.-H., Evans, G. J., McGuire, M. L., Chang, R. Y.-W., Abbatt, J. P. D., Zeromskiene, K., Mozurkewich, M., Li, S.-M., and Leaitch, W. R.: Particle formation and growth at five rural and urban sites, Atmos. Chem. Phys., 10, 7979-7995, doi:10.5194/acp10-7979-2010, 2010.

Jokinen, T., Berndt, T., Makkonen, R., Kerminen, V.-M., Junninen, H., Paasonen, P., Stratmann, F., Hermann, H., Guenther, A., Worsnop, D. R., Kulmala, M., Ehn, M., and Sipilä, M.: Production of extremely low volatile organic compounds from biogenic emissions: Measured yields and atmospheric implications, Proc. Nat. Acad. Sci., 112, 7123-7128, doi:10.1073/pnas.1423977112, 2015.

Jung, J. G., Pandis, S. N., Adams, P. J.: Evaluation of Nucleation Theories in a Sulfur-Rich Environment, Aerosol Sci. Tech., 42, 7, 495-504, doi:10.1080/02786820802187085, 2008.

Jung, J., Fountoukis, C., Adams, P. J., and Pandis, S. N.: Simulation of in situ ultrafine particle formation in the eastern United
States using PMCAMx-UF, J. Geophys. Res., 115, D03203, doi:10.1029/2009JD012313, 2010.

Kain, J. S.: The Kain-Fritsch convective parameterization: an update, J. Appl. Meteorol., 43, 170-181, doi:10.1175/15200450(2004)043<0170:TKCPAU>2.0.CO;2, 2004.

Kazil, J., Harrison, R. G., and Lovejoy, E. R.: Tropospheric new particle formation and the role of ions, Space Sci. Rev., 137, 241255, 2008.

Kerminen, V.-M. and Kulmala, M.: Analytical formulae connecting the "real" and the "apparent" nucleation rate and the nuclei number concentration for atmospheric nucleation events, J. Aerosol Sci., 33, 609-662, 2002.

Kerminen, V.-M., Paramonov, M., Anttila, T., Riipinen, I., Fountoukis, C., Korhonen, H., Asmi, E., Laakso, L., Lihavainen, H., Swietlicki, E., Svenningsson, B., Asmi, A., Pandis, S. N., Kulmala, M., and Petäjä, T.: Cloud condensation nuclei production associated with atmospheric nucleation: a synthesis based on existing literature and new results, Atmos. Chem. Phys., 12, 12037 12059, doi:10.5194/acp-12-12037-2012, 2012.

Kirkby, J., Curtius, J., Almeida, J., Dunne, E., Duplissy, J., Ehrhart, S., Franchin, A., Gagné, S., Ickes, L., Kürten, A., Kupc, A., Metzger, A., Riccobono, F., Rondo, L., Schobesberger, S., Tsagkogeorgas, G., Wimmer, D., Amorim, A., Bianchi, F., Breitenlechner, M., David, A., Dommen, J., Downard, A., Ehn, M., Flagan, R. C., Haider, S., Hansel, A., Hauser, D. Jud, W., Junninen, H., Kreissl, F., Kvashin, A., Laaksonen, A., Lehtipalo, K., Lima, J., Lovejoy, E. R., Makhmutov, V., Mathot, S., Mikkilä, J., Minginette, P., Mogo, S., Nieminen, T., Onnela, A., Pereira, P., Petäjä, T., Schnitzhofer, R., Seinfeld, J. H., Sipilä, M., Stozhkov, Y., Stratmann, F., Tomé, A., Vanhanen, J., Viisanen, Y., Vrtala, A., Wagner, P. E., Walther, H., Weingartner, E., Wex, H., Winkler, P. M., Carslaw, K. S., Worsnop, D. R., and Kulmala, M.: Role of sulphuric acid, ammonia and galactic cosmic rays in atmospheric aerosol nucleation, Nature, 476, 429-433, doi:10.1038/nature10343, 2011.

Kristensson, A., Dal Maso, M., Swietlicki, E., Hussein, T., Zhou, J., Kerminen, V.-M., and Kulmala, M.: Characterization of new particle formation events at a background site in Southern Sweden: relation to air mass history, Tellus B, 60, 330-344, doi:10.1111/j.1600-0889.2008.00345.x, 2008.

Kuang, C., McMurry, P. H., McCormick, A. V., and Eisele, F. L.: Dependence of nucleation rates on sulfuric acid concentration in diverse atmospheric locations, J. Geophys. Res., 113, D10209, doi:10.1029/2007JD009253, 2008.

Kuang, C., McMurry, P. H., and McCormick, A. V.: Determination of cloud condensation nuclei production from measured new particle formation events, Geophys. Res. Lett., 36, L09822, doi:10.1029/2009GL037584, 2009.

Kuang, C., Riipinen, I., Sihto, S.-L., Kulmala, M., McCormick, A. V., and McMurry, P. H.: An improved criterion for new particle formation in diverse atmospheric environments, Atmos. Chem. Phys., 10, 8469-8480, doi:10.5194/acp-10-84692010, 2010.

Kuang, C., Chen, M., Zhao, J., Smith, J., McMurry, P. H., and Wang, J.: Size and time-resolved growth rate measurements of 1 to $5 \mathrm{~nm}$ freshly formed atmospheric nuclei, Atmos. Chem. Phys., 12, 3573-3589, doi:10.5194/acp-12-3573-2012, 2012. 
Kulmala, M., Laaksonen, A., and Pirjola, L.: Parameterizations for sulphuric acid/water nucleation rates, J. Geophys. Res.,103, 8301-8307, doi:10.1029/97JD03718, 1998.

Kulmala, M., Lehtinen, K. E. J., and Laaksonen, A.: Cluster activation theory as an explanation of the linear dependence between formation rate of $3 \mathrm{~nm}$ particles and sulphuric acid concentration, Atmos. Chem. Phys., 6, 787-793, doi:10.5194/acp-6-787-2006, 2006.

Kuwata, M., Kondo, Y., Miyazaki, Y., Komazaki, Y., Kim, J. H., Yum, S. S., Tanimoto, H., and Matsueda, H.: Cloud condensation nuclei activity at Jeju Island, Korea in spring 2005, Atmos. Chem. Phys., 8, 2933-2948, doi:10.5194/acp-8-2933-2008, 2008.

Lee, Y. H., Pierce, J. R., and Adams, P. J.: Representation of nucleation mode microphysics in a global aerosol model with sectional microphysics, Geosci. Model Dev., 6, 1221-1232, doi:10.5194/gmd-6-1221-2013, 2013.

Levin, E. J. T., Prenni, A. J., Petters, M. D., Kreidenweis, S. M., Sullivan, R. C., Atwood, S. A., Ortega, J., DeMott, P. J., and Smith, J. N.: An annual cycle of size-resolved aerosol hygroscopicity at a forested site in Colorado, J. Geophys. Res., 117, 06201, doi:10.1029/2011JD016854, 2012.

Makkonen, R., Asmi, A., Korhonen, H., Kokkola, H., Järvenoja, S., Räisänen, P., Lehtinen, K. E. J., Laaksonen, A., Kerminen, V.M., Järvinen, H., Lohmann, U., Bennartz, R., Feichter, J., and Kulmala, M.: Sensitivity of aerosol concentrations and cloud properties to nucleation and secondary organic distribution in ECHAM5-HAM global circulation model, Atmos. Chem. Phys., 9, 1747-1766, doi:10.5194/acp-9-1747-2009, 2009.

Matsui, H., Koike, M., Kondo, Y., Takegawa, N., Wiedensohler, A., Fast, J. D., and Zaveri, R. A.: Impact of new particle formation on the concentrations of aerosols and cloud condensation nuclei around Beijing, J. Geophys. Res., 116, D19208, doi:10.1029/2011JD016025, 2011.

Matsui, H., Koike, M., Takegawa, N., Kondo, Y., Takami, A., Takamura, T., Yoon, S., Kim, S.-W., Lim, H.-C., and Fast, J. D.: Spatial and temporal variations of new particle formation in East Asia using an NPF-explicit WRF-chem model: north-south contrast in new particle formation frequency, J. Geophys. Res.Atmos., 118, 11647-11663, doi:10.1002/jgrd.50821, 2013.

McMurry, P. H.: Photochemical aerosol formation from $\mathrm{SO}_{2}$ : a theoretical analysis of smog chamber data, J. Colloid Interf. Sci., 78, 513-527, doi:10.1016/0021-9797(80)90589-5, 1980.

McMurry, P. H. and Friedlander, S. K.: New particle formation in the presence of an aerosol, Atmos. Environ., 13, 1635-1651, 1979.

McMurry, P. H., Woo, K. S., Weber, R., Chen, D.-R., and Pui, D. Y. H.: Size distributions of $3-10 \mathrm{~nm}$ atmospheric particles: implications for nucleation mechanisms, Philos. T. Roy. Soc. A, 358, 2625-2642, doi:10.1098/rsta.2000.0673, 2000.

Mei, F., Setyan, A., Zhang, Q., and Wang, J.: CCN activity of organic aerosols observed downwind of urban emissions during CARES, Atmos. Chem. Phys., 13, 12155-12169, doi:10.5194/acp-13-12155-2013, 2013.

Merikanto, J., Napari, I., Vehkamäki, H., Anttila, T., and Kulmala, M.: New parameterization of sulfuric acid-ammoniawater ternary nucleation rates at tropospheric conditions, J. Geophys. Res., 112, D15207, doi:10.1029/2006JD007977, 2007.
Merikanto, J., Spracklen, D. V., Mann, G. W., Pickering, S. J., and Carslaw, K. S.: Impact of nucleation on global CCN, Atmos. Chem. Phys., 9, 8601-8616, doi:10.5194/acp-9-8601-2009, 2009.

Metzger, A., Verheggen, B., Dommen, J., Duplissy, J., Prevot, A. S., Weingartner, E., Riipinen, I., Kulmala, M., Spracklen, D. V., Carslaw, K. S., and Baltensperger, U.: Evidence for the role of organics in aerosol particle formation under atmospheric conditions, P. Natl. Acad. Sci. USA, 107, 6646-6651, doi:10.1073/pnas.0911330107, 2010.

Morrison, H., Thompson, G., and Tatarskii, V.: Impact of cloud microphysics on the development of trailing stratiform precipitation in a simulated squall line: comparison of one- and two-moment schemes, Mon. Weather Rev., 137, 991-1007, doi:10.1175/2008MWR2556.1, 2009.

Napari, I., Noppel, M., Vehkamäki, H., and Kulmala, M.: Parameterization of ternary nucleation rates for $\mathrm{H}_{2} \mathrm{SO}_{4}-\mathrm{NH}_{3}-\mathrm{H}_{2} \mathrm{O}$ vapors, J. Geophys. Res., 107, 4381, doi:10.1029/2002JD002132, 2002.

O'Dowd, C. D. and Hoffmann, T.: Coastal new particle formation: a review of the current state-of-the-art, Environ. Chem., 2, 245255, doi:10.1071/EN05077, 2005.

Paasonen, P., Nieminen, T., Asmi, E., Manninen, H. E., Petäjä, T., Plass-Dülmer, C., Flentje, H., Birmili, W., Wiedensohler, A., Hõrrak, U., Metzger, A., Hamed, A., Laaksonen, A., Facchini, M. C., Kerminen, V.-M., and Kulmala, M.: On the roles of sulphuric acid and low-volatility organic vapours in the initial steps of atmospheric new particle formation, Atmos. Chem. Phys., 10, 11223-11242, doi:10.5194/acp-10-11223-2010, 2010.

Patoulias, D., Fountoukis, C., Riipinen, I., and Pandis, S. N.: The role of organic condensation on ultrafine particle growth during nucleation events, Atmos. Chem. Phys., 15, 6337-6350, doi:10.5194/acp-15-6337-2015, 2015.

Pierce, J. R. and Adams, P. J.: Uncertainty in global CCN concentrations from uncertain aerosol nucleation and primary emission rates, Atmos. Chem. Phys., 9, 1339-1356, doi:10.5194/acp-91339-2009, 2009.

Pierce, J. R., Riipinen, I., Kulmala, M., Ehn, M., Petäjä, T., Junninen, H., Worsnop, D. R., and Donahue, N. M.: Quantification of the volatility of secondary organic compounds in ultrafine particles during nucleation events, Atmos. Chem. Phys., 11, 90199036, doi:10.5194/acp-11-9019-2011, 2011.

Pierce, J. R., Leaitch, W. R., Liggio, J., Westervelt, D. M., Wainwright, C. D., Abbatt, J. P. D., Ahlm, L., Al-Basheer, W., Cziczo, D. J., Hayden, K. L., Lee, A. K. Y., Li, S.-M., Russell, L. M., Sjostedt, S. J., Strawbridge, K. B., Travis, M., Vlasenko, A., Wentzell, J. J. B., Wiebe, H. A., Wong, J. P. S., and Macdonald, A. M.: Nucleation and condensational growth to $\mathrm{CCN}$ sizes during a sustained pristine biogenic SOA event in a forested mountain valley, Atmos. Chem. Phys., 12, 3147-3163, doi:10.5194/acp-12-3147-2012, 2012.

Place Jr., P. F., Ziemba, L. D., and Griffin, R. J.: Observations of nucleation-mode particle events and size distributions at a rural New England site, Atmos. Environ., 44, 88-94, 2010.

Reddington, C. L., Carslaw, K. S., Spracklen, D. V., Frontoso, M. G., Collins, L., Merikanto, J., Minikin, A., Hamburger, T., Coe, H., Kulmala, M., Aalto, P., Flentje, H., Plass-Dülmer, C., Birmili, W., Wiedensohler, A., Wehner, B., Tuch, T., Sonntag, A., O’Dowd, C. D., Jennings, S. G., Dupuy, R., Baltensperger, U., 
Weingartner, E., Hansson, H.-C., Tunved, P., Laj, P., Sellegri, K., Boulon, J., Putaud, J.-P., Gruening, C., Swietlicki, E., Roldin, P., Henzing, J. S., Moerman, M., Mihalopoulos, N., Kouvarakis, G., Ždímal, V., Zíková, N., Marinoni, A., Bonasoni, P., and Duchi, R.: Primary versus secondary contributions to particle number concentrations in the European boundary layer, Atmos. Chem. Phys., 11, 12007-12036, doi:10.5194/acp-11-12007-2011, 2011.

Riccobono, F., Schoberberger, S., Scott, C. E., Dommen, J., Ortega, I. K., Rondo, L., Almeida, J., Amorim, A., Bianchi, F., Breitenlechner, M., David, A., Downard, A., Dunne, E. M., Duplissy, J., Ehrhardt, S., Flagan, R. C., Franchin, A., Hansel, A., Juuninen, H., Kajos, M., Keskinen, H., Kupc, A., Kürten, A., Kvashin, A. N., Laaksonen, A., Lehtipalo, K., Makkmutov, V., Mathot, S., Nieminen, T., Onnela, A., Petäjä, T., Praplan, A. P., Santos, F. D., Schallhart, S., Seinfeld, J. H., Sipilä, M., Spracklen, D. V., Stozhkov, Y., Stratmann, F., Tomé, A., Tsagkogeorgas, G., Vaattlovaara, P., Viisanen, Y., Vrtala, A., Wagner, P. E., Weingartner, E., Wex, H., Wimmer, D., Carslaw, K. S., Curtius, J., Donahue, N. M., Kirkby, J., Kulmala, M., Worsnop, D. R., and Baltensperger, U.: Oxidation products of biogenic emissions contribute to nucleation of atmospheric particles, Science, 344, 717721, 2014

Riipinen, I., Sihto, S.-L., Kulmala, M., Arnold, F., Dal Maso, M., Birmili, W., Saarnio, K., Teinilä, K., Kerminen, V.-M., Laaksonen, A., and Lehtinen, K. E. J.: Connections between atmospheric sulphuric acid and new particle formation during QUEST III-IV campaigns in Heidelberg and Hyytiälä, Atmos. Chem. Phys., 7, 1899-1914, doi:10.5194/acp-7-1899-2007, 2007.

Riipinen, I., Pierce, J. R., Yli-Juuti, T., Nieminen, T., Häkkinen, S., Ehn, M., Junninen, H., Lehtipalo, K., Petäjä, T., Slowik, J., Chang, R., Shantz, N. C., Abbatt, J., Leaitch, W. R., Kerminen, V.-M., Worsnop, D. R., Pandis, S. N., Donahue, N. M., and Kulmala, M.: Organic condensation: a vital link connecting aerosol formation to cloud condensation nuclei (CCN) concentrations, Atmos. Chem. Phys., 11, 3865-3878, doi:10.5194/acp-11-38652011, 2011.

Ritter, M., Müller, M. D., Tsai, M.-Y., and Parlow, E.: Air pollution modeling over very complex terrain: an evaluation of WRFChem over Switzerland for two 1 year periods, Atmos. Res., 132-133, 209-222, 2013.

Schobesberger, S., Junninen, H., Bianchi, F., Lönn, G., Ehn, M., Lehtipalo, K., Dommen, J., Ehrhart, S., Ortega, I. K., Franchin, A., Nieminen, T., Riccobono, F., Hutterli, M., Duplissy, J., Almeida, J., Amorim, A., Breitenlechner, M., Downard, A. J., Dunne, E. M., Flagan, R. C., Kajos, M., Keskinen, H., Kirkby, J., Kupc, A., Kürten, A., Kurtén, T., Laaksonen, A., Mathot, S., Onnela, A., Praplan, A. P., Rondo, L., Santos, F. D., Schallhart, S., Schnitzhofer, R., Sipilä, M., Tomé, A., Tsagkogeorgas, G., Vehkamäki, H., Wimmer, D., Baltensperger, U., Carslaw, K. S., Curtius, J., Hansel, A., Petäjä, T., Kulmala, M., Donahue, N. M., and Worsnop, D. R.: Molecular understanding of atmospheric particle formation from sulfuric acid and large oxidized organic molecules, P. Natl. Acad. Sci. USA, 110, 17223-17228, doi:10.1073/pnas.1306973110, 2013.

Sem, G. J.: Design and performance characteristics of three continuous-flow condensation particle counters: a summary, Atmos. Res., 62, 267-294, doi:10.1016/S0169-8095(02)00014-5, 2002.
Setyan, A., Zhang, Q., Merkel, M., Knighton, W. B., Sun, Y., Song, C., Shilling, J. E., Onasch, T. B., Herndon, S. C., Worsnop, D. R., Fast, J. D., Zaveri, R. A., Berg, L. K., Wiedensohler, A., Flowers, B. A., Dubey, M. K., and Subramanian, R.: Characterization of submicron particles influenced by mixed biogenic and anthropogenic emissions using high-resolution aerosol mass spectrometry: results from CARES, Atmos. Chem. Phys., 12, 8131-8156, doi:10.5194/acp-12-8131-2012, 2012.

Setyan, A., Song, C., Merkel, M., Knighton, W. B., Onasch, T. B., Canagaratna, M. R., Worsnop, D. R., Wiedensohler, A., Shilling, J. E., and Zhang, Q.: Chemistry of new particle growth in mixed urban and biogenic emissions - insights from CARES, Atmos. Chem. Phys., 14, 6477-6494, doi:10.5194/acp-14-64772014, 2014.

Shaw, W., Allwine, K. J., Fritz, B. G., Rutz, F. C., Rishel, J. P., and Chapman, E. G.: An evaluation of the wind erosion module in DUSTRAN, Atmos. Environ., 42, 1907-1921, 2008.

Shrivastava, M., Fast, J., Easter, R., Gustafson Jr., W. I., Zaveri, R. A., Jimenez, J. L., Saide, P., and Hodzic, A.: Modeling organic aerosols in a megacity: comparison of simple and complex representations of the volatility basis set approach, Atmos. Chem. Phys., 11, 6639-6662, doi:10.5194/acp-11-66392011, 2011.

Shrivastava, M., Zelenyuk, A., Imre, D., Easter, R., Beranek, J., Zaveri, R. A., and Fast, J.: Implications of low volatility SOA and gas-phase fragmentation reactions on SOA loadings and their spatial and temporal evolution in the atmosphere, J. Geophys. Res.-Atmos., 118, 3328-3342, 2013.

Shrivastava, M., Easter, R. C., Liu, X., Zelenyuk, A., Singh, B., Zhang, K., Ma, P. L., Chand, D., Ghan, S. J., Jiminez, J. L., Zhang, Q., Fast, J. D., Rasch, P. J., and Tiitta, P.: Global transformation and fate of SOA: Implications of Low Volatility SOA and Gas-Phase Fragmentation Reactions, J. Geophys. Res.-Atmos., 120, 4169-4195, doi:10.1002/2014JD022563, 2015.

Sihto, S.-L., Kulmala, M., Kerminen, V.-M., Dal Maso, M., Petäjä, T., Riipinen, I., Korhonen, H., Arnold, F., Janson, R., Boy, M., Laaksonen, A., and Lehtinen, K. E. J.: Atmospheric sulphuric acid and aerosol formation: implications from atmospheric measurements for nucleation and early growth mechanisms, Atmos. Chem. Phys., 6, 4079-4091, doi:10.5194/acp-64079-2006, 2006.

Sihto, S.-L., Mikkilä, J., Vanhanen, J., Ehn, M., Liao, L., Lehtipalo, K., Aalto, P. P., Duplissy, J., Petäjä, T., Kerminen, V.-M., Boy, M., and Kulmala, M.: Seasonal variation of CCN concentrations and aerosol activation properties in boreal forest, Atmos. Chem. Phys., 11, 13269-13285, doi:10.5194/acp-11-13269-2011, 2011.

Smith, J. N., Dunn, M. J., VanReken, T. M., Iida, K., Stolzenburg, M. R., McMurry, P. H., and Huey, L. G.: Chemical composition of atmospheric nanoparticles formed from nucleation in Tecamac, Mexico: evidence for an important role for organic species in nanoparticle growth, Geophys. Res. Lett., 35, L04808, doi:10.1029/2007GL032523, 2008.

Spracklen, D. V., Pringle, K. J., Carslaw, K. S., Chipperfield, M. P., and Mann, G. W.: A global off-line model of size-resolved aerosol microphysics: I. Model development and prediction of aerosol properties, Atmos. Chem. Phys., 5, 2227-2252, doi:10.5194/acp-5-2227-2005, 2005.

Spracklen, D. V., Carslaw, K. S., Kulmala, M., Kerminen, V.-M., Mann, G. W., and Sihto, S.-L.: The contribution of boundary 
layer nucleation events to total particle concentrations on regional and global scales, Atmos. Chem. Phys., 6, 5631-5648, doi:10.5194/acp-6-5631-2006, 2006.

Spracklen, D. V., Carslaw, K. S., Kulmala, M., Kerminen, V.-M., Sihto, S.-L., Riipinen, I., Merikanto, J., Mann, G. W., Chipperfield, M. P., Wiedensohler, A., Birmili, W., and Lihavainen, H.: Contribution of particle formation to global cloud condensation nuclei concentrations, Geophys. Res. Lett., 35, L06808, doi:10.1029/2007GL033038, 2008.

Spracklen, D. V., Carslaw, K. S., Merikanto, J., Mann, G. W., Reddington, C. L., Pickering, S., Ogren, J. A., Andrews, E., Baltensperger, U., Weingartner, E., Boy, M., Kulmala, M., Laakso, L., Lihavainen, H., Kivekäs, N., Komppula, M., Mihalopoulos, N., Kouvarakis, G., Jennings, S. G., O'Dowd, C., Birmili, W., Wiedensohler, A., Weller, R., Gras, J., Laj, P., Sellegri, K., Bonn, B., Krejci, R., Laaksonen, A., Hamed, A., Minikin, A., Harrison, R. M., Talbot, R., and Sun, J.: Explaining global surface aerosol number concentrations in terms of primary emissions and particle formation, Atmos. Chem. Phys., 10, 4775-4793, doi:10.5194/acp-10-4775-2010, 2010.

Turco, R. P., Zhao, J.-X., and Yu, F.: A new source of tropospheric aerosols: Ion-ion recombination, Geophys. Res. Lett., 25, 635638, doi:10.1029/98GL00253, 1998.

Vehkamäki, H., Kulmala, M., Napari, I., Lehtinen, K. E. J., Timmreck, C., Noppel, M., and Laaksonen, A.: An improved parameterization for sulfuric acid-water nucleation rates for tropospheric and stratospheric conditions, J. Geophys. Res., 107, 4622, doi:10.1029/2002JD002184, 2002.

Venzac, H., Sellegri, K., Villani, P., Picard, D., and Laj, P.: Seasonal variation of aerosol size distributions in the free troposphere and residual layer at the puy de Dôme station, France, Atmos. Chem. Phys., 9, 1465-1478, doi:10.5194/acp-9-1465-2009, 2009.

Westervelt, D. M., Pierce, J. R., Riipinen, I., Trivitayanurak, W., Hamed, A., Kulmala, M., Laaksonen, A., Decesari, S., and Adams, P. J.: Formation and growth of nucleated particles into cloud condensation nuclei: model-measurement comparison, Atmos. Chem. Phys., 13, 7645-7663, doi:10.5194/acp-13-76452013, 2013.

Westervelt, D. M., Pierce, J. R., and Adams, P. J.: Analysis of feedbacks between nucleation rate, survival probability and cloud condensation nuclei formation, Atmos. Chem. Phys., 14, 55775597, doi:10.5194/acp-14-5577-2014, 2014.

Wexler, A. S., Lurmann, F. W., and Seinfeld, J. H.: Modeling urban and regional aerosols. I. Model development, Atmos. Environ., 28, 531-546, doi:10.1016/1352-2310(94)90129-5, 1994.

Wiedensohler, A., Chen, Y. F., Nowak, A., Wehner, B., Achtert, P., Berghof, M., Birmili, W., Wu, Z. J., Hu, M., Zhu, T., Takegawa, N., Kita, K., Kondo, Y., Lou, S. R., Hofzumahaus, A., Holland, F., Wahner, A., Gunthe, S. S., Rose, D., Su, H., and Pöschl, U.: Rapid aerosol particle growth and increase of cloud condensation nucleus activity by secondary aerosol formation and condensation: a case study for regional air pollution in northeastern China, J. Geophys. Res., 114, 00G08, doi:10.1029/2008JD010884, 2009.

Yli-Juuti, T., Nieminen, T., Hirsikko, A., Aalto, P. P., Asmi, E., Hõrrak, U., Manninen, H. E., Patokoski, J., Dal Maso, M., Petäjä, T., Rinne, J., Kulmala, M., and Riipinen, I.: Growth rates of nucleation mode particles in Hyytiälä during 20032009: variation with particle size, season, data analysis method and ambient conditions, Atmos. Chem. Phys., 11, 12865-12886, doi:10.5194/acp-11-12865-2011, 2011.

Yli-Juuti, T., Barsanti, K., Hildebrandt Ruiz, L., Kieloaho, A.J., Makkonen, U., Petäjä, T., Ruuskanen, T., Kulmala, M., and Riipinen, I.: Model for acid-base chemistry in nanoparticle growth (MABNAG), Atmos. Chem. Phys., 13, 12507-12524, doi:10.5194/acp-13-12507-2013, 2013.

Yu, F.: A secondary organic aerosol formation model considering successive oxidation aging and kinetic condensation of organic compounds: global scale implications, Atmos. Chem. Phys., 11, 1083-1099, doi:10.5194/acp-11-1083-2011, 2011.

Yu, F. and Turco, R. P.: Ultrafine aerosol formation via ion-mediated nucleation, Geophys. Res. Lett., 27, 883-886, 2000.

Yu, F. and Turco, R. P.: From molecular clusters to nanoparticles: role of ambient ionization in tropospheric aerosol formation, J. Geophys. Res., 106, 4797-4814, 2001.

Yu, F., Wang, Z., Luo, G., and Turco, R.: Ion-mediated nucleation as an important global source of tropospheric aerosols, Atmos. Chem. Phys., 8, 2537-2554, doi:10.5194/acp-8-2537-2008, 2008.

Yu, F., Luo, G., Pryor, S. C., Pillai, P. R., Lee, S. H., Ortega, J., Schwab, J. J., Hallar, A. G., Leaitch, W. R., Aneja, V. P., Smith, J. N., Walker, J. T., Hogrefe, O., and Demerjian, K. L.: Spring and summer contrast in new particle formation over nine forest areas in North America, Atmos. Chem. Phys. Discuss., 15, 21271-21298, doi:10.5194/acpd-15-21271-2015, 2015.

Yue, D. L., Hu, M., Zhang, R. Y., Wu, Z. J., Su, H., Wang, Z. B., Peng, J. F., He, L. Y., Huang, X. F., Gong, Y. G., and Wiedensohler, A.: Potential contribution of new particle formation to cloud condensation nuclei in Beijing, Atmos. Environ., 45, 6070-6077, 2011.

Zaveri, R. A., Easter Jr., R. C., Fast, J. D., and Peters, L. K.: Model for Simulating Aerosol Interactions and Chemistry (MOSAIC), J. Geophys. Res.-Atmos., 113, D13204, doi:10.1029/2007JD008782, 2008.

Zaveri, R. A., Shaw, W. J., Cziczo, D. J., Schmid, B., Ferrare, R. A., Alexander, M. L., Alexandrov, M., Alvarez, R. J., Arnott, W. P., Atkinson, D. B., Baidar, S., Banta, R. M., Barnard, J. C., Beranek, J., Berg, L. K., Brechtel, F., Brewer, W. A., Cahill, J. F., Cairns, B., Cappa, C. D., Chand, D., China, S., Comstock, J. M., Dubey, M. K., Easter, R. C., Erickson, M. H., Fast, J. D., Floerchinger, C., Flowers, B. A., Fortner, E., Gaffney, J. S., Gilles, M. K., Gorkowski, K., Gustafson, W. I., Gyawali, M., Hair, J., Hardesty, R. M., Harworth, J. W., Herndon, S., Hiranuma, N., Hostetler, C., Hubbe, J. M., Jayne, J. T., Jeong, H., Jobson, B. T., Kassianov, E. I., Kleinman, L. I., Kluzek, C., Knighton, B., Kolesar, K. R., Kuang, C., Kubátová, A., Langford, A. O., Laskin, A., Laulainen, N., Marchbanks, R. D., Mazzoleni, C., Mei, F., Moffet, R. C., Nelson, D., Obland, M. D., Oetjen, H., Onasch, T. B., Ortega, I., Ottaviani, M., Pekour, M., Prather, K. A., Radney, J. G., Rogers, R. R., Sandberg, S. P., Sedlacek, A., Senff, C. J., Senum, G., Setyan, A., Shilling, J. E., Shrivastava, M., Song, C., Springston, S. R., Subramanian, R., Suski, K., Tomlinson, J., Volkamer, R., Wallace, H. W., Wang, J., Weickmann, A. M., Worsnop, D. R., Yu, X.-Y., Zelenyuk, A., and Zhang, Q.: Overview of the 2010 Carbonaceous Aerosols and Radiative Effects Study (CARES), Atmos. Chem. Phys., 12, 7647-7687, doi:10.5194/acp-12-7647-2012, 2012. 
Zaveri, R. A., Easter, R. C., Shilling, J. E., and Seinfeld, J. H.: Modeling kinetic partitioning of secondary organic aerosol and size distribution dynamics: representing effects of volatility, phase state, and particle-phase reaction, Atmos. Chem. Phys., 14, 5153-5181, doi:10.5194/acp-14-5153-2014, 2014.

Zhang, Y., Liu, P., Liu, X.-H., Jacobson, M. Z., McMurry, P. H., Yu, F., Yu, S., and Schere, K. L.: A comparative study of nucleation parameterizations: 2. Three dimensional model application and evaluation, J. Geophys. Res., 115, D20213, doi:10.1029/2010JD014151, 2010a
Zhang, Y., McMurry, P. H., Yu, F., and Jacobson, M. Z.: A comparative study of nucleation parameterizations: 1 . examination and evaluation of the formulations, J. Geophys. Res., 115, D20212, doi:10.1029/2010JD014150, 2010b.

Ziemba, L. D., Griffin, R. J., and Talbot, R. W.: Observations of elevated particle number concentration events at a rural site in northern New England, J. Geophys. Res., 111, D23S24, doi:10.1029/2006JD007607, 2006. 